Aus der Chirurgischen Klinik und Poliklinik der

Ludwig-Maximilians-Universität München, Klinikum Großhadern

Direktor: Prof. Dr. med. h.c. mult. K.W. Jauch

\title{
Die kompromittierte T-Zell-Funktion nach Trauma-Schock ist verantwortlich für die verminderte zell-vermittelte Immunantwort
}

\author{
Dissertation \\ zum Erwerb des Doktorgrades der Medizin \\ an der Medizinischen Fakultät der \\ Ludwig-Maximilians-Universität zu München
}

\author{
vorgelegt von \\ Christian Walz \\ aus \\ Augsburg \\ Jahr \\ 2008
}


Mit Genehmigung der Medizinischen Fakultät der Universität München

Berichterstatter:

Mitberichterstatter:

Dekan:

Tag der mündlichen Prüfung:
PD Dr. med. Martin K. Angele

Prof. Dr. med. Rudolf Wank

Prof. Dr. med. Sigurd Keßler

Prof. Dr. med. D. Reinhardt

08.05.2008 
Gewidmet

meiner verstorbenen

Mutter 


\section{Erklärung:}

Ich versichere hiermit, dass ich die vorliegende Doktorschrift ohne unerlaubte Hilfe angefertigt, das benutzte Schrifttum vollständig erwähnt habe und das die Doktorschrift noch von keiner anderen Fakultät abgelehnt worden ist.

\section{Neusäß, den 09.05.2008}

\section{Christian Walz}

\section{Auszüge der Arbeit wurden bei folgenden Kongressen vorgestellt:}

- Vortrag im Rahmen des jährlichen Schock-Meetings, Broomfield / USA im Juni 2006 (ausgezeichnet mit ,Joung Investigators Travel Award“)

- Vortrag und Posterpräsentation im Rahmen des 5. internationalen Kongresses für Trauma, Schock, Inflammation und Sepsis (TSIS), München im März 2007

- Vortrag auf dem 124. Deutschen Chirurgenkongress in München im Mai 2007

\section{Wissenschaftlichen Veröffentlichungen:}

- Depressed T cell-derived IFN-gamma following trauma-hemorrhage: a potential mechanism for diminished APC responses.

Walz CR, Zedler S, Schneider CP, Mayr S, Loehe F, Bruns CJ, Faist E, Jauch KW, Angele MK.

Langenbecks Arch Surg. 2007 Mai;392(3):339-43

- Depressed T-cell function is responsible for the persistent depression in cell-mediated immune responses following trauma-hemorrhage.

Walz CR, Zedler S, Schneider CP, Mayr S, Loehe F, Bruns CJ, Faist E, Chaudry IH, Jauch KW, Angele MK (eingereicht bei Journal of Shock) 


\section{Inhaltsverzeichnis}

ABKÜRZUNGSVERZEICHNIS.

1.1 PATHOPHYSIOLOGIE DES TRAUMATISCH HÄMORRHAGISCHEN SCHOCKS .......................................... 9

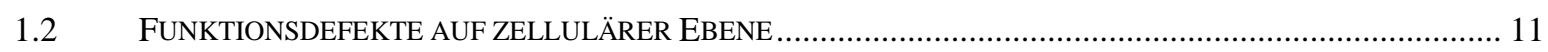

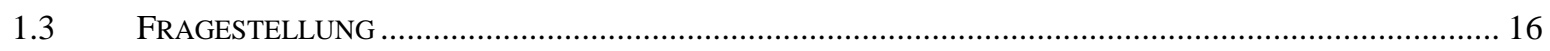

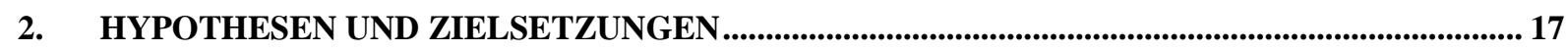

3. MATERIAL UND METHODEN ........................................................................................................ 18

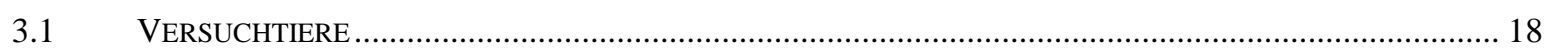

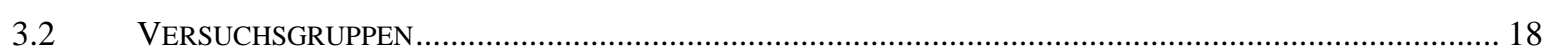

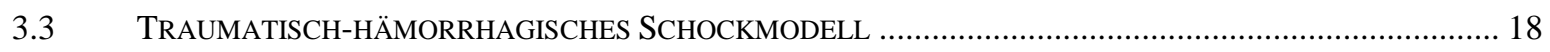

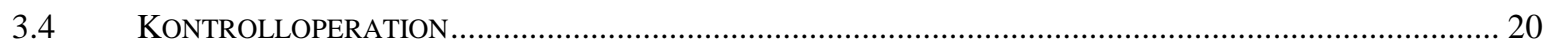

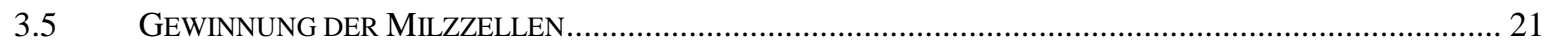

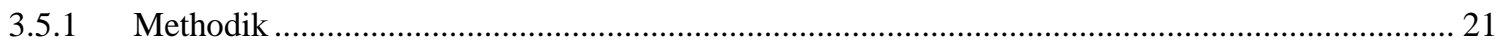

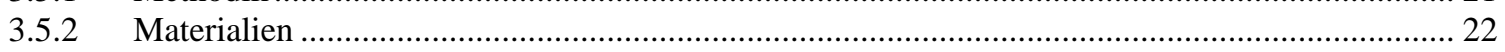

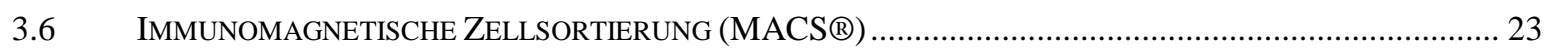

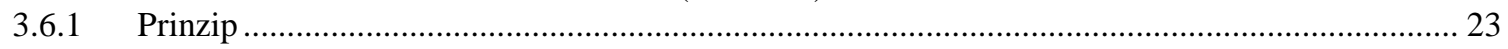

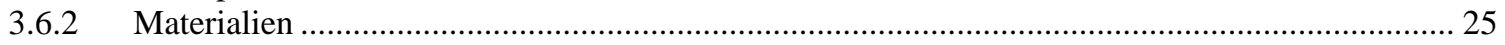

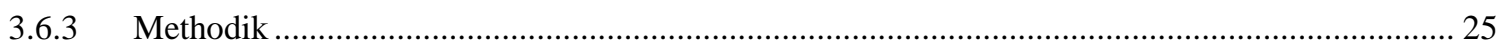

3.7 GEWINNUNG DER ANTIGENPRÄSENTIERENDEN ZELLEN …………………………………………..... 27

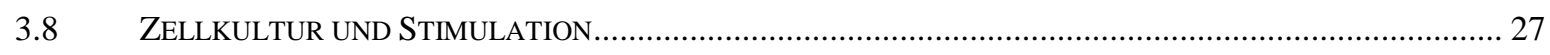

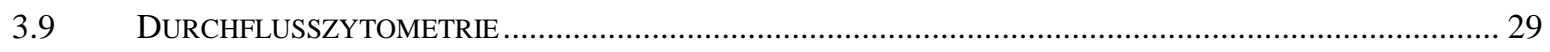

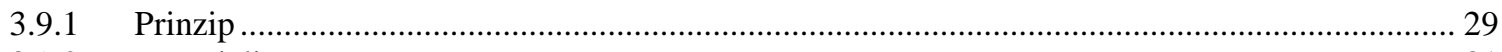

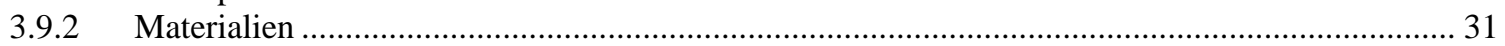

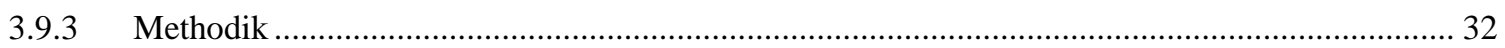

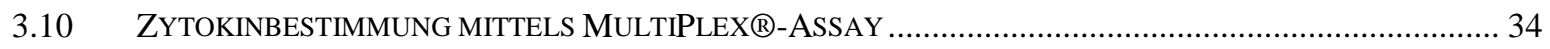

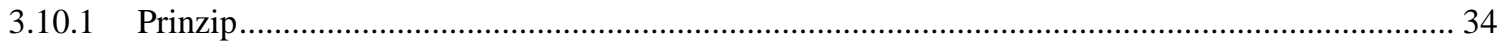

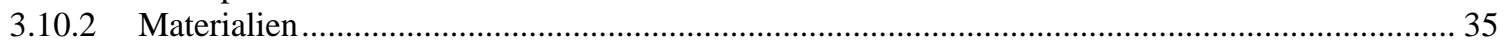

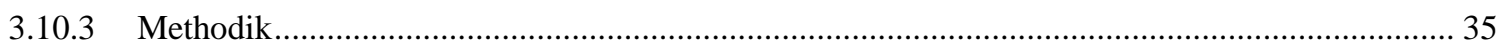

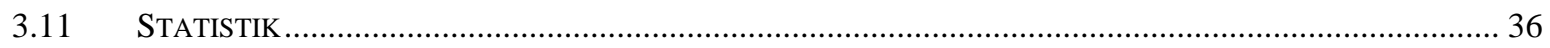

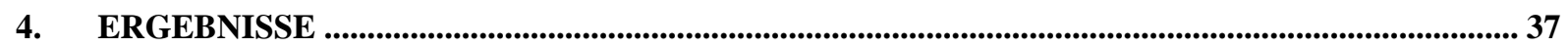

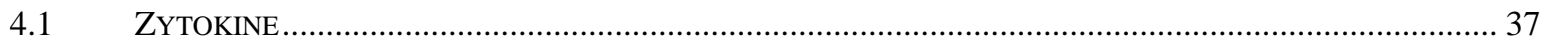




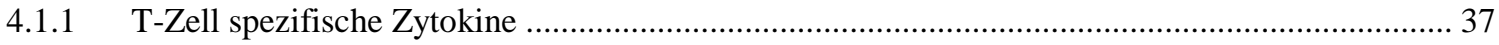

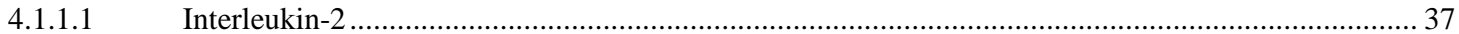

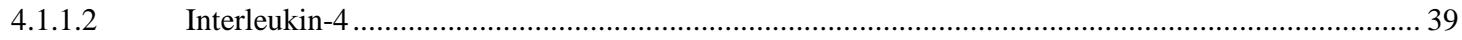

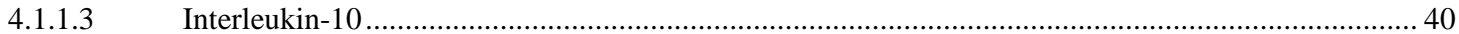

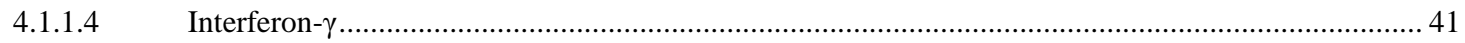

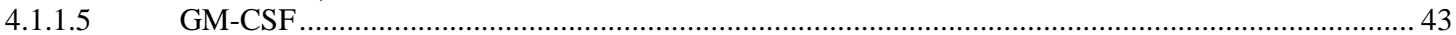

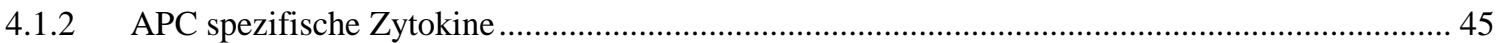

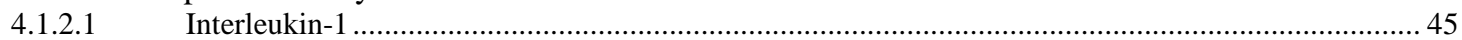

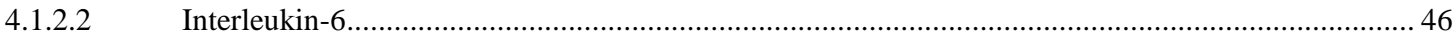

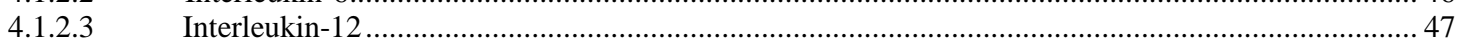

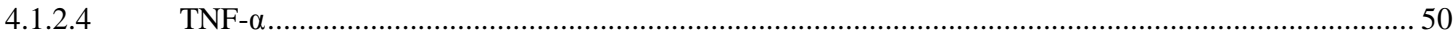

4.1.3 Zytokinkonzentrationen stimulierter Monokulturen ............................................................ 51

EXPRESSION VON OBERFLÄCHENMOLEKÜLEN

4.2.1 T-Zell spezifische Oberflächenmarker ....................................................................... 52

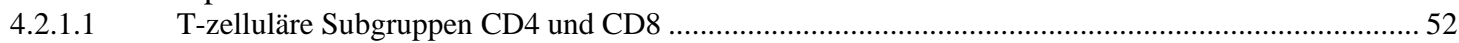

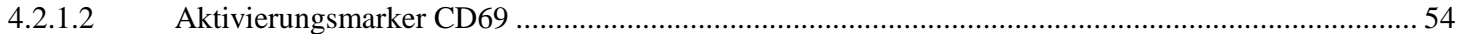

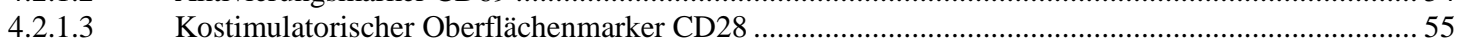

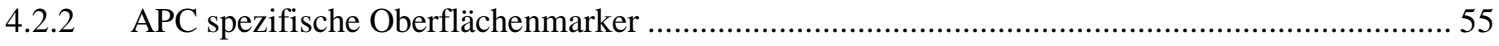

4.2.2.2 Kostimulatorische Oberflächenmarker CD80 und CD86 …..................................................... 57

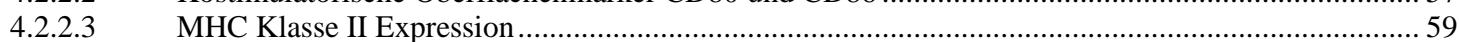

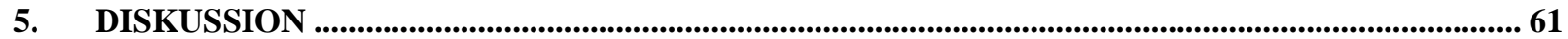

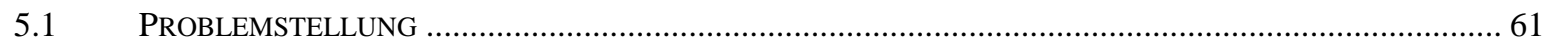

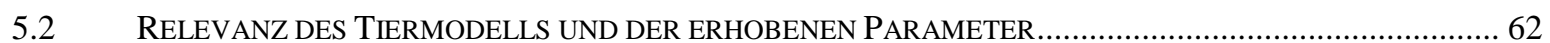

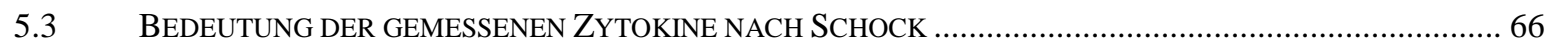

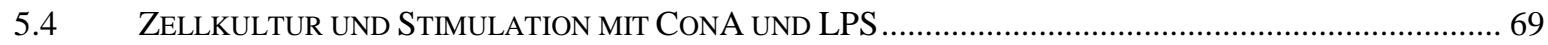

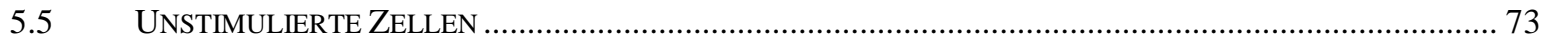

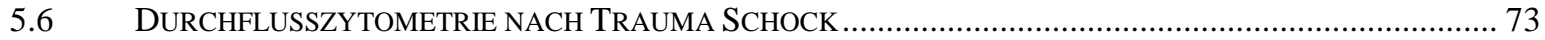

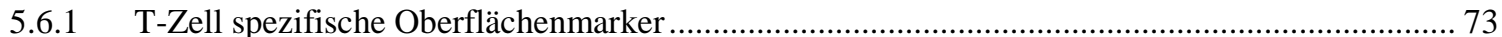

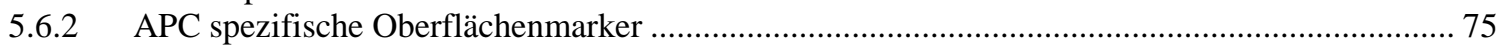

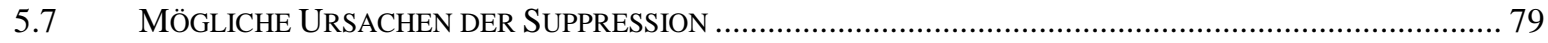

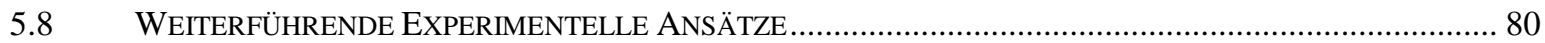

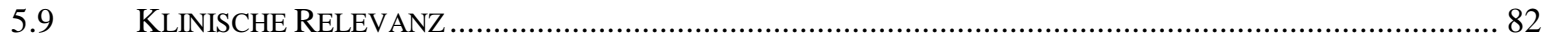

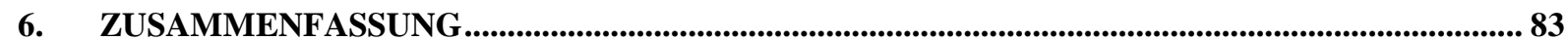

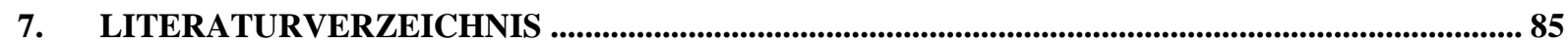

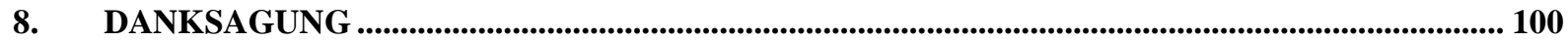




\section{Abkürzungsverzeichnis}

Abb.

Ak.

Alexa

Aqua dest.

APC

BSA.

bzw.

ca.

CARS.

$\mathrm{CD}$

Column

ConA

CRP

${ }^{\circ} \mathrm{C}$.

DC.

DMEM

ECD.

EDTA

ELISA.

et al.

FACS.

Fig.

FCS

FITC

FL-1,-2,-3,-4.

FSC

g.

GM-CSF

IFN- $\gamma$

IL-1,-2,-4,-6,-10,-12.

$L B P$

LPS.
Abbildung

Antikörper

Alexa Fluor ${ }^{\circledR} 488$

..Destilliertes Wasser

Antigen-Presenting-Cells

bovines Serumalbumin

..beziehungsweise

circa

..Compensatory Antiinflammatory Response Syndrome

Cluster of Differentiation

Säule

..Concanavalin A

..C-reaktives Protein

.Grad Celsius

..Dendritic Cells; Dendritische Zellen

Dulbecco`s Modified Eagle Medium

..Phycoerythrin - Texas Red®

.Ethylen-Diamin-Tetra-Acetat

.Enzyme Linked Immunosorbent Assay

..et altera

Fluorescence Activated Cell Sorter

Figur

.Fetal calf serum

Fluoreszeinisothiozyanat

.Fluoreszenz 1, 2, 3, 4

Forward-Scatter

Gramm

Granulocyte-Macrophage-Colony-Stimulating-Factor

.Interferon-gamma

Interleukin -1,-2,-4,-6,-10,-12

Lipopolyssacharide Binding Protein

..Lipopolysaccharid 


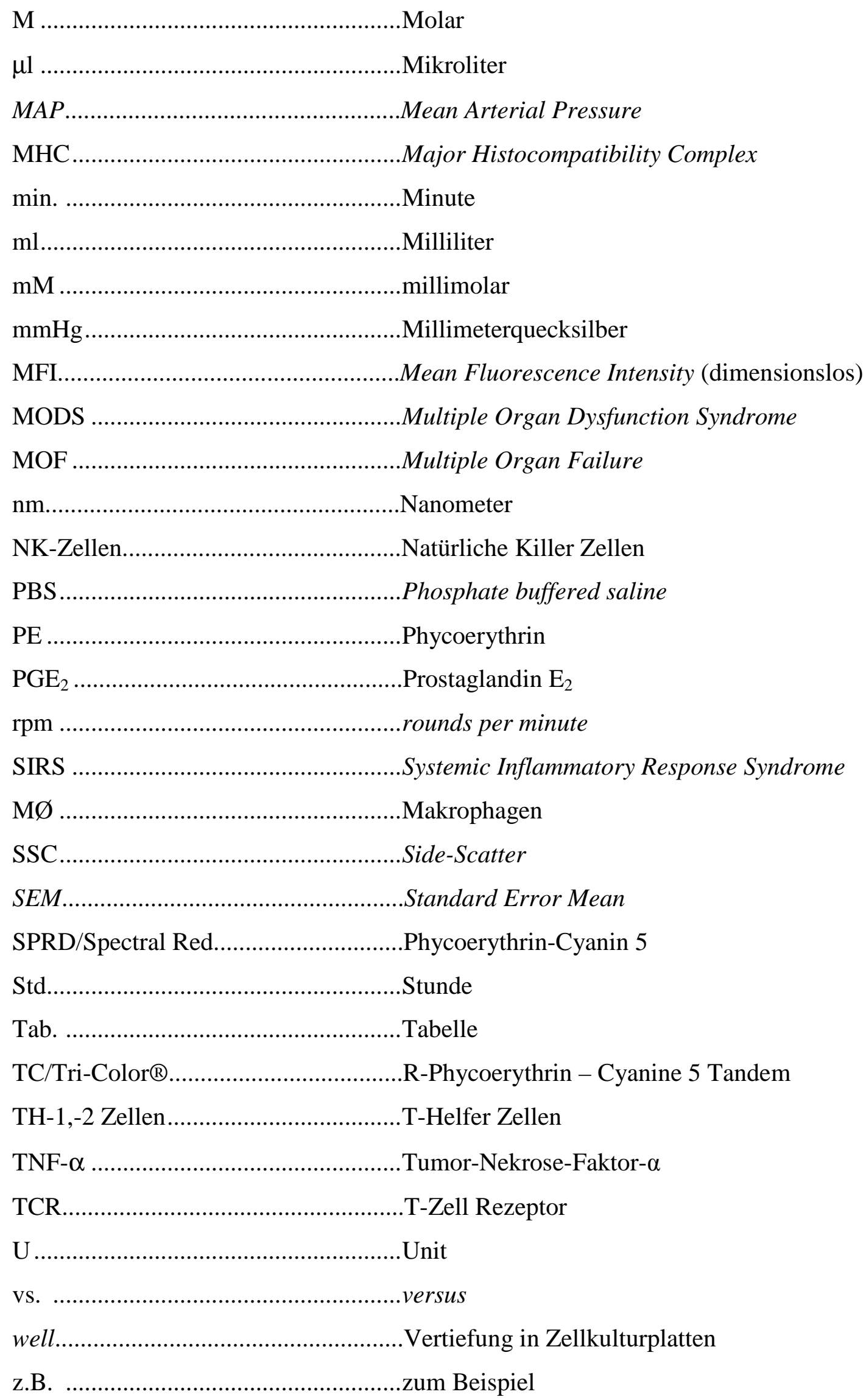




\section{Einleitung}

\subsection{Pathophysiologie des traumatisch-hämorrhagischen Schocks}

Der traumatisch-hämorrhagische Schock, im Rahmen von unfallbedingten Polytraumata oder ausgedehnten operativen Eingriffen, geht mit weitreichenden immunologischen Veränderungen und damit verbundener Komplikationen einher ${ }^{1,7,35}$.

Unmittelbare oder sehr frühe Todesfälle nach Traumata sind zumeist auf schwerste Schädelhirnverletzungen oder nicht kompensierbare Blutverluste zurückzuführen, wohingegen im zeitlichen Verlauf zunehmend Immundysfunktionen als Todesursache in den Vordergrund rücken ${ }^{81}$. Diese These wird durch das vermehrte Risiko für die Entwicklung von septischen Komplikationen gestützt ${ }^{35,38,44,45}$, welche wiederum mit einer massiv erhöhten Mortalität assoziiert sind ${ }^{63,83}$.

Direkt nach Trauma lösen ortständige Makrophagen zur Kontrolle der Gewebsverletzung und zur Einleitung von Abräummechanismen, eine „Akute Phase Reaktion“ aus ${ }^{81}$. In Zuge dessen kommt es zu massiver Ausschüttung von proinflammatorischen Zytokinen, deren steigende Konzentrationen in direktem Zusammenhang mit der Entwicklung weitreichender und deletärer Dysfunktionen stehen ${ }^{35}$.

Dem kommt eine multifaktoriell bedingte Minderperfusion des betroffenen Gewebes hinzu. Hier spielen v.a. hypovolämiebedingte Zentralisierung des zirkulierenden Blutvolumens, Freisetzung vasoaktiver Substanzen oder reduzierte katecholaminerge Sensibilität im betroffenen Gewebe eine Rolle ${ }^{26}$. In dessen Verlauf bildet sich eine Endothelleckage aus, die die Ausbildung eines lokalen Ödemes begünstigt, was die Perfusion des Gewebes zusätzlich reduziert und in der Ausbildung eines Circulus vitiosus der Minderperfusion und damit verbundener akzidentellen Gewebehypoxie münden kann ${ }^{26}$.

Bei Fortbestehen kommt es zur Ausschwemmung der proinflammatorischen Zytokine in anfänglich nicht betroffene Organe, was zu systemischen Entzündungsreaktionen des Körpers (SIRS = Systemic Inflammatory Response Syndrome) führen kann ${ }^{81,107}$. Eine generalisierte Inflammation ermöglicht die Ausbildung von Organdysfunktionen vor allem in Lunge, Niere und Leber was potentiell in der Entwicklung eines Multiorganversagen (MOF $=$ Multiple Organ Failure) mündet ${ }^{37,126}$. 
Interessanterweise löst im Verlauf der initialen Hyperinflammation die erhöhte Konzentration der proinflammatorischen Zytokine auch eine Ausschüttung einer Reihe von Mediatoren (z.B. $\mathrm{PGE}_{2}$ aus Makrophagen) aus, welche potenteste immunosuppressive Effekte auf T-Zellen und Makrophagenfunktion aufweisen ${ }^{7}$. Das resultiert in dieser Phase in einem synchronen Auftreten von Hyperinflammation (und damit verbundenem SIRS) und sich kompensatorisch entwickelnder Immunosuppression (CARS = Compensatory Antiinflammatory Response Syndrome) ${ }^{81}$ (Fig. 1).

Eine Gegenregulation der Hyperinflammation mit resultierender Immunosuppression kann als Versuch des Immunsystems gedeutet werden einerseits Reparaturmechanismen einzuleiten und andererseits einer überschießenden autoaggressiven Hyperinflammation entgegenzuwirken, was zu einer sekundären Gewebedestruktion und Infektanfälligkeit führt 81.

Im Verlauf dieses komplexen Schemas aus Hyperinflammation und Immunosuppression stellen sich auf zellulärer Ebene weitreichende Defizite der involvierten Immunzellen ein. Beispielsweise kommt es zur Deaktivierung von Makrophagen und reduzierter Antigenpräsentation, Anergie der T-Zellen, und einer Verschiebung des Gleichgewichts der T-Helfer-Zellen von TH-1 zu einer antiinflammatorischer TH-2 Antwort ${ }^{48}$. 
Fig. 1:

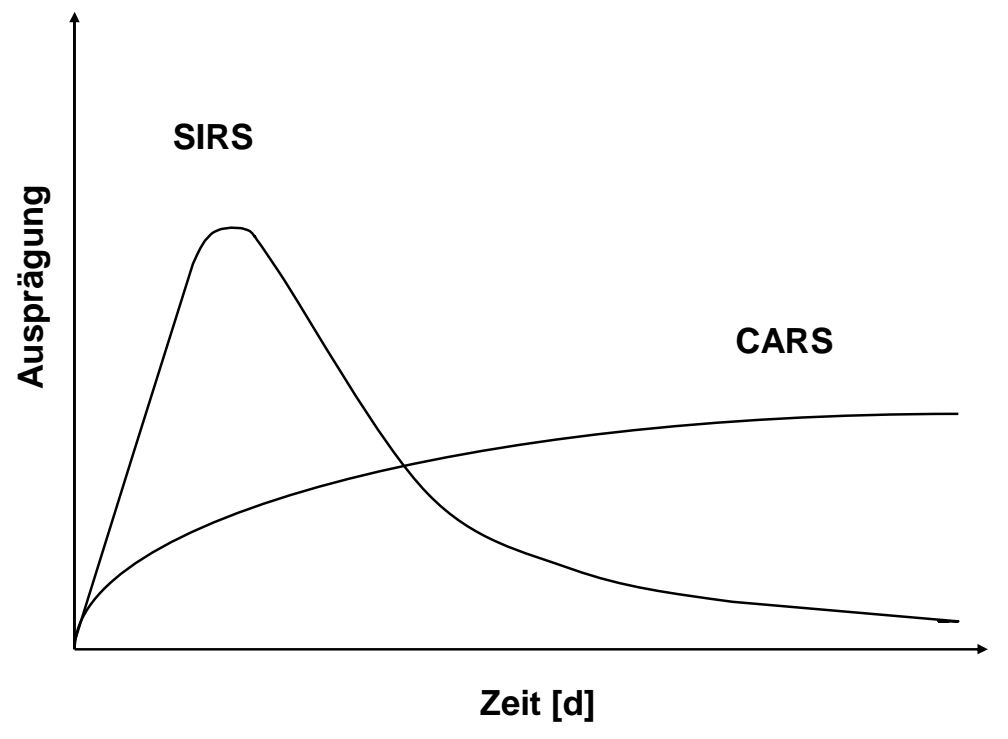

Fig. 1: Nach schwerer Infektion, Trauma oder ausgedehnter Operationen kommt es zunächst zu einer Phase mit dominierender systemischer Immunaktivierung (SIRS),wobei im zeitlichen Intervall eine Phase mit dominierender Antiinflammation (CARS) auftritt, in der der Organismus einer erhöhten Infektanfälligkeit ausgesetzt ist.

\subsection{Funktionsdefekte auf zellulärer Ebene}

In der Induktion und Aufrechterhaltung der Immunkompetenz übernehmen die Antigenpräsentierenden Zellen wie beispielsweise Makrophagen, Dendritische Zellen und BZellen eine entscheidende Rolle ${ }^{134}$. Sie weisen im Rahmen der systemischen Entzündungsreaktion nach Polytraumata und ausgedehnter chirurgischer Therapie eine reduzierte Sekretionsfähigkeit für proinflammatorische Zytokine wie IL-1, IL-6 und TNF- $\alpha$ auf ${ }^{7}$. Diese Beobachtung bestätigt sich in zahlreichen humanen und tierexperimentellen Studien mit unterschiedlichen Verletzungsmustern (Traumatisch-hämorrhagischer Schock, Verbrennungen, Knochenfrakturen) 1,2,37,77,81. Antigenpräsentierende Zellen aus unterschiedlichen Kompartimenten wie Milz, Peritoneum und Lunge zeigen nach Trauma und Blutverlust eine Suppression der Zytokinsekretion von IL-1B, IL-6 und TNF- $\alpha^{5,7,47,99,133}$, die bis zu sieben Tage anhält ${ }^{141}$. 
Diese Zytokine stehen im Zentrum der Vermittlung einer „Akute-Phase-Reaktion“, welche für eine zu diesem frühem Zeitpunkt adäquate Immunreaktion unerlässlich ist ${ }^{6,10,72,95}$.

Dem hinzukommend offenbart sich zusätzlich eine reduzierte Ausschüttung von IL-12 aus den Antigenpräsentierenden Zellen ${ }^{7,81}$. Dieses Zytokin spielt eine wichtige Rolle in der Initiierung und Steuerung der T-Zell-Antwort ${ }^{7,81}$. Im Rahmen einer Patientenstudie von Weihgardt et al. wurde ein selektiver Defekt in der Produktion von IL-12 durch Monozyten identifiziert, was einen prädiktiven Wert für die Entwicklung einer Sepsis und postoperativer Mortalität darstellte ${ }^{139}$.

Darüber hinaus existiert eine positive Rückkopplung von APC sezerniertem IL-12 und von TZellen exprimiertem IFN- $\gamma$. IL-12 stimuliert T-Zellen zur Produktion von IFN- $\gamma$ und fördert eine zytotoxische TH-1 Antwort der T-Zellen. IFN- $\gamma$ für sich stimuliert die Antigenpräsentierenden Zellen zur Ausschüttung von proinflammatorischer Zytokinen und nimmt darüber hinaus Einfluss auf die Antigenpräsentation via MHC II ${ }^{53}$.

Über diesen MHC II Komplex (Major Histocompatibility Complex) besitzen Antigenpräsentierende Zellen die außerordentliche Fähigkeit Bakterien oder Fremdantigene durch Phagozytose zu internalisieren, zu fragmentieren und über den T-Zell-Rezeptor von CD4 (+) T-Lymphozyten zu präsentieren ${ }^{19}$. In diesem Zusammenhang werden nur Antigene erkannt, die über diesen Komplex exprimiert werden ${ }^{33,121}$.

Im Tiermodel nach traumatisch-hämorrhagischem Schock und nach großer abdomineller Chirurgie scheint die Oberflächenexpression von MHC II reduziert ${ }^{19,61,94}$. Ayala et al. konnte zeigen, dass eine reduzierte Antigenpräsentation mit dieser verminderten MHC II Expression in Zusammenhang steht, was $\mathrm{zu}$ schwerer Immundefizienz ${ }^{89}$ und erhöhten Raten an Infektionen und Sepsis führt ${ }^{56,136}$. Darüber hinaus wies Janeway et al. nach, dass mit einer quantitativen Variation von MHC II und der damit verbundenen Antigenpräsentation eine Reihe von Erkrankungen wie beispielsweise das Hodgkin-Lymphom, lepromatöse Lepra, Sarkoidose sowie auch AIDS assoziiert sind ${ }^{76}$.

Die Fähigkeit zur Antigenpräsentation via MHC II vor allem von Dendritischen Zellen wird dabei unter anderem durch die zwei von T-Zellen sezernierten Wachstumsfaktoren IL-4 und GM-CSF gesteuert. Darüber hinaus weist das IL-4 wirksame Eigenschaften eines TH-2 Zytokins auf ${ }^{18,57,102}$. Die Präsentation von Antigenen über MHC II an CD4 (+) T-Zellen wird diesbezüglich durch eine Vielzahl von kostimulatorischen Botenstoffen und Molekülen moduliert.

Der vollen Stimulation beider beteiligten Zelltypen bedarf es aber nicht nur der Verbindung des T-Zell-Rezeptors (TCR) mit dem MHC II Oberflächenmolekül und der sezernierten 
Zytokine (IL-1, IL-6, TNF- $\alpha$, IFN- $\gamma$ ) 16,19,99,135, sondern auch die Bindung von kostimulatorischen Molekülen auf den Zelloberflächen beider Zelltypen - CD28 auf T-Zellen und auf Antigenpräsentierenden Zellen CD80 (B7.1) und CD86 (B7.2) ${ }^{66,67,87}$.

Diese „Verzahnung“ der T-Zellen und Antigenpräsentierenden Zellen inklusive der kostimulatorischen Oberflächenmarkern werden in Zuge dessen auch als „Immunologische Synapse“ bezeichnet ${ }^{46,97}$. Störungen in dieser Interaktion haben ebenfalls einen kompromittierenden Effekt auf die Immunantwort ${ }^{104}$, wobei dessen zugrunde liegenden Mechanismen jedoch noch weitgehend ungeklärt sind.

Bisherige Studien aus dem Bereich der Sepsisforschung zeigten unterschiedliche Effekte auf diese Oberflächenmoleküle. Newton. et al wies in einem Sepsismodell der Maus eine verminderte Präsentation von CD86 auf Peritonealmakrophagen nach ${ }^{99}$, wohingegen Ding et al. in gleichem Modell keine Änderung in der Expression von CD86 auf Dendritischen Zellen des Peritoneums ${ }^{47}$ zeigen konnte.

Fig.2:

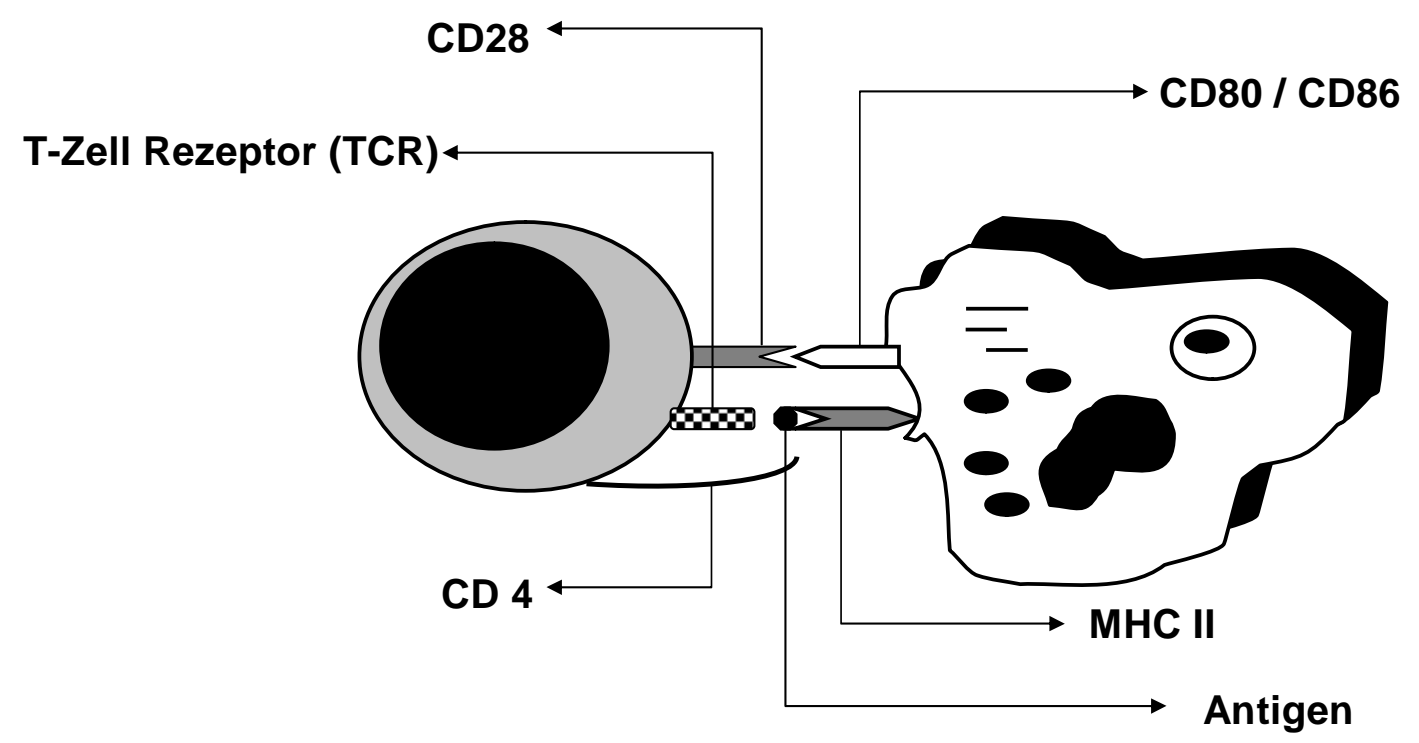

Fig. 2: Interaktion zwischen T-Zellen und Antigenpräsentierenden Zellen

Neben den funktionellen Defiziten der Antigenpräsentierenden Zellen im Bereich der Zytokinsekretion und der Antigenpräsentation, sowie der gestörten Interaktion zu T-Zellen offenbaren auch die T-Zellen selbst tief greifende Störungen ihrer Zellfunktion in klinischen und tierexperimentellen Studien ${ }^{7,37}$. 
So zeigen T-Zellen nach traumatisch hämorrhagischem Schock, ausgedehnten operativen Eingriffen und Verbrennungen eine reduzierte Fähigkeit der adäquaten Reaktion auf Stimulation durch beispielsweise das Mitogen Concanavalin A ${ }^{13,37}$.

Ferner resultiert nach traumatisch hämorrhagischem Schock auf identischen mitogenen Reiz eine verminderte T-zelluläre Proliferationsfähigkeit ${ }^{15,37}$, was auch mit einer erhöhten Rate septischer Komplikationen korreliert ${ }^{8,37}$.

Im Anbetracht der Immunsuppression sind auch Veränderungen im Bereich der T-HelferZellen und deren Subtypen TH-1 und TH-2 erfasst worden. Ein adäquates TH-1/TH-2 Verhältnis ist für eine suffiziente Immunabwehr unerlässlich ${ }^{57}$. Nach traumatisch hämorrhagischem Schock verschiebt sich, wie bereits erwähnt, das Gleichgewicht der THelfer-Zellen in Richtung einer antiinflammatorischer TH-2-Antwort ${ }^{9}$.

In diesem Zusammenhang sind im Verlauf nach Trauma und Blutverlust erniedrigte Konzentrationen des proinflammatorischen TH-1 Zytokins IL-2 und gegenläufig dazu gesteigerte Konzentrationen des TH-2 Zytokins IL-10 messbar 7,10,31,35,37,141. Beide Änderungen sind vergesellschaftet mit einer erhöhten Rate an septischen Komplikationen ${ }^{8,37}$. Dem ursächlich könnte sowohl das noch in der Hyperinflammation von APC sezernierte $\mathrm{PGE}_{2}$ als auch der Mangel an IL-12 zu Grunde liegen ${ }^{7,95}$, was für einen suppressiven Effekt der APC auf T-Zellen spräche.

Andererseits stellt in der Aktivierung der Antigenpräsentierenden Zellen das auch als Makrophagen-aktivierender-Faktor (MAF-1) bezeichnete IFN- $\gamma$ eine entscheidende Substanz dar. In zahlreichen Studien offenbart sich nach traumatisch hämorrhagischem Schock ein massiver Mangel an IFN- $\gamma^{4,89,101}$, wobei jener direkt mit einer verminderten Expression von MHC II und damit einhergehender Antigenpräsentation assoziiert ist ${ }^{66}$. Dem zu Folge könnten auch T-Zellen einen suppressiven Effekt auf die Antigenpräsentierenden Zellen hervorrufen. 
Fig.3:

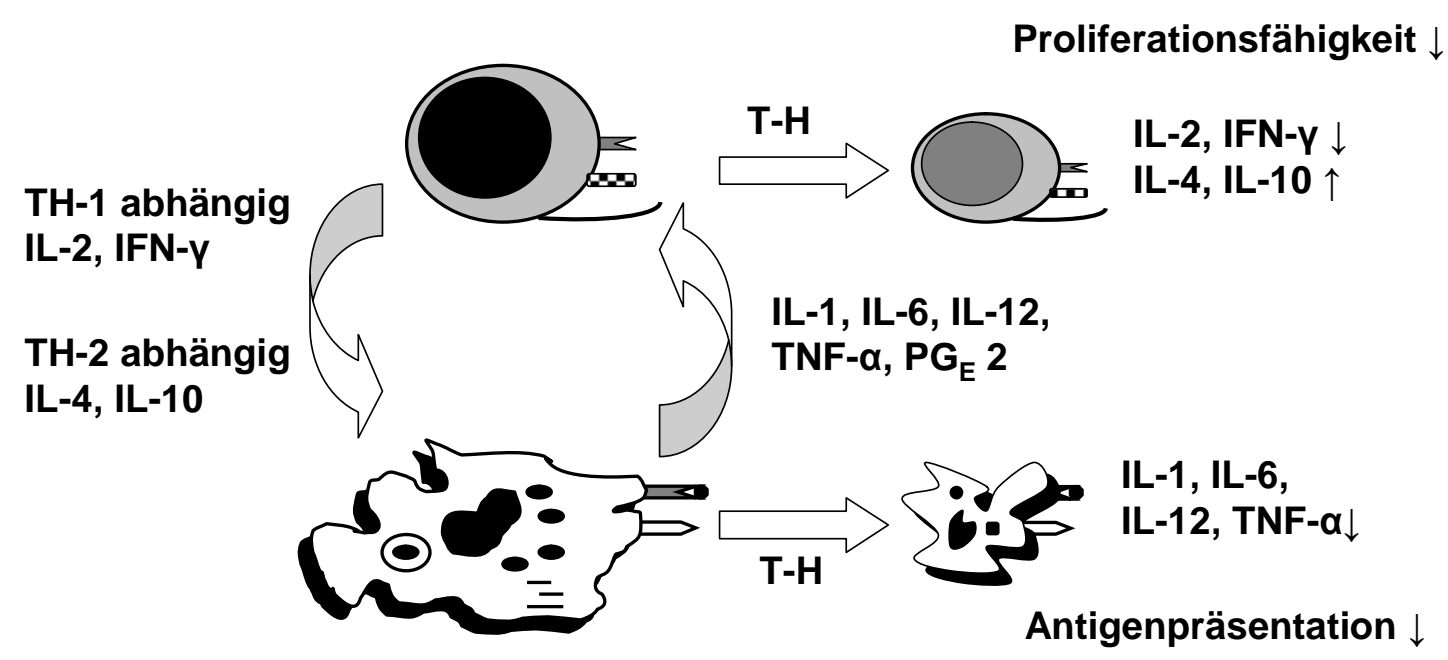

Fig. 3: Zeigt die komplexe Interaktion zwischen T-Zellen und APC in Bezug auf Zytokinsekretion und -interaktion in Zusammenhang mit der Antigenpräsentation im Rahmen eines traumatisch-hämorrhagischen Schocks $(T-H)$. 


\subsection{Fragestellung}

Durch die pathophysiologischen Abläufe der posttraumatischen Hyperinflammation mit im Verlauf zunehmender Immunosuppression, kommt es zu einer Störung der Interaktion von Antigenpräsentierenden Zellen und T-Zellen.

Ziel dieser Studie war es zu eruieren, welche dieser Immunzelle für die persistierende Immunsuppression nach traumatisch-hämorrhagischen Schock verantwortlich ist. 


\section{Hypothesen und Zielsetzungen}

Um die oben erörterte Problematik der zellulären Funktionsstörungen nach traumatischhämorrhagischem Schock genauer $\mathrm{zu}$ untersuchen, wurde im Rahmen dieser tierexperimentellen Studie die Zytokinsekretion der aus der Milz stammenden Antigenpräsentierenden Zellen und der T-Zellen 24 Stunden nach Trauma und hämorrhagischem Schock bestimmt. Zusätzlich wurde die Expression von Oberflächenmolekülen, wie beispielsweise die kostimulatorischen Moleküle und die Expression von MHC II auf Antigenpräsentierenden Zellen durchflusszytometrisch bestimmt.

- T-Zellen und Antigenpräsentierende Zellen zeigen nach traumatischhämorrhagischem Schock eine reduzierte Sekretion von Zytokinen wie beispielsweise IFN- $\gamma$ und IL. 12.

Ist dies eine direkte Folge des Schocks, oder wird dies durch eine Funktionsstörung einer der beiden interagierenden Zellen vermittelt?

Welche Immunzelle ist für die persistierende Immunosuppression nach traumatischhämorrhagischem Schock verantwortlich?

- Auch die Antigenpräsentation durch APC wird durch die Interaktion von T-Zellen und APC beeinflusst.

Wird die Antigenpräsentation durch eine T-Zell-Funktionsstörung nach Trauma und Schock kompromittiert?

- Kostimulatorische Moleküle, die auf den Oberflächen Zelloberflächen exprimiert werden, sind erforderlich für die Interaktion zwischen T-Zellen und APC.

Wird die Interaktion zwischen den Immunzellen durch eine Einschränkung deren Expression beeinflusst? 


\section{Material und Methoden}

\subsection{Versuchtiere}

Es wurden männliche Mäuse des Stammes $\mathrm{C} 3 \mathrm{H} / \mathrm{HeN}$ von Charles River aus Sulzfeld, Deutschland verwendet. Die Tiere waren zum Zeitpunkt der Versuche sechs bis acht Wochen alt und hatten ein Gewicht zwischen 20 und $26 \mathrm{~g}$.

Alle Prozeduren wurden von der Regierung von Oberbayern und der Ludwig-MaximiliansUniversität München bewilligt und von der deutschen Forschungsgesellschaft (DFG AN 357/1-1) gefördert.

Die Tiere wurden in Macrolon® Nr. 2 - Käfigen gehalten, mit einer Standarddiät (ssniff® R/M-H, ssniff Spezialdiäten $\mathrm{GmbH}$, Soest, Deutschland) ernährt und erhielten Wasser $a d$ libitum.

Während der gesamten Studie befanden sich die Tiere in der Tierhaltung des Institutes für Chirurgische Forschung der Ludwig-Maximilians-Universität München unter tierärztlicher Kontrolle.

\subsection{Versuchsgruppen}

Die Mäuse wurden in zwei Gruppen aufgeteilt:

Gruppe I: Traumatisch-hämorrhagischer Schock

Gruppe II: Kontrolloperation, d.h. kein Trauma, kein Blutverlust

\subsection{Traumatisch-hämorrhagisches Schockmodell}

Für die Durchführung des traumatisch-hämorrhagischen Schocks wurden die Tiere der Gruppe I mit einer Mischung aus Isoflurane (Forene®), Lachgas $\left(\mathrm{N}_{2} \mathrm{O}\right)$ und Sauerstoff $\left(\mathrm{O}_{2}\right)$ anästhesiert. In Rückenlage gebracht, wurden die Tiere rasiert und mit Hautantiseptikum desinfiziert. Als Weichteiltrauma wurde eine Mittellinienlaparotomie unter sterilen Operationsbedingungen durchgeführt. Nach Freipräparation der Muskelschicht eröffnete man das Peritoneum auf einer Länge von 2,5 cm und verschloss es anschließend wieder mit einem 6-0 Faden (Ethibond, Johnson-Johnson, Belgien). Die Haut wurde mit einem 5-0 Faden (Ethibond, Johnson-Johnson, Belgien) verschlossen. 
Anschließend wurde ein hämorrhagischer Schock initiiert. Hierfür eröffnete man beidseits die Leisten auf einer Länge von $0,5 \mathrm{~cm}$ und stellte die Oberschenkelarterien unter mikroskopischer Kontrolle dar. Beide Arterien wurden distal ligiert und mit Polyethylen Katheter (SIMS Portex, UK) kanüliert. Über beide Katheter konnte entweder durch Aspiration den Versuchtieren Blut zur Blutdruckreduktion entnommen werden, oder kontinuierlich der mittlere arterielle Blutdruck gemessen $(M A P)$ werden. Dies geschah mittels eines computergesteuerten Messprogrammes (Digi-Med, Louisville, KY). Der herkömmliche MAP einer Maus von ca. 90mmHg wurde innerhalb von zehn Minuten auf Werte von $35 \pm 5 \mathrm{mmHg}$ über einen der beiden Katheter gesenkt und für $90 \mathrm{~min}$ auf diesem Niveau gehalten. In Fig.4 ist der Blutdruckverlauf während der Dauer des Schocks und der Reperfusion dargestellt.

Während dieses Zeitraumes des Schocks befanden sich die Versuchtiere nicht in Narkose, da die hypothensive Wirkung der Inhalationsnarkotika eine standardisierte Durchführung des Blutdruck-kontrollierten Schockmodells unmöglich gemacht hätte.

Im Anschluss an die hypothensive Phase wurde den Versuchtieren über einen der Katheter das Vierfache des entnommenen Blutvolumens in Form von Ringer-Laktat (B. Braun Melsungen AG, Melsungen, Deutschland) im Zeitraum über 30 min zugeführt.

Nach Beendigung der Reperfusion wurden die Tiere wieder narkotisiert, die Katheter entfernt, die Femoralarterien ligiert und die Haut mit einem 5-0 Ethicon® Faden verschlossen.

Vor Wundverschluss wurde auf den Wundbereich noch Xylocain ${ }^{\circledR}$ (Lidocain, AstraZeneca $\mathrm{GmbH}$, Wedel, Deutschland) zur Lokalanästhesie aufgebracht. 
Fig.4:

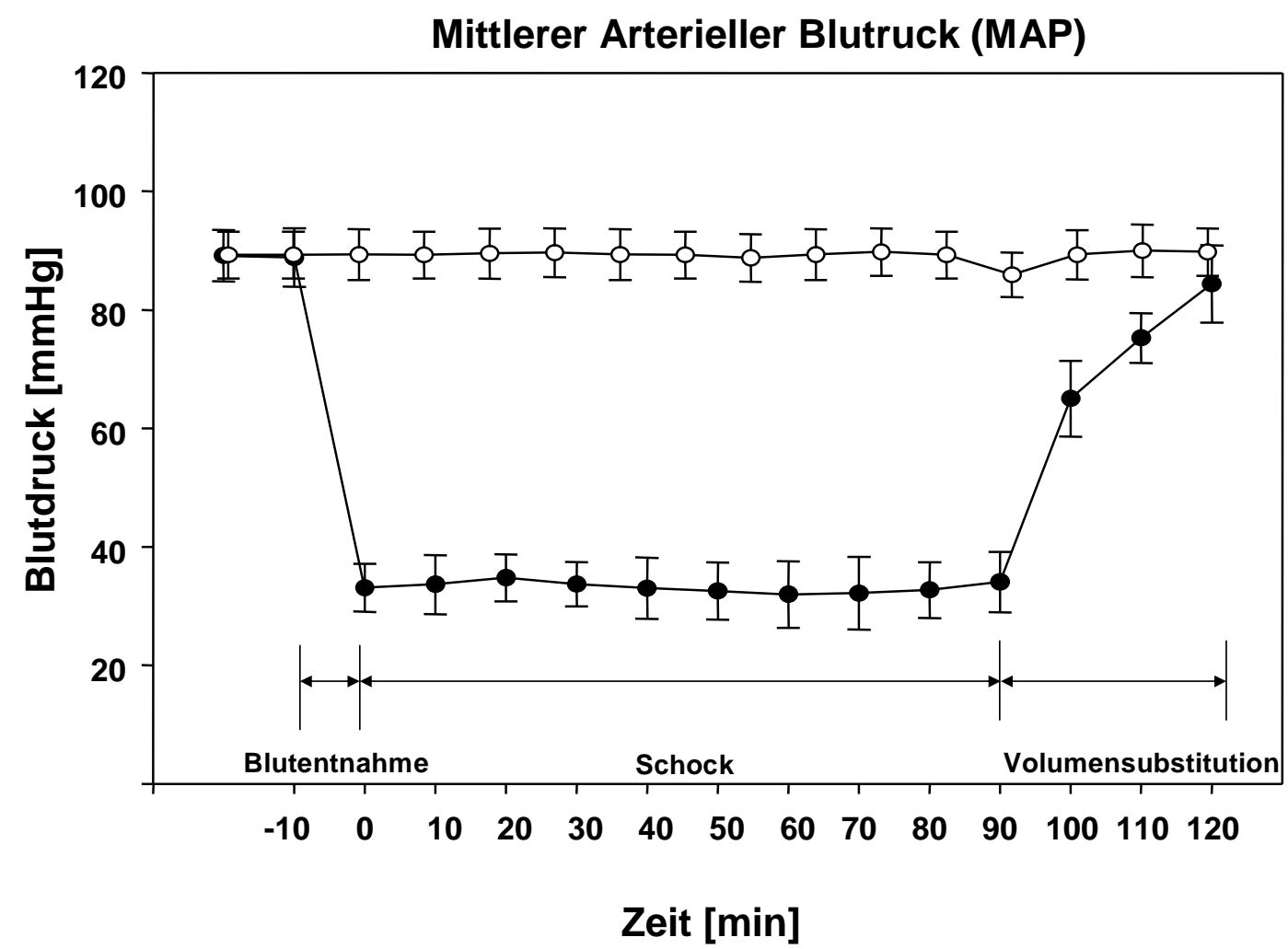

Fig. 4: Blutdruckkurve (schwarz) im Rahmen der hämorrhagischen Phase des Schocks (90 min) und anschließender Flüssigkeitssubstitution $(30 \mathrm{~min}) . \quad$ Weiß dargestellt der Blutdruckverlauf der Kontrolltiere ohne hämorrhagischen Schock.

\subsection{Kontrolloperation}

Die Kontrolloperation (Fig.4) der Versuchtiere in Gruppe II beinhaltete ebenfalls das Einlegen der Katheter in die Femoralarterien unter der gleichen Narkose (Forene $\left.{ }^{\circledR}+\mathrm{N}_{2} \mathrm{O}+\mathrm{O}_{2}\right)$, Blutdruckmessung über 90 min, Ligatur der Arterien und der Hautverschluss mit 5-0 Faden. Dabei wurde jedoch weder Blut entnommen, noch eine Eröffnung des Peritoneums durchgeführt.

Die Versuche wurden immer zur gleichen Tageszeit durchgeführt, um möglichen zirkadianen Schwankungen der Plasmahormonspiegel vorzubeugen.

24 Std. nach Schock wurden die Versuchstiere durch eine Überdosis Narkosegas (Forene $\left.{ }^{\circledR}\right)$ eingeschläfert. 


\subsection{Gewinnung der Milzzellen}

\subsubsection{Methodik}

24 Stunden nach Schock wurden pro Versuchsansatz die Milz aus jeweils einer Maus der zwei Versuchsgruppen gewonnen. Dazu wurde die Bauchhöhle unter sterilen Operationsbedingungen eröffnet, die Milz freipräpariert, abgesetzt und in einer sterilen, eisgekühlten Phosphat gepufferten Salzlösung (PBS; Merck, Darmstadt, Deutschland) asserviert.

Die Milzzellen gewann man indem man die jeweilige Milz zwischen zwei gekühlten Objektträgern vorsichtig zerrieb. Die daraus gewonnenen Zellsuspensionen (je eine Suspension aus einer geschockten Maus und einer kontrolloperierten Maus) wurden bei 1400 $r p m$ für 15 min und $4^{\circ} \mathrm{C}$ zentrifugiert und resuspendiert.

Darin enthaltene Erythrozyten lysierte man durch Zugabe von sterilem Aqua dest. Die Lyse wurde durch Zugabe von 10 x konzentriertem PBS nach circa fünfzehn Sekunden gestoppt. Noch in Lösung befindliche Erythrozytenfragmente konnten aufgrund ihrer Eigenschaft zur Adhäsion an Glasoberflächen mittels Titration durch eine Glaspipette herausgefiltert werden. Anschließend zentrifugierte man die Zellsuspensionen erneut bei $1400 \mathrm{rpm}$ und $4^{\circ} \mathrm{C}$ für 15 $\min$.

Noch bevor mit der Separation der T-Zellen und APC begonnen wurde, asservierte man pro Suspension $2 \times 10^{6}$ Zellen, die für die Detektion der Oberflächenmarker direkt 24 Stunden und noch vor Stimulation und Zellkultur bestimmt waren. Der genaue Ablauf der Zellfärbung und Durchflusszytometrie entsprach denselben unten beschriebenen Verfahren. 


\subsubsection{Materialien}

Tab.1:

\begin{tabular}{|c|c|}
\hline Geräteart & Herkunft/Firma \\
\hline Brutschrank & US-AUTO-Flow ${ }^{\circledR}$, NuAir, Phymouth, Minnesota, USA \\
\hline Arbeitsbank & $\begin{array}{l}\text { Gelaire }^{\circledR}, \text { BSB 6A, Flow Laboratories GmbH, Meckenheim, } \\
\text { Deutschland }\end{array}$ \\
\hline Mikroskop & IDO 3, Zeiss, Deutschland \\
\hline Zentrifuge & Rotixa / PR, Hettich, Tuttlingen, Deutschland \\
\hline Vortexgerät & Bender \& Hobein AG, Zürich, Schweiz \\
\hline Pipettierhilfe Easypet & Eppendorf, Deutschland \\
\hline $\begin{array}{l}\text { Handpipetten } \\
10 \mu 1,100 \mu 1 \text { und } 1000 \mu 1\end{array}$ & Eppendorf, Deutschland \\
\hline $50 \mathrm{ml}$ Zentrifugiergefäße & Blue Max $^{\mathrm{Tm}}$, Falcon, BD, Heidelberg, Deutschland \\
\hline $15 \mathrm{ml}$ Zentrifugiergefäße & TPP, Trasadingen, Schweiz \\
\hline $\begin{array}{l}\text { sterile Pipettenspitzen }(5 \mathrm{ml}, \\
10 \mathrm{ml}, 25 \mathrm{ml})\end{array}$ & Costar $^{\circledR}$, Corning, NY, USA \\
\hline $\begin{array}{l}\text { sterile Pipettenspitzen }(10 \mu 1, \\
100 \mu 1,1000 \mu \mathrm{l})\end{array}$ & Rainin, Leiden, Niederlande \\
\hline Gewebekulturplatte (24-well) & Nunclon ${ }^{\mathrm{TM}}$ Surface, Nunc ${ }^{\mathrm{TM}}$, Wiesbaden, Deutschland \\
\hline $\begin{array}{l}\text { Zell-Zählkammer nach } \\
\text { Neubauer }\end{array}$ & Karl Hecht KG, Sondheim, Germany \\
\hline
\end{tabular}

Tab.: 1 zeigt im Verlauf der Zellkultur verwendete Geräte und Hilfsmittel. 


\subsection{Immunomagnetische Zellsortierung (MACS®)}

Nachdem aus den zwei Versuchstieren die Milzen gewonnen wurden, die Zellen in Lösung gebracht, die Erythrozyten lysiert und die Zellen gezählt wurden, konnte mit der Separation der T-Zellen begonnen werden. Für diese Auftrennung verwendete man sich der immunomagnetischen Zellseparation der Firma Miltenyi (Bergisch Gladbach, Deutschland).

\subsubsection{Prinzip}

Die Technik basiert auf der Verwendung von MACS® Microbeads - dies sind supermagnetische Kleinstpartikel (ca. 50nm) konjugiert an monoklonale Antikörper. Die Antikörper für sich sind hochspezifisch für charakteristische Oberflächenantigene $(C D$, Cluster of Differentiation), die die verschiedenen Zellpopulationen durch deren Expression differenzierbar machen.

Hier verwendete Antikörper waren spezifisch für die Oberflächenmarker CD11b, CD45R, DX-5 und Ter-119. Damit wurden folgende Zellreihen magnetisch markiert: B-Zellen, Natürliche Killerzellen (NK), Dendritische Zellen (DC), Makrophagen (MØ), Granulozyten und Erythrozyten.

Nicht markiert und damit nicht magnetisierbar waren alle Subpopulationen der T-Zell-Reihe, wobei sich diese Art der Zellauftrennung für T-Zellen Negativselektion nennt. 
Fig. 5:

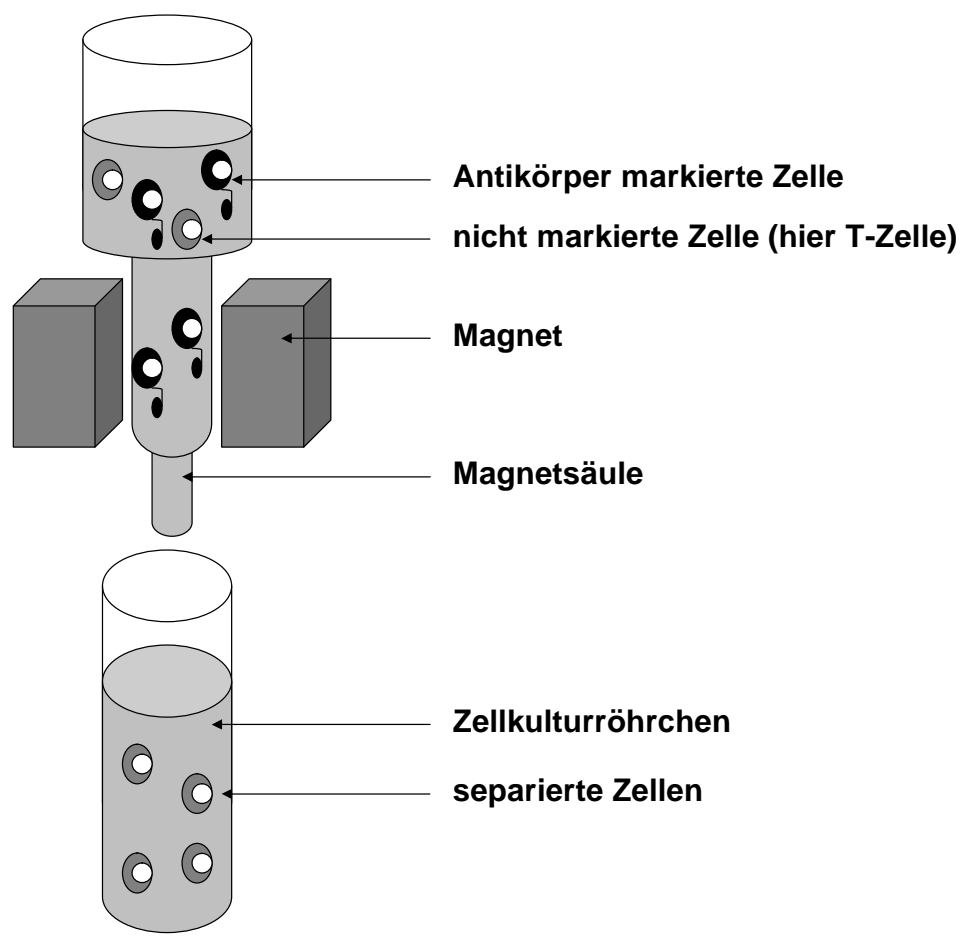

Fig. 5: Schematische Darstellung der MACS® Zellseparation. Die Antikörper-Markierten Zellen werden in dem Magnetfeld zurückgehalten, die unmarkierten Zellen, respektive T-Zellen, fließen ungehindert durch die MACS® Column in das Zellkulturröhrchen. 


\subsubsection{Materialien}

Tab. 2:

\begin{tabular}{|l|l|l|}
\hline Produkte & Enthalten & Herkunft \\
\hline MACS-Puffer & $\begin{array}{l}\text { 11 PBS, ph7,2 } \\
+0,5 \mathrm{~g} \text { BSA } \\
+2 \mathrm{mM} \text { EDTA }\end{array}$ & $\begin{array}{l}\text { (für Zellseparation nach } \\
\text { Angaben des Herstellers } \\
\text { hergestellt) }\end{array}$ \\
\hline $\begin{array}{l}\text { Biotin-Antibody- } \\
\text { Cocktail }\end{array}$ & $\begin{array}{l}\text { Cocktail enthält biotin-konjugierte, } \\
\text { monoklonale Antikörper gegen: } \\
\text { CD11b, CD45R, DX5 und Ter-119 }\end{array}$ & $\begin{array}{l}\text { Miltenyi Biotec, Bergisch } \\
\text { Gladbach, Deutschland }\end{array}$ \\
\hline $\begin{array}{l}\text { Anti-Biotin } \\
\text { MicroBeads® }\end{array}$ & $\begin{array}{l}\text { Superparamagnetische } \\
\text { MicroBeads® konjugiert an } \\
\text { monoklonale Antikörper }\end{array}$ & $\begin{array}{l}\text { Miltenyi Biotec, Bergisch } \\
\text { Gladbach, Deutschland }\end{array}$ \\
\hline $\begin{array}{l}\text { MACS® LS- } \\
\text { Columns }\end{array}$ & $\begin{array}{l}\text { Magnetsäule mit } \\
\text { kunststoffumhüllten magnetischen } \\
\text { Fasern }\end{array}$ & $\begin{array}{l}\text { Miltenyi Biotec, Bergisch } \\
\text { Gladbach, Deutschland }\end{array}$ \\
\hline $\begin{array}{l}\text { MidiMACS } \\
\text { Separations Kit }\end{array}$ & $\begin{array}{l}\text { MACS LS Column-Adapter + } \\
\text { Haltervorrichtung }\end{array}$ & $\begin{array}{l}\text { Miltenyi Biotec, Bergisch } \\
\text { Gladbach, Deutschland }\end{array}$ \\
\hline
\end{tabular}

Tab. 2: zeigt die bei der immunomagnetischen Zellseparation der T-Zellen verwendeten Materialien.

\subsubsection{Methodik}

Nach erneutem Waschen der Zellsuspensionen, nur diesmal mit dem eigens für die Separation angesetzten Puffer (Tab.2), wurden die Überstände abgesaugt, resuspendiert und $1 \mu 1$ pro $10^{6}$ Zellen des Biotin-Antibody-Cocktails (Tab.2) zugegeben. Nach zehn Minuten Inkubation bei $4-8^{\circ} \mathrm{C}$, wurden in einem zweiten Arbeitsschritt $2 \mu 1 / 10^{6}$ Zellen der Anti-Biotin-MicroBeadsLösung (Tab.2) hinzu pipettiert. Nach 15 minütiger Inkubation bei $4-8^{\circ} \mathrm{C}$ wurden die Zellsuspensionen mit $4 \mathrm{ml}$ Pufferlösung gewaschen und $10 \mathrm{~min}$ bei $1200 \mathrm{rpm}$ und $4^{\circ} \mathrm{C}$ zentrifugiert. 
Nach Verwerfen des Überstandes wurden die Zellen resuspendiert, mit $5 \mathrm{ml}$ Puffer verdünnt und die zwei Zellsuspensionen aus den Milzen der geschockten- und der kontrolloperiertenMaus durch jeweils eine MACS® Column (Tab.2) pipettiert. Diese mit Stahlwolle gefüllten Säulen für sich befanden sich in einer Vorrichtung mit einem starken Magnetfeld.

Beim Durchfluss durch dieses Magnetfeld wurden alle magnetisch markierten Zellen in den Säulen gehalten, alle nicht markierten Zellen - in diesem Falle die T-Zellen - konnten ungehindert die Säule passieren und in einem Zellkulturgefäß aufgefangen werden.

Nach viermaligem Waschen der Säulen mit jeweils $3 \mathrm{ml}$ Puffer und Herausnehmen der MACS ${ }^{\circledR}$ Columns aus der Vorrichtung konnten nun die vorher im Magnetfeld gebundenen Zellen durch zweimaliges Spülen mit $5 \mathrm{ml}$ Pufferlösung gewonnen werden.

Auf diese Weise erreichte man einen Reinheitsgrad der T-Zellen in der Suspension von durchschnittlich 93\%, welche durch mehrere eigens angefertigte durchflusszytometrische Messungen bestätigt wurde.

Fig. 6a und 6b:

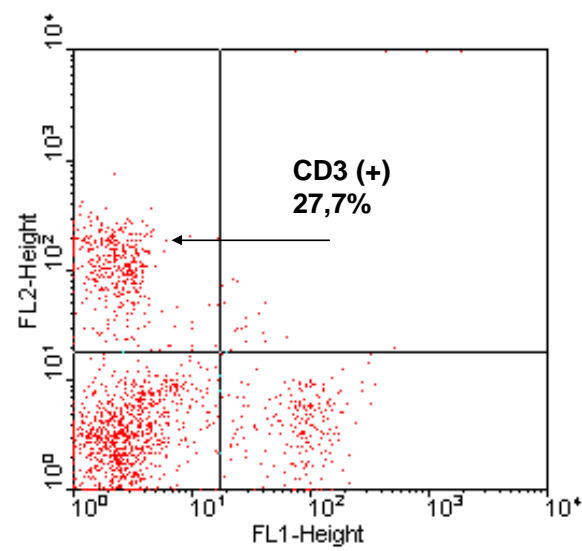

Fig. 6a:

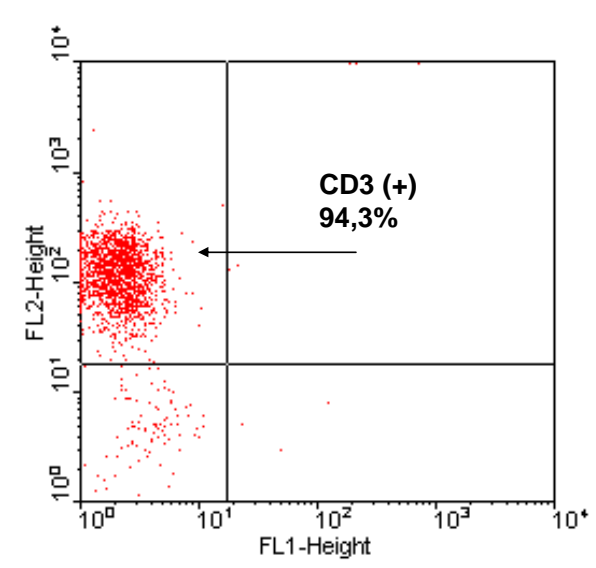

Fig. 6b:

FL-1 Makrophagenmarker CD11b (+); FL-2 T-Zellmarker CD3 (+) vor(6a) und nach(6b) MACS® Zellseparation. 
Nach Separierung der T-Lymphozyten wurden die vier Zellsuspensionen (jeweils die separierten T-Zellen und die Zellsuspensionen der „Nicht-T-Zellen“ der kontrolloperierten und der geschockten Maus) nochmals bei 1200 rpm für 10 min zentrifugiert, in Nährmedium aufgenommen, gezählt und auf die später für die Zellkultur benötigten Konzentrationen verdünnt.

\subsection{Gewinnung der Antigenpräsentierenden Zellen}

Nachdem aus den Zellsuspensionen die T-Lymphozyten separiert wurden, konnten daraus die Antigenpräsentierenden-Zellen durch deren Eigenschaft der Adhärenz auf Plastikoberflächen aufgereinigt werden. Hierzu wurde in die im weiteren Verlauf zur Zellkultur verwendeten 24well-Zellkulturplatten pro well eine Million Zellen pipettiert und bei $37^{\circ} \mathrm{C}$ und $5 \% \mathrm{CO}_{2} \mathrm{im}$ Kulturschrank inkubiert.

Nach zwei Stunden entfernte man vorsichtig das Nährmedium und wusch die einzelnen wells noch weitere vier Mal mit warmem Nährmedium behutsam, um die nicht adhärenten Zellen aus den wells zu entfernen.

\subsection{Zellkultur und Stimulation}

Zu den adhärenten Zellen - respektive Antigenpräsentierenden-Zellen - (ca. 100.000 Zellen) wurden pro well 500.000 T-Zellen hinzu pipettiert. Dadurch entstanden vier Kokulturen mit dem physiologischen Quotienten von 1:5 aus T-Zellen und Antigenpräsentierenden Zellen, die entweder aus den Milzen einer geschockten oder einer kontrolloperierten Maus gewonnen wurden (Fig.7). Diese Ansätze wurden für 48 Stunden bei $37^{\circ} \mathrm{C}$ und $5 \% \mathrm{CO}_{2}$ in $1 \mathrm{ml} /$ well Zellkulturmedium (DMEM $+10 \%$ FCS $+1 \%$ L-Glutamin $)$ inkubiert und mit unterschiedlichen Substanzen stimuliert. 
Fig. 7:
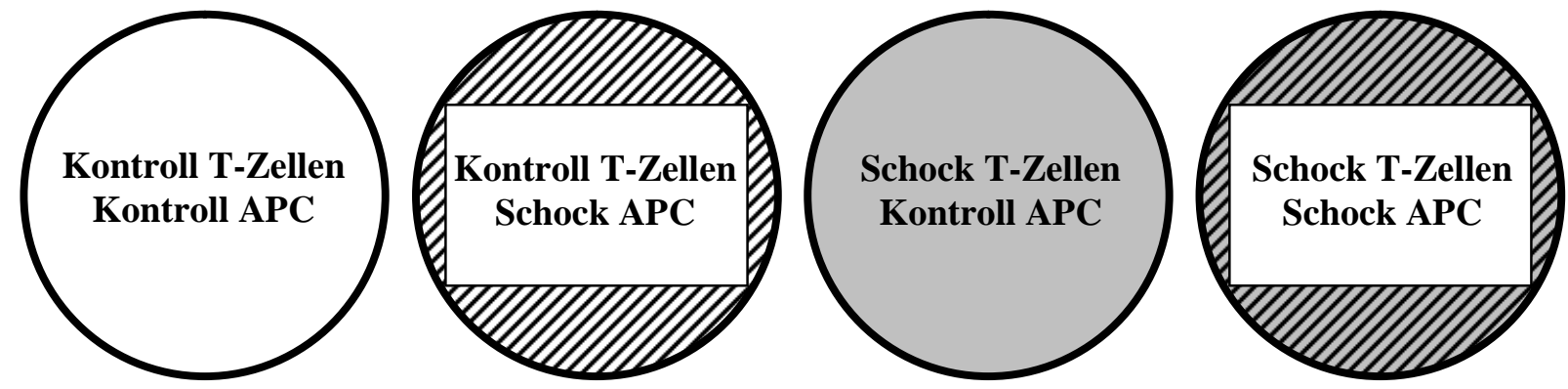

Fig. 7: Kokulturen von zuvor separierten T-Zellen und APC aus geschockten (Schock) und kontrolloperierten (Kontroll) Mäusen 24 Stunden nach traumatisch-hämorrhagischem Schock

Für die Stimulation der T-Zellen wurde das Polysaccharid Concanavalin A (ConA) gewählt, das beispielsweise nach Zugabe in die Zellkultur zur Sekretion von IL-2 und IFN- $\gamma$ führt ${ }^{105}$. Für die Stimulation der Antigenpräsentierenden Zellen verwendete man Lipopolysaccharid (LPS). Dieser Bestandteil der Zellmembran von Escherichia coli führt über die Bindung an den CD14 Rezeptor zu einer Aktivierung der Antigenpräsentierenden Zellen ${ }^{84}$.

Zusätzlich $\mathrm{zu}$ diesen Kokulturen setzte man Monokulturen der T-Zellen und Antigenpräsentierenden Zellen mit gleichem Stimulationsmuster an, darüber hinaus wurden zusätzlich unstimulierte Zellkulturen angesetzt.

Nach 48 Stunden Inkubation der Zellen im Brutschrank wurden die Überstände aliquotiert und bei $70^{\circ} \mathrm{C}$ asserviert - die zurückbleibenden Zellen zur Bestimmung und Quantifizierung von Oberflächenmolekülen der Durchflusszytometrie zugeführt. 


\subsection{Durchflusszytometrie}

\subsubsection{Prinzip}

Die Durchflusszytometrie ist eine Methode zur Analyse der Fluoreszenz- und Streulichteigenschaften von Einzelzellen in Suspension. Dabei können die Zellen mittels spezifischer, fluoreszenzmarkierter, monoklonaler Antikörper anhand ihrer Oberflächenantigene (CD) charakterisiert werden, was eine Unterscheidung von Zellen mit ähnlichen morphologischen Eigenschaften ermöglicht.

Die zu untersuchende Zellsuspension wird über eine Kapillare mit Überdruck in den Messbereich befördert. Dieser Druck beschleunigt die Zellen beim Eintreffen am Analysepunkt, so dass sie in der Suspension einzeln aneinandergereiht vorliegen. Zellaggregate werden durch diesen Vorgang, der auch als hydrodynamische Fokussierung bezeichnet wird, aufgelöst.

Am Analysenpunkt trifft monochromatisches Licht einer Wellenlänge von $488 \mathrm{~nm}$, das mittels eines fokussierten Argonlaserstrahls generiert wird, auf die Einzelzelle.

Jede Zellart streut entsprechend ihrer Größe, der Struktur ihrer Zellmembran und der Art ihrer intrazellulären Bestandteile das auftreffende Licht in spezifischer Weise. Der größte Anteil des Lichtes wird vorwärts gestreut, wobei das Vorwärtsstreulicht (FSC) nach Ausblendung des ungebrochenen Zentralstrahles ein Maß für die Größe der Zelle darstellt.

Ein weiterer Teil des Lichtes wird im rechten Winkel zum einfallenden Lichtstrahl gestreut und als Seitwärtsstreulicht (SSC) bezeichnet. Das Maß der Seitwärtsstreuung ist dabei von der Granularität der Zelle abhängig.

Die zu bestimmenden Zellen werden zusätzlich mit monoklonalen Antikörpern markiert, die ihrerseits mit verschiedenfarbigen Fluoreszenzfarbstoffen konjugiert sind.

Die Farbstoffe werden durch das vom Laser generierte Licht mit der Wellenlänge $488 \mathrm{~nm}$ zur Fluoreszenz angeregt und emittieren daraufhin Licht unterschiedlicher Wellenlängen. Die Maxima der Fluoreszenzspektren sind in Tabelle 3 ersichtlich.

Über Spiegel- und Filtersysteme werden die von jeder einzelnen Zelle ausgesandten Fluoreszenz- und Streulichtsignale auf Photoverstärkerröhren geleitet. Diese Signale werden von Detektoren erfasst. Es wird die Amplitude des Pulses bestimmt und zur quantitativen Auswertung auf den angeschlossenen Computer (Coulter EPICS XL, Beckman Coulter Inc., CA, USA) übertragen. 
Fig. 8:

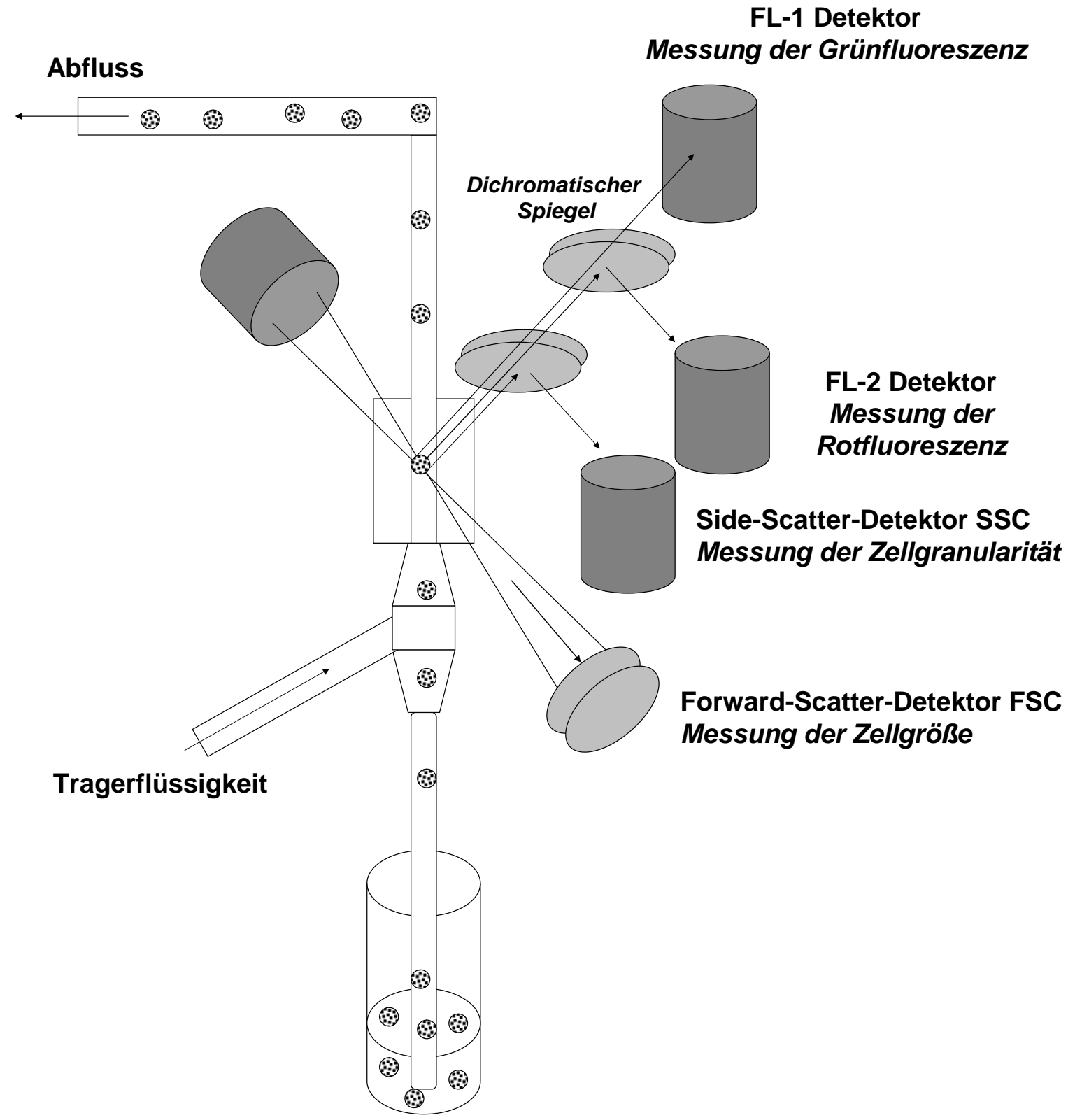

Fig.8: $\quad$ Schematische Darstellung des Funktionsprinzips einer durchflusszytometrischen Messung. 


\subsubsection{Materialien}

Tab. 3:

\begin{tabular}{|l|l|l|}
\hline Fluoreszenzfarbstoff & Kürzel/Synonym & Emissionsmaximum \\
\hline Fluorescein Isothiocyanat & FITC & $520 \mathrm{~nm}$ (gelb-grün) \\
\hline Alexa Fluor® 488 & Alexa & $520 \mathrm{~nm}$ (gelb-grün) \\
\hline Phycoerythrin & PE & $575 \mathrm{~nm}$ (orange-rot) \\
\hline Phycoerythrin-Cyanin 5 & SPRD/Spectral Red & $670 \mathrm{~nm}$ (rot-violett) \\
\hline R-Phycoerythrin - Cyanine 5 Tandem & TC/Tri-Color ${ }^{\circledR}$ & $670 \mathrm{~nm}$ (rot-violett) \\
\hline Phycoerythrin - Texas Red® & ECD & $620 \mathrm{~nm}$ (rot) \\
\hline
\end{tabular}

Tab.3: verwendete Fluoreszenzfarbstoffe bei der Durchflusszytometrie.

Tab. 4:

\begin{tabular}{|l|l|}
\hline Produkte & Herkunft \\
\hline FACS-Puffer $\left(0.1 \% \mathrm{NaN}_{3}, 1 \%\right.$ BSA in PBS $)$ & Sigma-Aldrich, Deutschland \\
\hline Rundbodenröhrchen für FACS-Analyse & $\begin{array}{l}\text { Becton Dickinson, Meylan Cedex, } \\
\text { Frankreich }\end{array}$ \\
\hline Arbeitsbank & $\begin{array}{l}\text { Gelaire®,BSB 6A, Flow Laboratories } \\
\text { GmbH, Meckenheim, Deutschland }\end{array}$ \\
\hline Vortexgerät & Bender \& Hobein AG, Zürich, Schweiz \\
\hline Handpipetten $10 \mu 1,100 \mu 1$ und $1000 \mu 1$ & Eppendorf, Deutschland \\
\hline
\end{tabular}

Tab.4: zeigt die bei der Durchflusszytometrie verwendeten Materialien. 
Tab.5:

\begin{tabular}{|c|c|c|c|c|}
\hline Antikörper & Konjugat & Klon & Firma & Isotyp \\
\hline $\mathrm{CD} 3 \varepsilon$ & FITC & $145-2 \mathrm{C} 11$ & $\begin{array}{c}\text { B\&D } \\
\text { pharmingen }\end{array}$ & $\begin{array}{c}\text { Armen. Hamster } \\
\operatorname{IgG~} 2 \kappa\end{array}$ \\
\hline CD4 & ECD & RM4-5 & Caltag & Ratte IgG 2a \\
\hline CD8a & Tri-Color & $5 \mathrm{H} 10$ & Caltag & Ratte IgG 2b \\
\hline CD11b & ECD & M1/70.15 & Caltag & Ratte IgG 2b \\
\hline CD11c & Alexa Fluor 488 & N418 & Caltag & Hamster IgG \\
\hline CD11c & $\mathrm{PE}$ & N418 & Caltag & Hamster IgG \\
\hline CD28 & PE & 37.51 & $\begin{array}{l}\text { Beckman } \\
\text { Coulter }\end{array}$ & Hamster IgG \\
\hline CD69 & PE & $\mathrm{H} 1.2 \mathrm{~F} 3$ & $\begin{array}{c}\text { B\&D } \\
\text { pharmingen }\end{array}$ & $\begin{array}{c}\text { Armen. Hamster } \\
\text { IgG } 1 \lambda\end{array}$ \\
\hline CD80 & FITC & 16-10A1 & $\begin{array}{c}\text { B\&D } \\
\text { pharmingen }\end{array}$ & $\begin{array}{c}\text { Armen. Hamster } \\
\text { IgG } 2 \kappa\end{array}$ \\
\hline CD86 & FITC & GL1 & $\begin{array}{c}\mathrm{B} \& \mathrm{D} \\
\text { pharmingen }\end{array}$ & Ratte IgG $2 \mathrm{a} \kappa$ \\
\hline MHC II & SPRD & NIMR-4 & $\begin{array}{l}\text { Beckman } \\
\text { Coulter }\end{array}$ & Ratte IgG 2b \\
\hline $\begin{array}{c}\text { Anti-Maus CD16/CD32 } \\
\text { F }_{c} \text {-Blocker }\end{array}$ & --- & $2.4 \mathrm{G} 2$ & $\mathrm{~B} \& \mathrm{D}$ & --- \\
\hline
\end{tabular}

Tab.5: zeigt die verwendeten Antikörper bei der Flowzytometrie. Jeder Antikörper wurde durch die Verwendung einer hierfür speziellen Isotypkontrolle verifiziert.

\subsubsection{Methodik}

Nach Gewinnung der Überstände und deren Asservierung, wurden die noch in den einzelnen wells befindlichen Zellen (ca. 600.000 Zellen) durch die Verwendung eines konventionellen Zellschabers und warmen Zellkulturmediums entfernt und in FACS-Rundbodenröhrchen (Tab.4) überführt.

Anschließend wusch die Zellen mit FACS-Puffer ( 4 min bei $4^{\circ} \mathrm{C}$ und $1200 \mathrm{rpm}$ ), und mit $2 \mu \mathrm{l}$ $\mathrm{F}_{\mathrm{c}}$-Blocker (Tab.5) für 10 Minuten bei Dunkelheit inkubiert. Dies diente der Blockierung der zahlreichen $\mathrm{F}_{\mathrm{c}}$-Bindungsstellen auf Antigenpräsentierenden Zellen. Danach wurden die Röhrchen erneut mit 3ml FACS-Puffer gewaschen und resuspendiert.

Dieser Prozedur folgend wurden die eigentlichen Zellfärbungen durchgeführt. Die jeweils benötigten Antikörpervolumina der verwendeten Fluoreszenzfarbstoffe ermittelte man in 
Vorversuchen durch Verdünnungsreihen im Bereich der Sättigungscharakteristik. Zur Kontrolle unspezifischer Bindungen und Autofluoreszenz wurde eine jeweils passende Isotypkontrolle mit baugleichem Antikörper (Tab. 5) durchgeführt.

Die Intensitätsmaxima der jeweiligen Isotypkontrollen justierte man in der erste log-Dekade und beließ diese Einstellungen für die nachfolgenden Proben. Als ein positives Ereignis galt jedes Intensitätssignal, welches höher als die Fluoreszenz der Isotypkontrolle der Vergleichsprobe lag. Diese Grenzen wurden jeweils für eine Probe der jeweils gemessenen Farbkombinationen festgelegt und bei den anderen äquivalenten $\mathrm{zu}$ bestimmenden Proben belassen. Eine Vergleichbarkeit der Proben aus den jeweiligen verschiedenen Gruppen war hiermit für jeden einzelnen Versuchstag möglich.

Fig. 9:

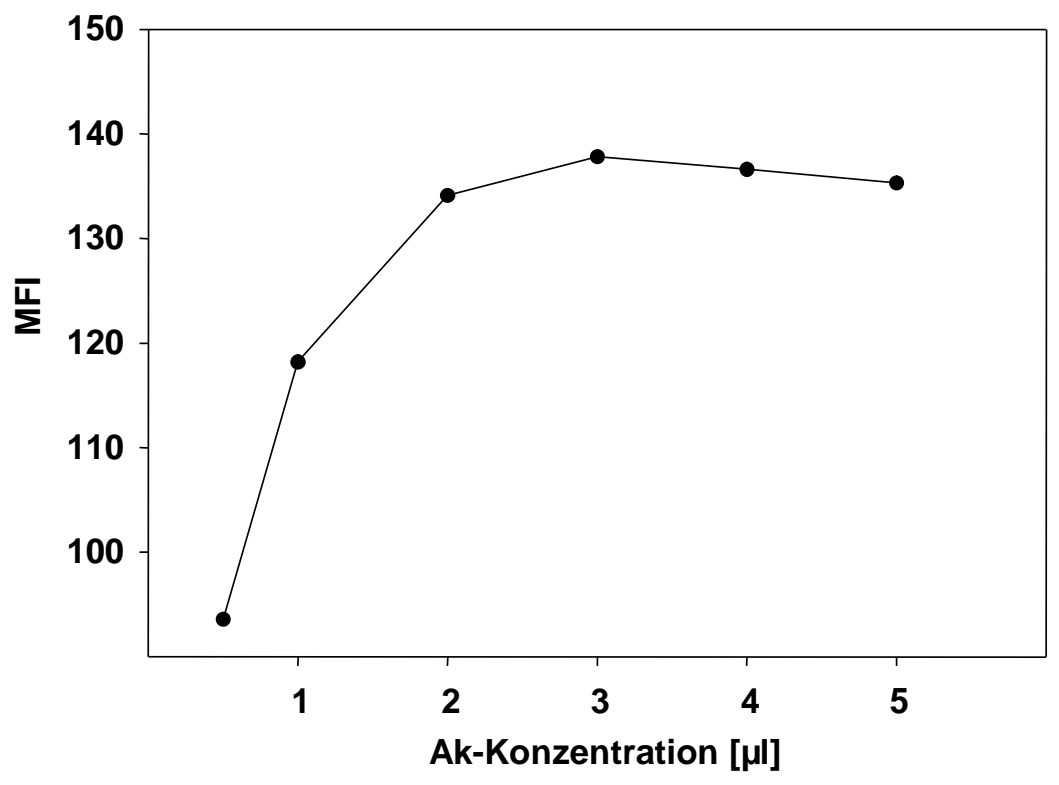

Fig.9: Antikörpertitration für die Bestimmung des Sättigungsbereiches am Beispiel CD8 Die Leuchtintensität der Zellen nimmt pro zusätzlich verwendeten $\mu l$ Antikörper zu

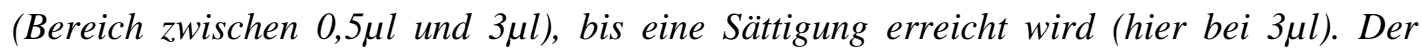
anschließende Abfall der Fluoreszenz lässt sich durch Übersättigung und der damit einhergehenden Konkurrenz der Antikörper um die Bindungsstellen erklären. 


\subsection{Zytokinbestimmung mittels MultiPlex®-Assay}

Für die Messung von Zytokinkonzentrationen mittels eines Multiplex-Assays von BioRad® benötigte man pro zu messendem Ansatz 50 $\mu 1$ der aliquotierten und asservierten Überstände.

\subsubsection{Prinzip}

Die Messung von Proteinen aus den Zellsuspensionsüberständen beruht auf einem Multiplex Prinzip, das von der Firma Biorad entwickelt wurde. Dabei werden mit spezifischen Antikörpern beschichtete synthetische Kügelchen (Beads) mit den Überständen inkubiert, die in ihrem Inneren eine Mischung aus mehreren Fluoreszenzfarbstoffen mit spezifischer Absorptions- und Emissionswellenlängen besitzen. Ein zweiter Detektionsantikörper bindet das jeweilige Zytokin an einem anderen Epitop. Nun wird dieser Antikörper über Streptavidin an den Fluoreszenzfarbstoff Phycoerythrin (PE) gekoppelt. Aus der Anzahl spezifisch leuchtender Beads und der simultanen Messung der durch PE hervorgerufenen Emission pro Bead, lässt sich mittels einer Standardverdünnungsreihe einer definierten Zytokinmischung die jeweiligen Zytokinkonzentrationen aus den Überständen bestimmen. 


\subsubsection{Materialien}

Tab. 6:

\begin{tabular}{|l|l|}
\hline Produkte & Herkunft \\
\hline $\begin{array}{l}\text { Mikrotiterplatte inkl. Abdeckung und } \\
\text { Ablagewanne }\end{array}$ & BioRad laboratories, Hercules, CA; USA \\
\hline Bio-Plex assay buffer & BioRad laboratories, Hercules, CA; USA \\
\hline Bio-Plex wash buffer & BioRad laboratories, Hercules, CA; USA \\
\hline Bio-Plex detection antibody diluent & BioRad laboratories, Hercules, CA; USA \\
\hline $\begin{array}{l}\text { Streptavidin-PE } \\
\text { Spezifisch für IL-1 } \beta, \text { IL-2, IL-4, IL-6, IL-10, } \\
\text { IL-12p40, IL-12p70, IFN- } \gamma, \text { GM-CSF und } \\
\text { TNF- } \alpha\end{array}$ & BioRad laboratories, Hercules, CA; USA \\
\hline $\begin{array}{l}\text { Schüttler } \\
\text { Bio-Plex array reader }\end{array}$ & BioRad laboratories, Hercules, CA; USA \\
\hline
\end{tabular}

Tab. 6: zeigt die bei dem Multiplex-Assay verwendeten Materialien.

\subsubsection{Methodik}

$\mathrm{Zu}$ Beginn wurden die Primärantikörper gegen die $\mathrm{zu}$ bestimmenden Zytokine in einem vorgegebenen Schema in dem Assay-Buffer (Tab. 6) diluiert und für 30 min. auf Eis gelegt. In der Zwischenzeit wurde die Mikrotiterplatte (Tab. 6) ebenfalls zweimal mit assay-buffer gewaschen.

Für die Herstellung einer Standardverdünnungsreihe wurde der lyophilisierte

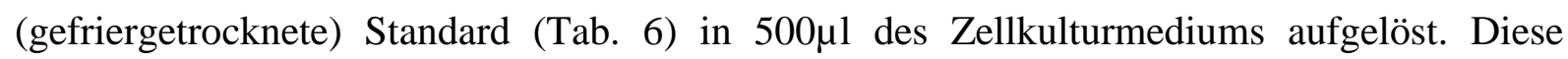
Lösung verdünnte man sukzessive in 7 Verdünnungsstufen im Verhältnis 1:4 und inkubierte diese ebenfalls für ca. 30 min auf Eis. 
Danach wurden je 50 $\mu 1$ des Standards und der Proben (Zellkulturüberstände) in die dafür vorgesehenen wells nach einem festen Schema pipettiert und für 60 min. bei Dunkelheit auf einem Schüttler (Tab. 6) bei $300 \mathrm{rpm}$ inkubiert. Währendessen verdünnte man die Detektionsantikörper (Tab. 6) für die zu bestimmenden Zytokine in einem vorgeschriebenen Verhältnis mit dem detection-antibody-diluent (Tab. 6). Nach Ablauf der 60 min. wusch man

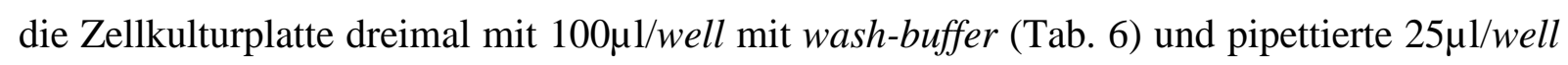
der detection-antibody-Lösung in die wells und inkubierte diese nach Abdeckung erneut für 30 min. auf dem Schüttler.

Im Intervall konnte der Streptavidin-Antikörper (Tab. 6) in vorgeschriebenem Verhältnis mit dem assay-buffer verdünnt werden.

Nach Ablauf der 30 min. wurde die Platte erneut dreimal gewaschen und der StreptavidinAntikörper in die wells pipettiert $(50 \mu \mathrm{l} /$ well $)$ und wiederum für $10 \mathrm{~min}$. auf dem Schüttler abgedunkelt inkubiert.

Schließlich diluierte man die Lösungen in den wells mit je $100 \mu \mathrm{l}$ assay-buffer und die Platte war damit bereit für die computergestützte Auswertung im Bio-Plex-Gerät.

\subsection{Statistik}

Für alle statistischen Untersuchungen wurde ein Signifikanzniveau von $\mathrm{p}<0,05$ als signifikant angenommen. Für die Datenanalyse der Zytokinsekretion nach Trauma und Blutverlust in vitro und der Oberflächenexpression der oben genannten Marker wurde mit One-Way ANOVA mit Student-Newman-Keuls als post-hoc Test oder ANOVA on Ranks durchgeführt. 


\section{Ergebnisse}

\subsection{Zytokine}

Im Folgenden werden die Ergebnisse der mittels Bioplex Assay® gemessenen Zytokine aus den Zellkulturüberständen aufgeführt. Zuerst werden die den T-Zellen zugeordneten Zytokine aufgeführt, gefolgt von den Zytokinen der APC.

\subsubsection{T-Zell spezifische Zytokine}

\subsubsection{Interleukin-2}

Im Zellkulturansatz mit der Doppelstimulation ConA und LPS (Figur 10) zeigte sich eine signifikant reduzierte IL-2 Sekretion in der Kokultur von geschockten T-Zellen und geschockten Antigenpräsentierenden Zellen (Gruppe 4) im Vergleich zu derer von kontrolloperierter T-Zellen und kontrolloperierten APC (Gruppe 1). Diese Beobachtung ist auch in den Monokulturen der T-Zellen zu beobachten - auch hier zeigt sich ein suppressiver Effekt der Trauma-Schock-Prozedur auf die isolierten T-Zellen im Vergleich zu den kontrolloperierten T-Zellen (Tab. 7).

Darüber hinaus deutet sich eine statistisch nicht signifikante Reduktion der IL-2 Konzentation in den Gruppen 2 (kontrolloperierte T-Zellen in Kokultur mit schockierten APC) und 3 (schockierte T-Zellen kokultiviert mit kontrolloperierten APC) gegenüber der Kontrollgruppe 1 (kontrolloperierte T-Zellen und APC) an. 
Fig. 10:

\section{IL-2 [pg/ml]}

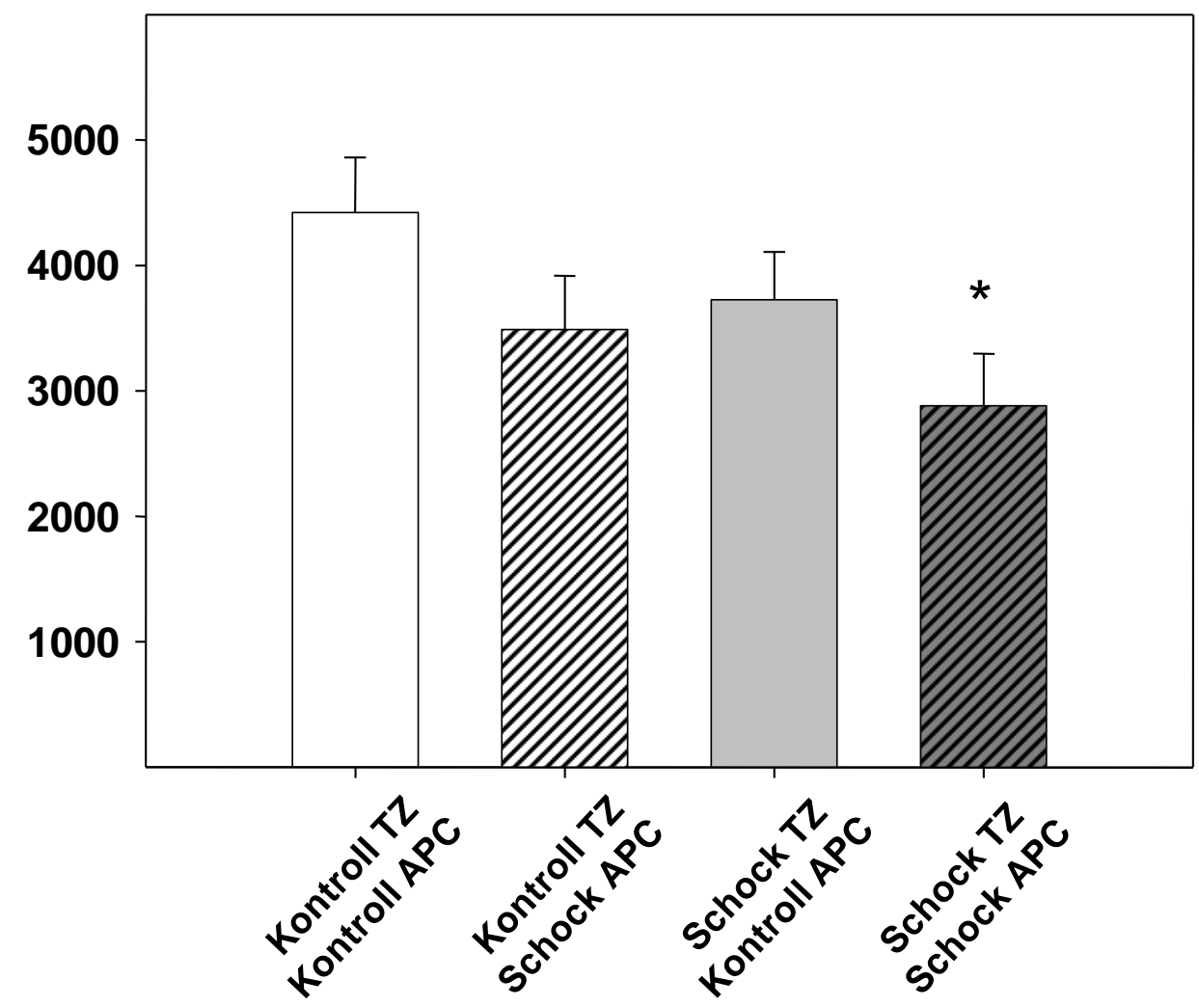

Fig. 10: IL-2 Konzentrationen $(\mathrm{pg} / \mathrm{ml})$ in den Überständen 24 Stunden nach entweder traumatisch-hämorrhagischem Schock (Schock) oder Kontrolloperation (Kontroll) unter Stimulation mit ConA und LPS nach Zellkultur über 48 Stunden.

Gruppen 1-4: Kokulturen von T-Zellen und APC:

Gruppe 1: Kontroll T-Zellen + Kontroll APC; Gruppe 2: Kontroll T-Zellen + Schock APC, Gruppe 3: Schock T-Zellen + Kontroll APC, Gruppe 4: Schock T-Zellen + Schock APC;

$N=8-10$ pro Gruppe, Mean \pm SEM, ANOVA,

*p<0.05 vs. Gruppe 1 


\subsubsection{Interleukin-4}

Figur 11 zeigt die Freisetzung von IL-4 unter Stimulation mit ConA und LPS. Das T-Zell spezifische Zytokin war in den Zellkulturüberständen von geschockten T-Zellen signifikant reduziert - unabhängig, ob die geschockten T-Zellen mit kontrolloperierten (Gruppe 3) oder geschockten APC (Gruppe 4) inkubiert waren. Im Gegensatz dazu hatten geschockte APC keinen Einfluss auf die IL-4 Sekretion von kontrolloperierten T-Zellen (Gruppe 2). Der suppressive Effekt des traumatisch-hämorrhagischen Schocks auf die IL-4 Sekretion von TZellen zeigte sich auch in den Monokulturen der T-Zellen. Auch hier ist die Freisetzung von IL-4 signifikant reduziert im Vergleich zu kontrolloperierten T-Zellen (Tab.7).

Fig. 11:

\section{IL-4 [pg/ml]}

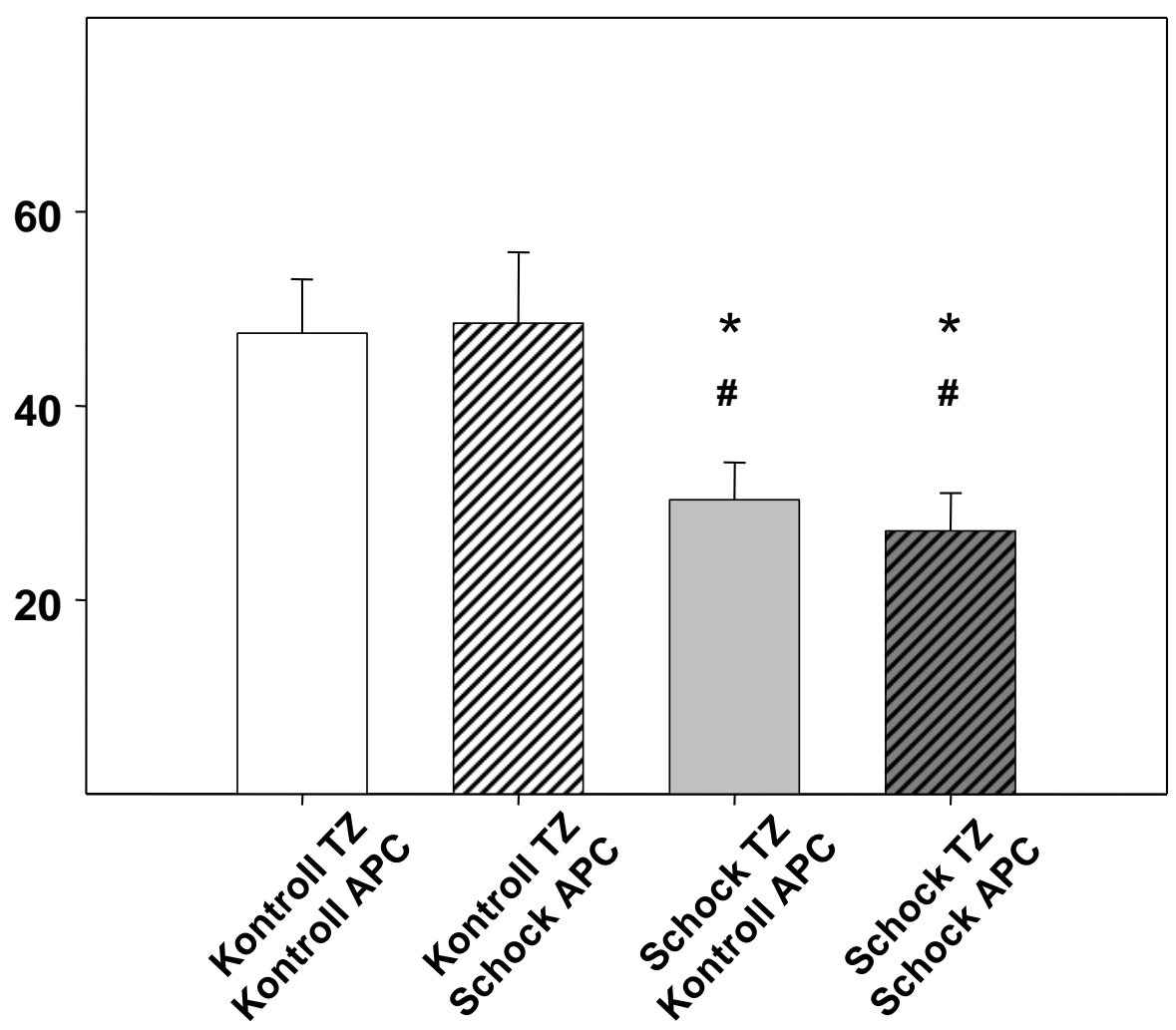

Fig. 11: IL-4 Konzentrationen ( $\mathrm{pg} / \mathrm{ml})$ in den Überständen 24 Stunden nach entweder traumatisch-hämorrhagischem Schock (Schock) oder Kontrolloperation (Kontroll) unter Stimulation mit ConA und LPS nach Zellkultur über 48 Stunden.

Gruppen 1-4: Kokulturen von T-Zellen und APC:

Gruppe 1: Kontroll T-Zellen + Kontroll APC; Gruppe 2: Kontroll T-Zellen + Schock APC, Gruppe 3: Schock T-Zellen + Kontroll APC, Gruppe 4: Schock T-Zellen + Schock APC; $N=8-10$ pro Gruppe, Mean \pm SEM, ANOVA, ${ }^{*} p<0.05$ vs. Gruppe 1; ${ }^{\#} p<0.05$ vs. Gruppe 2 


\subsubsection{Interleukin-10}

In diesem Versuchsansatz wies das IL-10 (Fig. 12) im Stimulationsansatz mit ConA und LPS zwischen den einzelnen Gruppen keine signifikanten Unterschiede auf.

Tendenziell zeigt sich jedoch eine reduzierte Sekretion von IL-10 nach Trauma und hämorrhagischem Schock der T-Zellen und APC (Gruppe 4 vs. Gruppe 1) - dieser Unterschied war jedoch aufgrund der relativ großen Standardabweichungen in den einzelnen Gruppen nicht signifikant.

Fig. 12:

\section{IL-10 [pg/ml]}

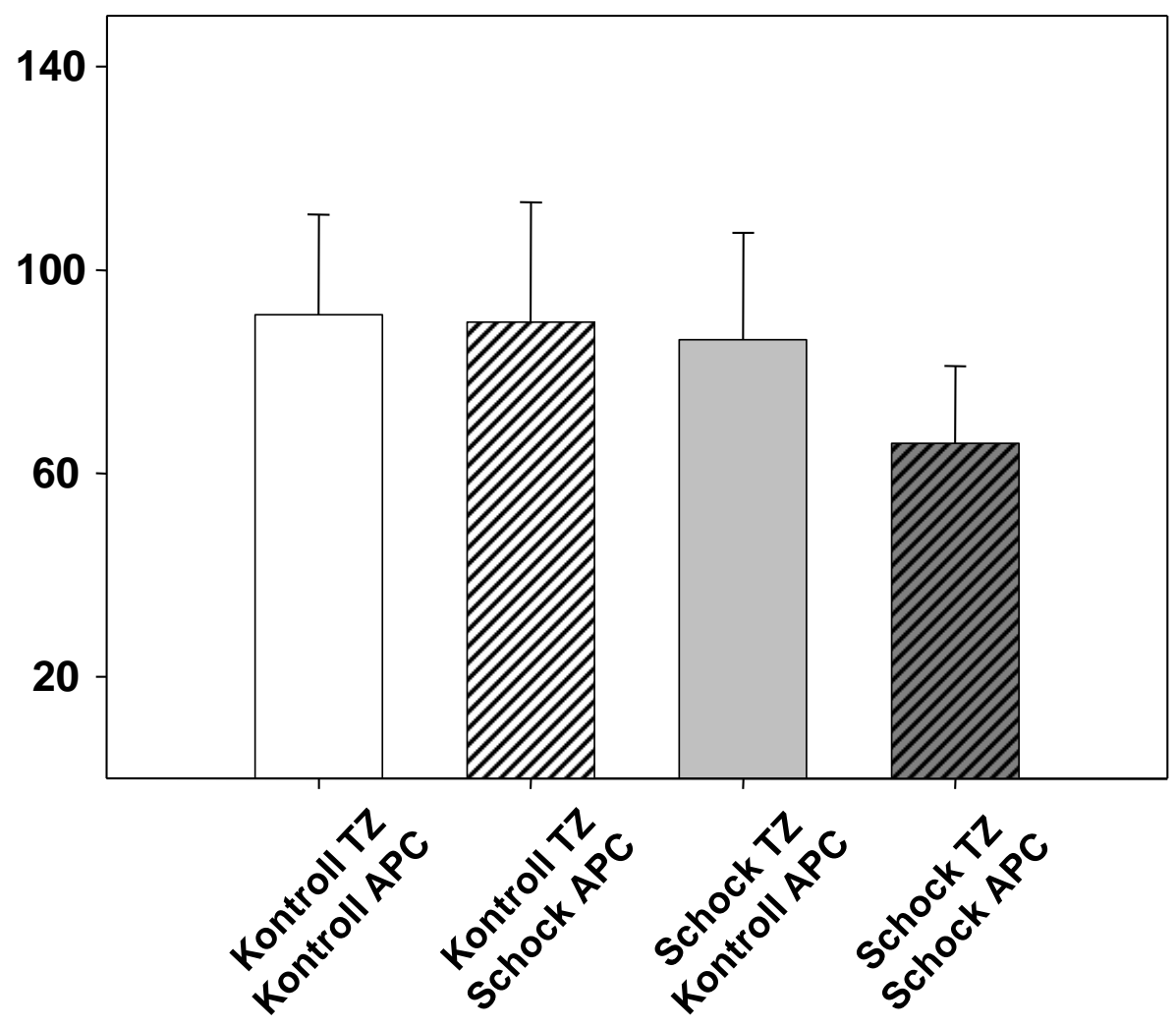

Fig. 12: IL-10 Konzentrationen in den Überständen 24 Stunden nach entweder traumatisch-hämorrhagischem Schock (Schock) oder Kontrolloperation (Kontroll) unter Stimulation mit ConA und LPS nach Zellkultur über 48 Stunden.

Gruppen 1-4: Kokulturen von T-Zellen und APC:

Gruppe 1: Kontroll T-Zellen + Kontroll APC; Gruppe 2: Kontroll T-Zellen + Schock APC, Gruppe 3: Schock T-Zellen + Kontroll APC, Gruppe 4: Schock T-Zellen + Schock APC $N=8-10$ pro Gruppe, Mean \pm SEM, ANOVA, 


\subsubsection{Interferon- $\gamma$}

In Figur 13 ist die Ausschüttung von IFN- $\gamma$ in den Zellkulturüberständen dargestellt.

Unter Stimulation mit ConA und LPS führte der traumatische hämorrhagische Schock zu einer signifikanten Reduktion der IFN- $\gamma$ Sekretion aus T-Zellen (Gruppe 3 und 4 vs. Gruppe 1 und 2) - unabhängig, ob in den Kokulturen kontrolloperierte (Gruppe 3) oder geschockte Antigenpräsentierenden Zellen (Gruppe 4) vorhanden waren.

Der Zustand der APC hatte auf die Produktion von IFN- $\gamma$ keinen messbaren Einfluss: die Kokultur von kontrolloperierten T-Zellen mit schockierten APC (Gruppe 2) führte im Gegensatz zu keiner geringeren IFN- $\gamma$ Freisetzung aus T-Zellen.

Darüber hinaus konnten kontrolloperierte APC die verminderte Sekretion von IFN- $\gamma$ in Gruppe 3 nicht wiederherstellen.

Interessanterweise zeigen geschockte T-Zellen bereits ohne Interaktion mit APC in den Monokulturen eine signifikant supprimierte IFN- $\gamma$ Sekretion gegenüber kontrolloperierter TZellen (Tab. 7).

Zusammenfassend führte Trauma und Blutverlust zu einer verringerten IFN- $\gamma$ Freisetzung der T-Zellen. Diese Beobachtung war unabhängig, ob APC kokultiviert wurden, oder nicht. Im Falle einer Kokultur zeigte die unterzogene Prozedur der APC (Trauma-Schock oder Kontrolloperation) keinen positiven oder negativen Einfluss auf die IFN- $\gamma$ Sekretion. 
Fig. 13:

\section{IFN-y $[\mathrm{pg} / \mathrm{ml}]$}

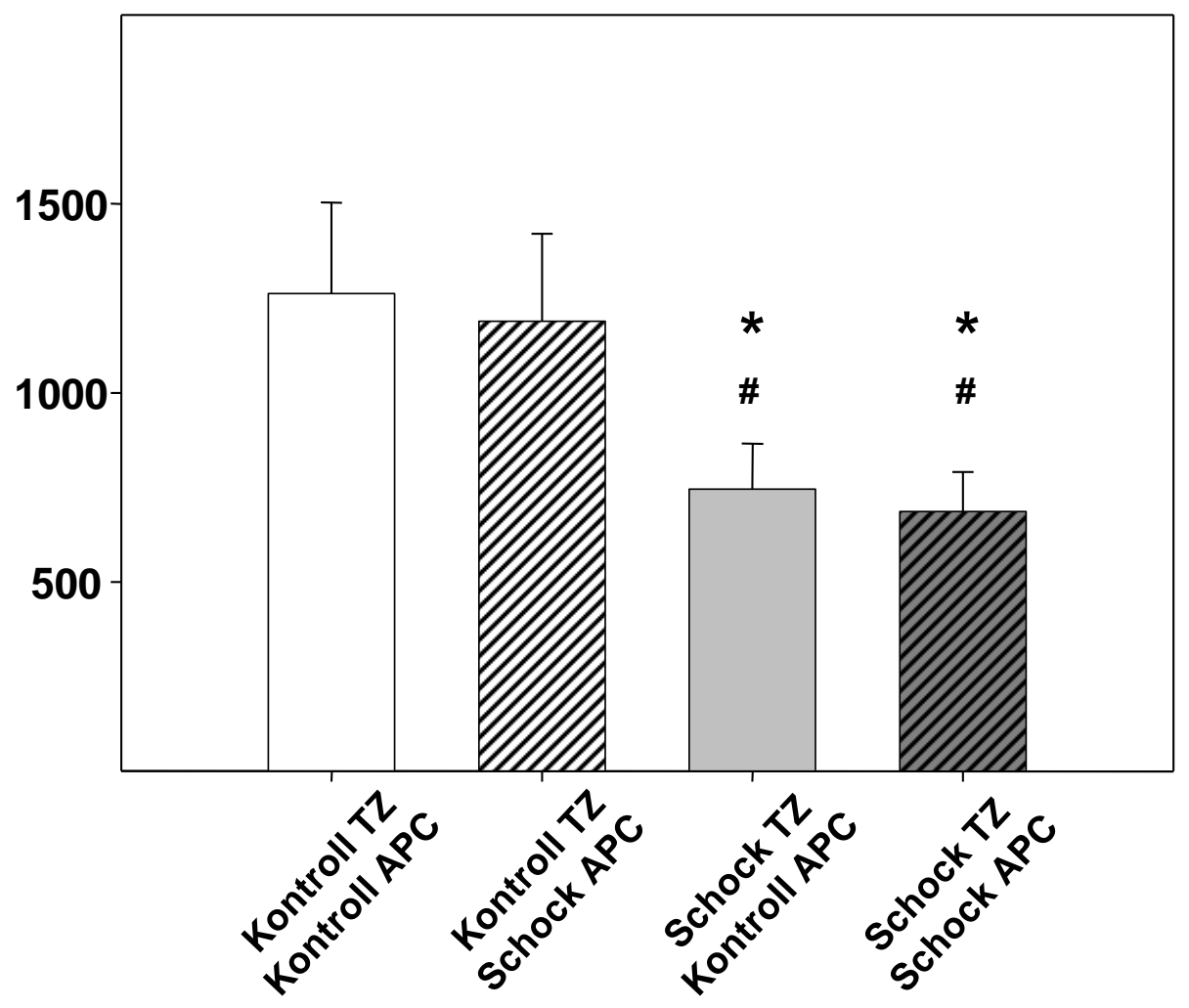

Fig. 13: IFN- $\gamma$ Konzentrationen $(\mathrm{pg} / \mathrm{ml})$ in den Überständen 24 Stunden nach entweder traumatisch-hämorrhagischem Schock (Hem) oder Kontrolloperation (Kontroll) unter Stimulation mit ConA und LPS nach Zellkultur über 48 Stunden.

Gruppen 1-4: Kokulturen von T-Zellen und APC:

Gruppe 1: Kontroll T-Zellen + Kontroll APC; Gruppe 2: Kontroll T-Zellen + Schock APC, Gruppe 3: Schock T-Zellen + Kontroll APC, Gruppe 4: Schock T-Zellen + Schock APC;

$N=8-10$ pro Gruppe, Mean \pm SEM, ANOVA,

*p<0.05 vs. Gruppe 1; \# p<0.05 vs. Gruppe 2 


\subsubsection{GM-CSF}

Die Sekretion von GM-CSF unter ConA und LPS Stimulation offenbarte identische Ergebnisse wie das IFN- $\gamma$ nach traumatischem hämorrhagischem Schock der T-Zellen: es zeigt eine signifikante Suppression unabhängig, ob sezernierenden T-Zellen mit geschockten APC (Gruppe 4) oder kontrolloperierten APC (Gruppe 3) inkubiert waren (Fig. 14). Umgekehrt konnten auch hier kontrolloperierte APC die Ausschüttung von GM-CSF aus geschockten T-Zellen nicht wieder auf das Niveau von kontrolloperierten T-Zellen steigern (Gruppe 2).

In den Monokulturen der T-Zellen zeigt ebenfalls ein suppressiver Effekt der Trauma-Schock Prozedur auf die T-Zellen (Tab. 7) ohne den Einfluss der APC. 
Fig. 14:

\section{GM-CSF $[p g / m l]$}

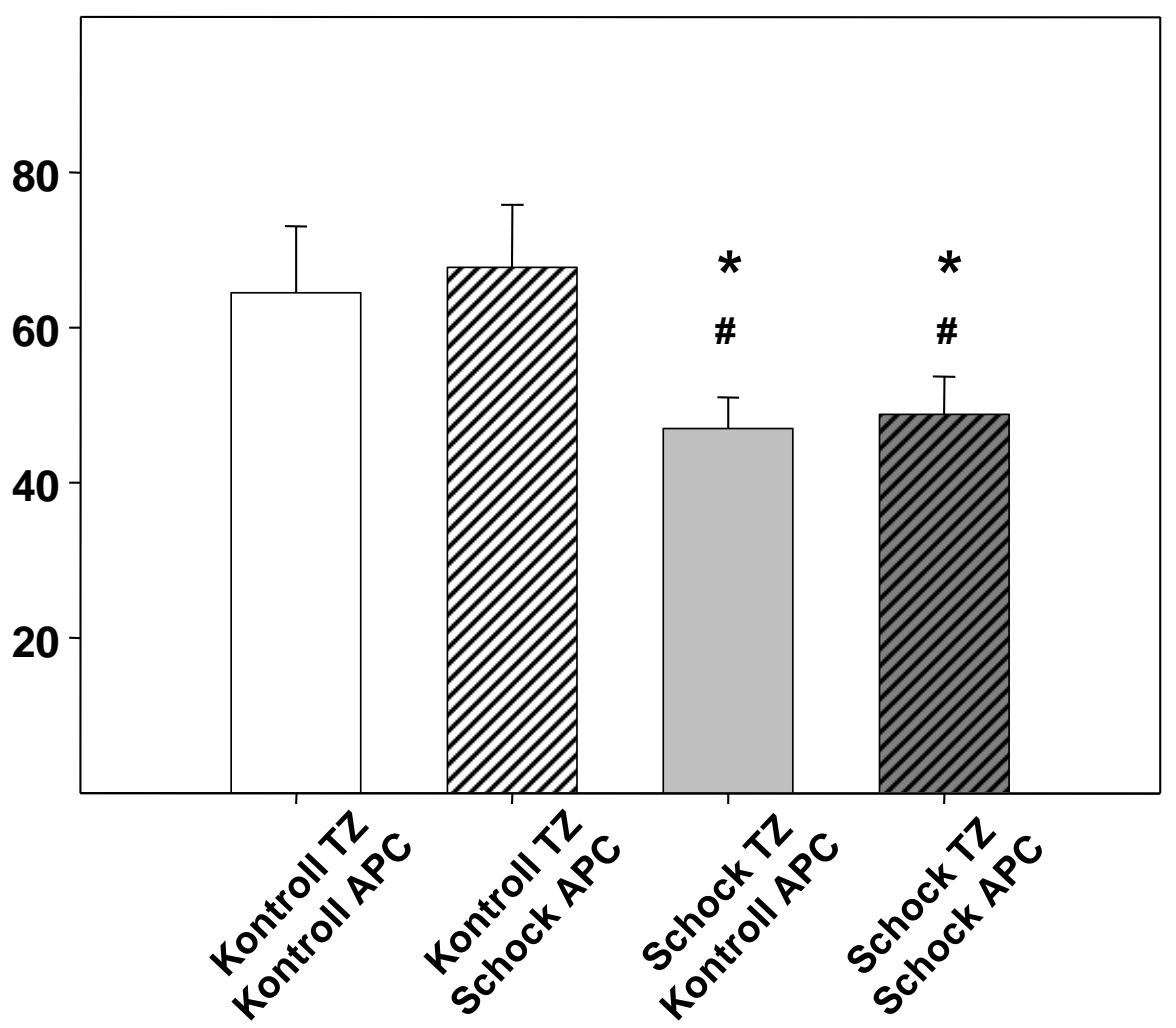

Fig. 14: GM-CSF Konzentrationen ( $\mathrm{pg} / \mathrm{ml})$ in den Überständen 24 Stunden nach entweder traumatisch-hämorrhagischem Schock (Schock) oder Kontrolloperation (Kontroll) unter Stimulation mit ConA und LPS nach Zellkultur über 48 Stunden.

Gruppen 1-4: Kokulturen von T-Zellen und APC:

Gruppe 1: Kontroll T-Zellen + Kontroll APC; Gruppe 2: Kontroll T-Zellen + Schock APC, Gruppe 3: Schock T-Zellen + Kontroll APC, Gruppe 4: Schock T-Zellen + Schock APC;

$N=8-10$ pro Gruppe, Mean \pm SEM, ANOVA,

*p<0.05 vs. Gruppe 1;\# $p<0.05$ vs. Gruppe 2 


\subsubsection{APC spezifische Zytokine}

\subsubsection{Interleukin-1}

24 Stunden nach traumatisch-hämorrhagischem Schock konnte kein Unterschied in der Zytokinsekretion von IL-1 zwischen den vier Versuchsgruppen nachgewiesen werden (Fig. 15). Interessanterweise zeigten die separierten APC in ihren Monokulturen keine messbare Zytokinproduktion. Im Gegensatz dazu war in den Monokulturen der T-Zellen (Tab. 7) geringe Konzentrationen von IL-1 zu messen, was entweder einer spontanen Sekretion von IL-1 der T-Zellen entspricht, oder einer Verunreinigung der T-zellulären Monokultur durch $\mathrm{APC}$ verursacht ist.

Fig. 15:

\section{IL-1 [pg/ml]}

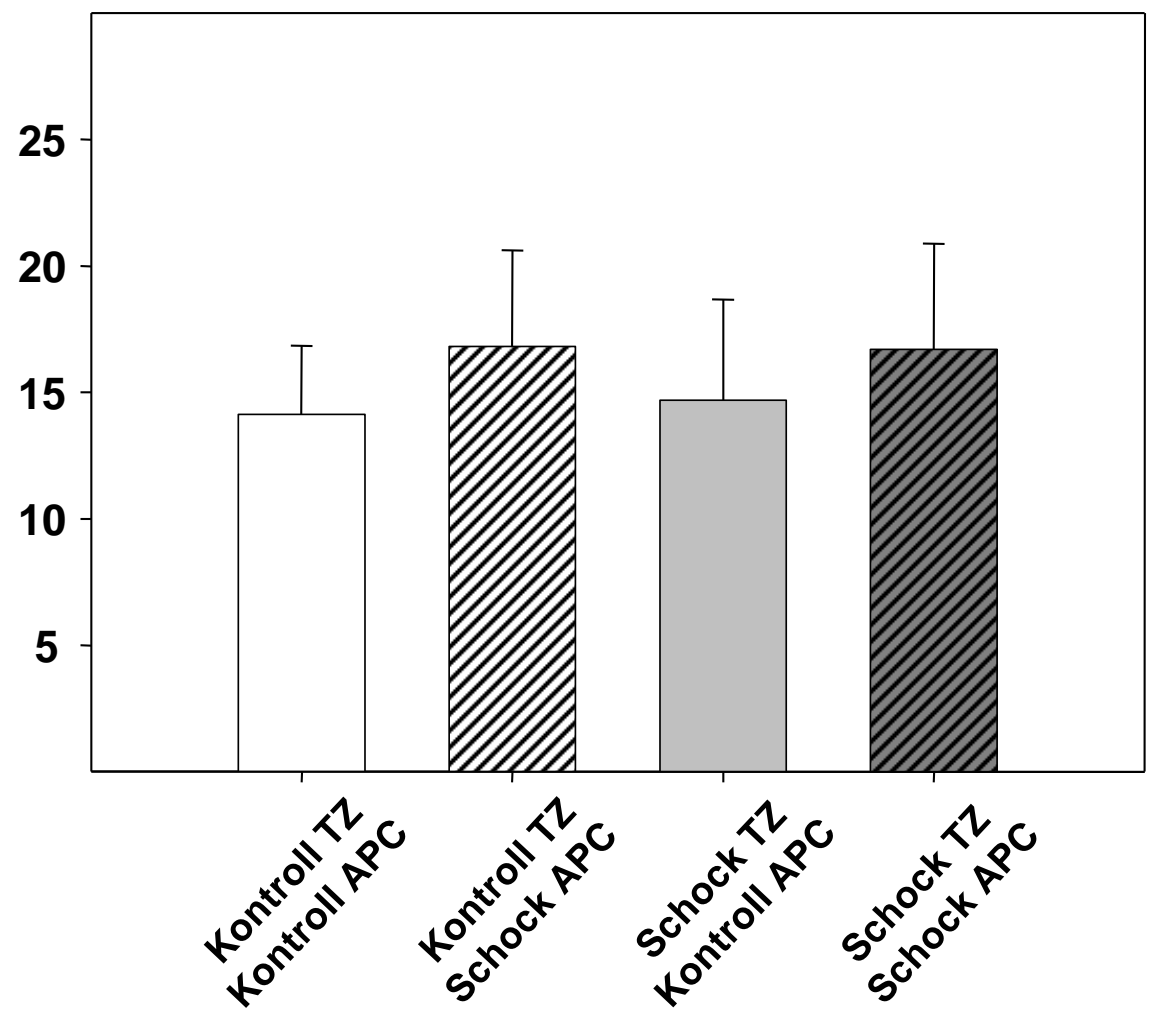

Fig. 15: IL-1 Konzentrationen $(\mathrm{pg} / \mathrm{ml})$ in den Überständen 24 Stunden nach entweder traumatisch-hämorrhagischem Schock (Schock) oder Kontrolloperation (Kontroll) unter Stimulation mit ConA und LPS nach 48 Stunden Zellkultur.

Gruppe 1: Kontroll T-Zellen + Kontroll APC; Gruppe 2: Kontroll T-Zellen + Schock APC, Gruppe 3: Schock T-Zellen + Kontroll APC, Gruppe 4: Schock T-Zellen + Schock APC; $N=8$-10 pro Gruppe, Mean \pm SEM, ANOVA 


\subsubsection{Interleukin-6}

Das hauptsächlich von APC ausgeschüttete Zytokin IL-6 zeigte unter der Doppelstimulation mit ConA und LPS keine signifikanten Unterschiede zwischen den einzelnen Gruppen der Kokulturen (Figur 16). Aus den Monokulturen der T-Zellen und APC (Tab. 10) könnte man schließen, dass beide Populationen IL-6 in geringen Mengen produzieren, wobei sich auch in diesen keine signifikanten Unterschiede in den IL-6 Konzentrationen nachweisen ließen.

Fig. 16:

\section{IL-6 [pg/ml]}

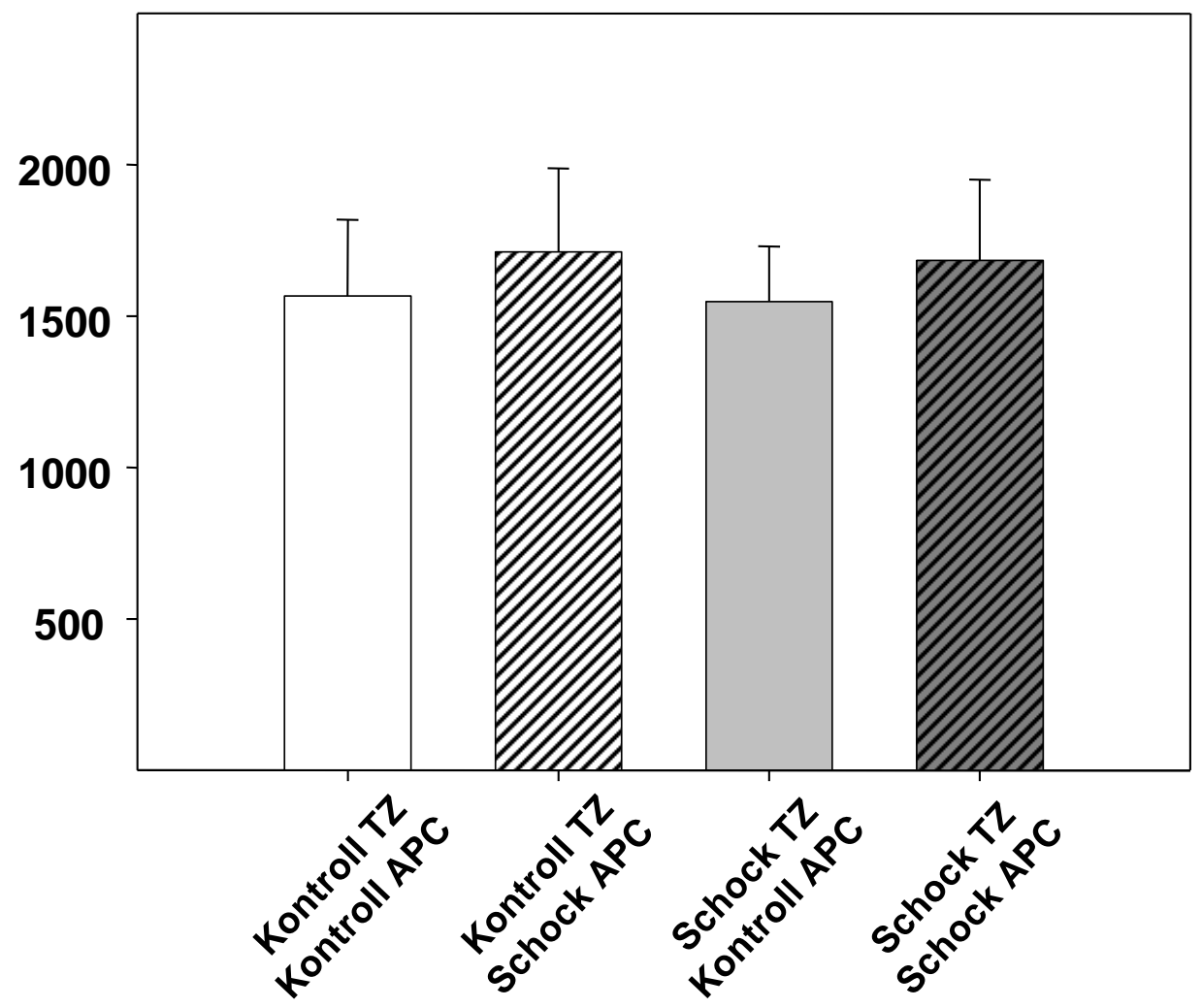

Fig. 16: IL-6 Konzentrationen $(\mathrm{pg} / \mathrm{ml})$ in den Überständen 24 Stunden nach entweder traumatisch-hämorrhagischem Schock (Schock) oder Kontrolloperation (Kontroll) unter Stimulation mit ConA und LPS nach Zellkultur über 48 Stunden

Gruppen 1-4: Kokulturen von T-Zellen und APC:

Gruppe 1: Kontroll T-Zellen + Kontroll APC; Gruppe 2: Kontroll T-Zellen + Schock APC, Gruppe 3: Schock T-Zellen + Kontroll APC, Gruppe 4: Schock T-Zellen + Schock APC; $N=8$-10 pro Gruppe, Mean \pm SEM, ANOVA 


\subsubsection{Interleukin-12}

Im Falle des Interleukin-12 (Fig. 17 und 18) wurde sowohl das bioaktive IL-12 (p70), wie auch dessen Vorstufe IL12 (p40) in den Zellkulturüberständen gemessen.

24 Stunden nach traumatisch-hämorrhagischem Schock zeigte sich eine supprimierte IL12p40 Sekretion der APC in den Zellkulturansätzen mit geschockten T-Zellen (Gruppen 3 und 4 vs. Gruppen 1 und 2).

Wurden geschockte APC mit kontrolloperierten T-Zellen inkubiert, resultierte daraus keine unterdrückte IL-12(p40) Sekretion (Gruppe 1 vs. 2), was daraufhin deutet, dass der traumatisch-hämorrhagische Schock per se keine supprimierende Wirkung auf die IL-12 Sekretion der APC zu haben scheint.

Interessanterweise führte eine Koinkubation von schockierten T-Zellen mit kontrolloperierten APC (Gruppe 3) zu einer signifikant verminderten Freisetzung von IL-12 aus primär nicht geschädigten APC.

In den Monokulturen der APC konnte kein signifikanter Effekt des traumatischhämorrhagischen Schocks nachgewiesen werden (Tab. 7). Darüber hinaus zeigte sich in den Monokulturen der T-Zellen eine basale Rate an IL-12(p40), was möglicherweise auf eine geringe Verunreinigung der Monokultur durch APC hindeutet (Tab. 7). 
Fig. 17:

\section{IL-12 p40 [pg/ml]}

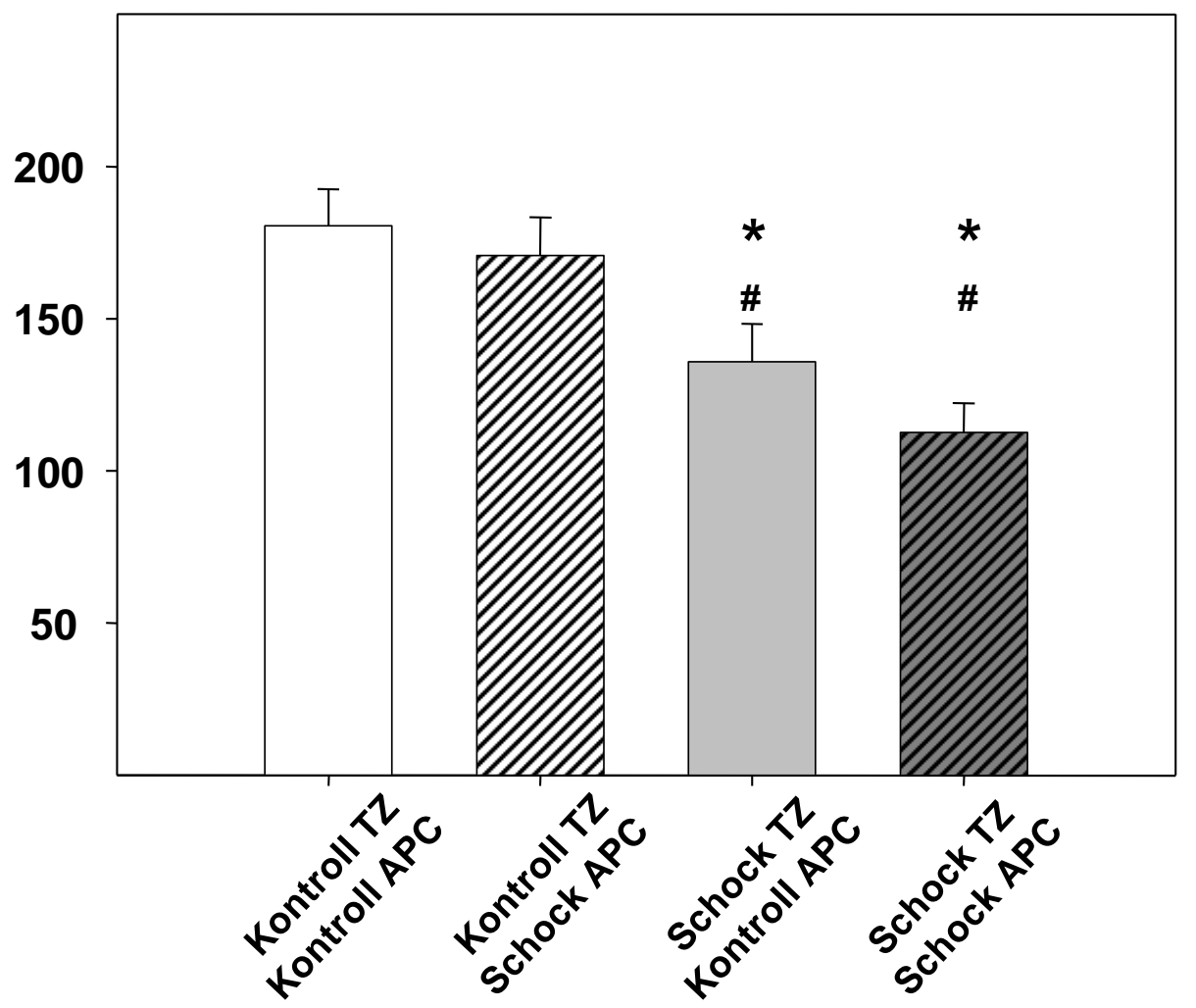

Fig. 17: IL-12p40 Konzentrationen $(\mathrm{pg} / \mathrm{ml})$ in den Überständen 24 Stunden nach entweder traumatisch-hämorrhagischem Schock (Schock) oder Kontrolloperation (Kontroll) unter Stimulation mit ConA und LPS nach Zellkultur über 48 Stunden.

Gruppen 1-4: Kokulturen von T-Zellen und APC:

Gruppe 1: Kontroll T-Zellen + Kontroll APC; Gruppe 2: Kontroll T-Zellen + Schock APC, Gruppe 3: Schock T-Zellen + Kontroll APC, Gruppe 4: Schock T-Zellen + Schock APC;

$N=8-10$ pro Gruppe, Mean \pm SEM, ANOVA,

*p<0.05 vs. Gruppe 1; \# p<0.05 vs. Gruppe 2

Das bioaktive IL-12(p70) zeigte ein nahezu identisches Bild im Vergleich zu IL-12(p40). Einzig ist die fehlende Signifikanz zwischen den Gruppen Gruppe 2 vs. Gruppe 3 anzumerken. Dies schränkt aber nur die Aussage über den suppressiven Effekt der schockierten T-Zellen auf kontrolloperierte APC ein. Die Kernaussage, dass schockierte TZellen die IL-12 Sekretion von APC hemmt (Gruppe 3 und 4) und andererseits die Kokultur von kontrolloperierten T-Zellen mit schockierten APC (Gruppe 2) zu keiner signifikanten Suppression der IL-12 Ausschüttung führt, bleibt erhalten. 
Kongruent $\mathrm{zu}$ den Ergebnissen aus den Monokulturen der Messungen von IL-12(p40) offenbaren sich keine signifikanten Unterschiede zwischen Trauma-Schock und den Kontrolloperationen bei der Sekretion von IL-12(p70).

Fig. 18:

\section{IL-12 p70 [pg/ml]}

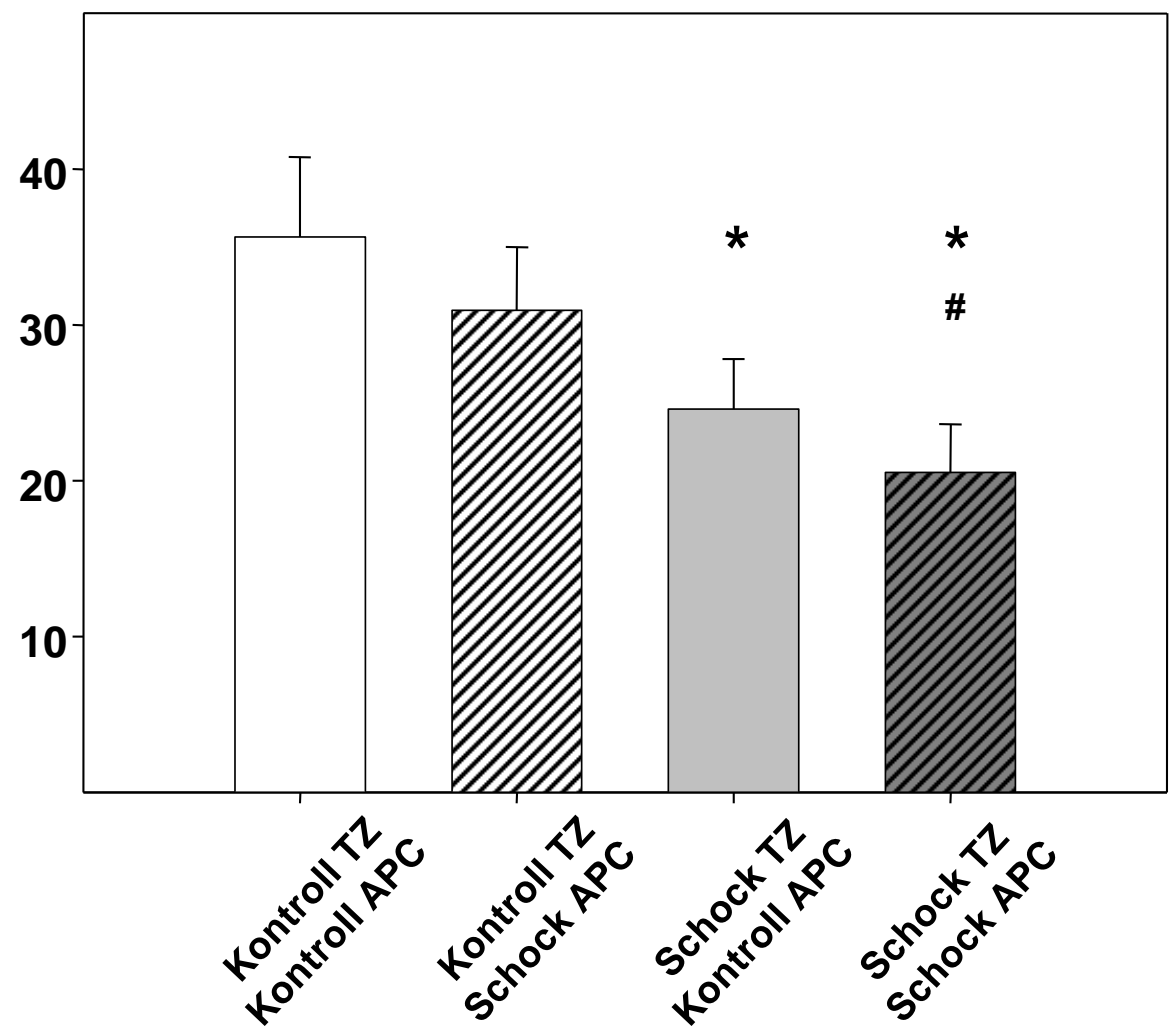

Fig. 18: IL-12p70 Konzentrationen ( $\mathrm{pg} / \mathrm{ml})$ in den Überständen 24 Stunden nach entweder traumatisch-hämorrhagischem Schock (Schock) oder Kontrolloperation (Kontroll) unter Stimulation mit ConA und LPS nach Zellkultur über 48 Stunden.

Gruppen 1-4: Kokulturen von T-Zellen und APC:

Gruppe 1: Kontroll T-Zellen + Kontroll APC; Gruppe 2: Kontroll T-Zellen + Schock APC, Gruppe 3: Schock T-Zellen + Kontroll APC, Gruppe 4: Schock T-Zellen + Schock APC;

$N=8-10$ pro Gruppe, Mean \pm SEM, ANOVA,

$*_{p}<0.05$ vs. Gruppe 1; \# p<0.05 vs. Gruppe 2 


\subsubsection{TNF- $\alpha$}

Das hauptsächlich von APC sezernierte Zytokin zeigt sich 24 Stunden durch den traumatischhämorrhagischem Schock nicht beeinflusst (Fig.19). Die Sekretion ist in den vier Kokulturen der T-Zellen und APC vergleichbar.

Fig. 19:

TNF- $\alpha[p g / m l]$

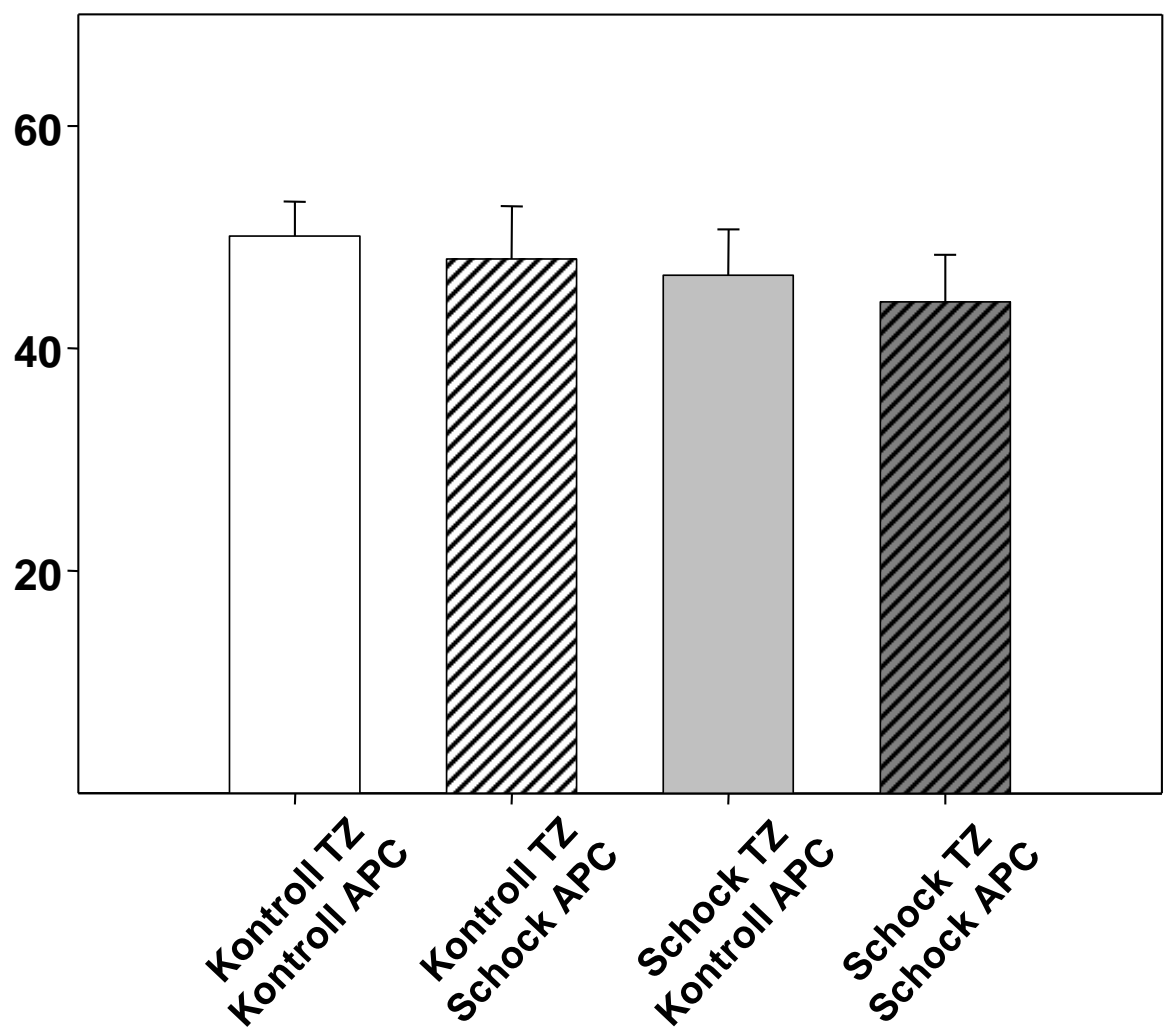

Fig. 19: TNF- $\alpha$ Konzentrationen ( $\mathrm{pg} / \mathrm{ml})$ in den Überständen 24 Stunden nach entweder traumatisch-hämorrhagischem Schock (Schock) oder Kontrolloperation (Kontroll unter Stimulation mit ConA und LPS nach Zellkultur über 48 Stunden.

Gruppen 1-4: Kokulturen von T-Zellen und APC:

Gruppe 1: Kontroll T-Zellen + Kontroll APC; Gruppe 2: Kontroll T-Zellen + Schock APC, Gruppe 3: Schock T-Zellen + Kontroll APC, Gruppe 4: Schock T-Zellen + Schock APC;

$N=8-10$ pro Gruppe, Mean \pm SEM, ANOVA 


\subsubsection{Zytokinkonzentrationen stimulierter Monokulturen}

In der nachfolgenden Tabelle sind die Mittelwerte der Zytokinkonzentrationen nach traumatisch-hämorrhagischem Schock in den Monokulturen von T-Zellen und APC abgebildet.

Hier zeigen sich folgende signifikante Änderungen der Zytokinsekretionen:

IL-2, IL-4, IFN- $\gamma$ und GM-CSF zeigen signifikant reduzierte Konzentrationen in den Kulturen von schockierten T-Zellen gegenüber den Messungen von kontrolloperierten T-Zellen.

Tab. 7:

\begin{tabular}{|c|c|c|c|c|}
\hline Zytokine & Kontroll APC & Schock APC & Kontroll TZ & Schock TZ \\
\hline IL-1 (pg/ml) & $(-)$ & $(-)$ & $(-)$ & $(-)$ \\
\hline IL-2 (pg/ml) & $(-)$ & $(-)$ & $1104 \pm 144$ & $622 \pm 82^{*}$ \\
\hline IL-4 (pg/ml) & $(-)$ & $(-)$ & $279 \pm 145$ & $116 \pm 85^{*}$ \\
\hline IL-6 (pg/ml) & $369 \pm 77$ & $450 \pm 80$ & $144 \pm 48$ & $160 \pm 41$ \\
\hline IL-10 (pg/ml) & $(-)$ & $(-)$ & 1 & 2 \\
\hline IL-12p40 (pg/ml) & $36 \pm 3$ & $24 \pm 2$ & $130 \pm 18$ & $70 \pm 16$ \\
\hline IL-12p70 (pg/ml) & $9 \pm 2$ & $14 \pm 2$ & $13 \pm 4$ & $5 \pm 0,5$ \\
\hline IFN- $\gamma(\mathbf{p g} / \mathbf{m l})$ & $(-)$ & $(-)$ & $245 \pm 118$ & $67 \pm 13^{*}$ \\
\hline GM-CSF (pg/ml) & $(-)$ & $(-)$ & $21 \pm 5$ & $10 \pm 2^{*}$ \\
\hline TNF- $\boldsymbol{\alpha}(\mathbf{p g} / \mathbf{m l})$ & $4 \pm 0,8$ & $4 \pm 1$ & $10 \pm 4$ & $8 \pm 3$ \\
\hline
\end{tabular}

Tab. 7: Zeigt die Zytokinkonzentrationen ( \pm SEM) in den Monokulturen der T-Zellen (TZ) und APC 24 Stunden nach traumatisch-hämorrhagischem Schock (Schock) oder Kontrolloperation (Kontroll) unter Stimulation mit ConA und LPS für 48 Stunden. N=8-10 pro Gruppe, Mean \pm SEM, ANOVA; *p<0.05 vs. Kontroll TZ

$(-)=$ nicht nachweisbar 


\subsection{Expression von Oberflächenmolekülen}

Für die Detektion von Oberflächenmolekülen wurden pro Versuchsansatz zwei Zeitpunkte für die Durchführung einer Durchflusszytometrie gewählt. Einerseits wurden Milzzellen aus jeweils einer geschockten- und einer kontrolloperierten Maus direkt vor der T-Zellseparation für die Analyse abgezweigt (folglich auch unstimuliert), andererseits die Zellen nach der 48stündigen Inkubation und Stimulation der Durchflusszytometrie zugeführt.

\subsubsection{T-Zell spezifische Oberflächenmarker}

\subsubsection{T-zelluläre Subgruppen CD4 und CD8}

Nach traumatisch-hämorrhagischem Schock offenbart dich sowohl direkt nach der Zellgewinnung, als auch nach der 48-stündigen Zellkultur und Stimulation keine Änderung bezüglich der Expression der Oberflächenmarker CD4 und CD8 (Fig. 20). Es zeigt sich kein Verschieben des Gleichgewichts der T-zellulären Subpopulationen CD8 (zytotoxische TZellen) oder CD4 (T-Helferzellen), wobei generell beide Oberflächenmarker in allen vier Zellkulturansätzen in ihrer Quantität geringer exprimiert waren (Fig. C+D, Gruppen 3-6). Dies lässt sich an der reduzierten Mittleren Fluoreszenzintensität (MFI) als Maß der Rezeptordichte auf den Zelloberflächen ablesen (Fig. 20 C+D).

Im Gegensatz dazu konnte eine gleichmäßige Abnahme in Prozent an CD4 (+) und CD8 (+) Zellen nach der 48-stündiger Zellkultur nachgewiesen werden (Fig. A+B, Gruppen 3-6 vs. Gruppen 1 und 2). Zwischen den Versuchgruppen der Kokulturen erweist sich jedoch kein signifikanter Unterschied sowohl in der Rezeptordichte, wie auch in den prozentualen Anteilen der CD4 (+) oder CD8 (+) T-Zellen.

Diese Ergebnisse deuten darauf hin, dass die Änderungen durch die Zellkulturbedingungen verursacht wurden - ein Einfluss des traumatisch-hämorrhagischen Schocks auf die Expression der Oberflächenmarker CD4 und CD8 lässt sich demnach nicht nachweisen. 
Fig. 20:
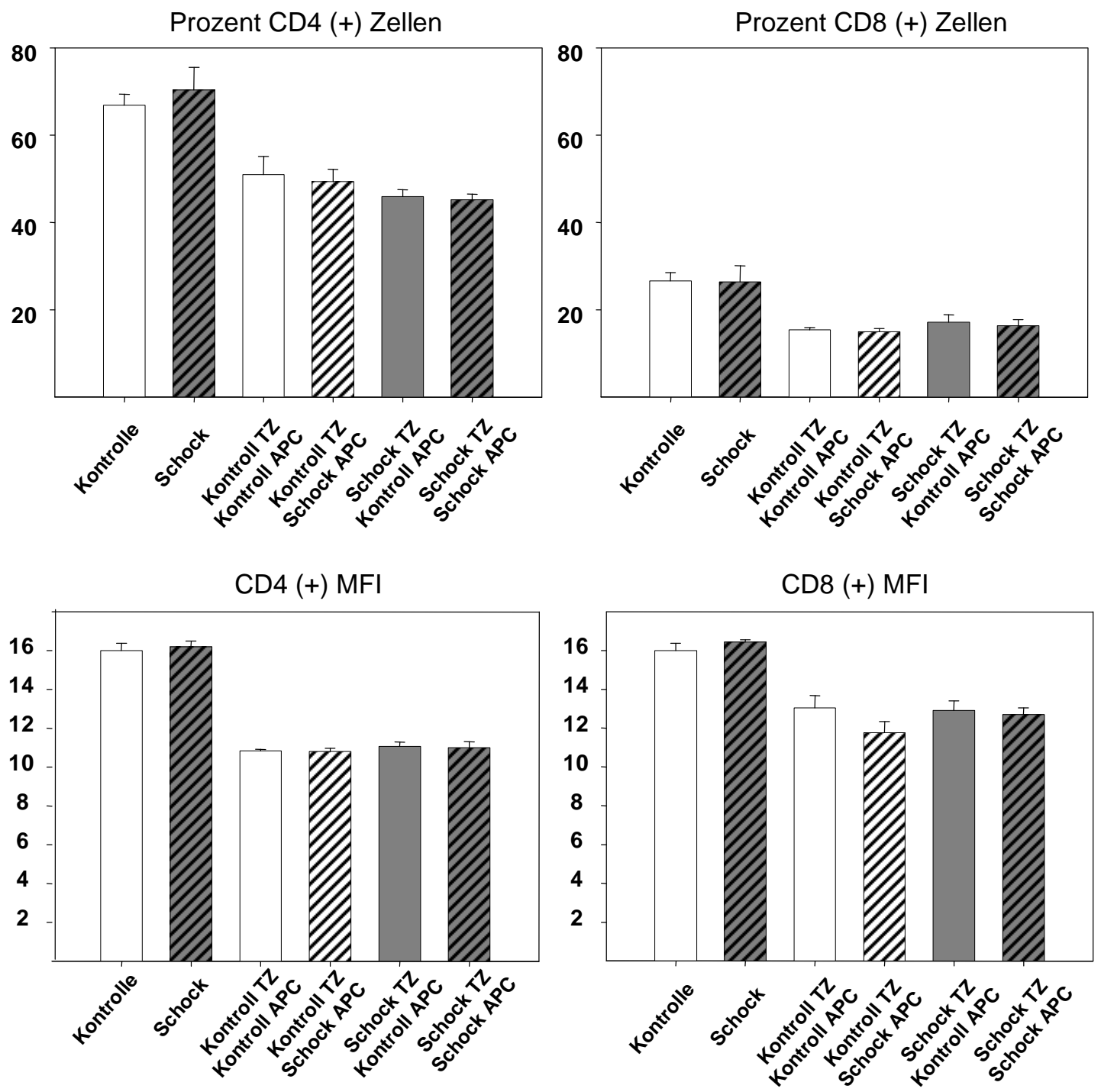

Figur 20 A und B:

Prozentzahl CD4 (+) und CD8 (+) Zellen:

Gruppe 1 und 2: jeweils unseparierte und unstimulierte Milzzellen vor Zellkultur

Gruppe 3-6: 48 Stunden nach Zellkultur unter Stimulation mit ConA und LPS.

Figur 20 C und D:

Mittlere Fuoreszenzintensität (MFI) der CD4 (+) und CD8 (+) Zellen

Gruppe 1 und 2: jeweils unseparierte und unstimulierte Milzzellen vor Zellkultur

Gruppe 3-6: 48 Stunden nach Zellkultur unter Stimulation mit ConA und LPS.

$N=6$ pro Gruppe

Es wurden pro Messung mindestens 10.000 Zellen via Durchflusszytometrie analysiert. 


\subsubsection{Aktivierungsmarker CD69}

Im Gegensatz zu den Markern CD4 und CD8 wurde der als „very early-antigen“ bezeichnete Oberflächenmarker CD69 nach der Zellkultur und Stimulation stärker auf den Zelloberflächen der T-Zellen exprimiert (Gruppen 1 und 2 vs. Gruppen 3-6), wobei sich auch hier kein signifikanter Unterschied zwischen den Versuchsgruppen der Kokulturen offenbarte.

Fig. 21:
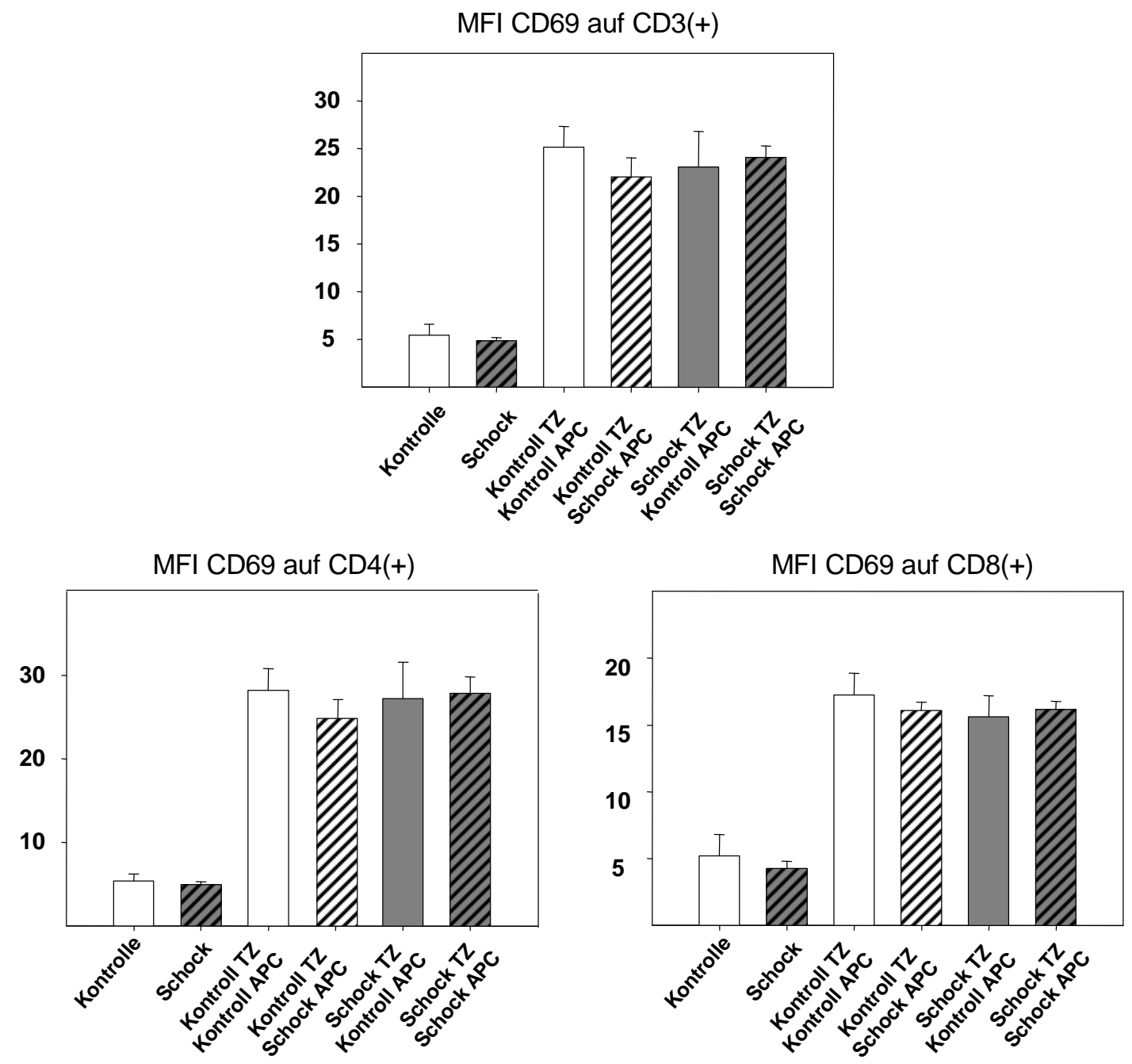

Fig. 21:

zeigt die Mittlere Fluoreszenzintensität des Aktivierungsmarkers CD69 auf CD3 (+)(A), CD4 (+) (B) und CD8 (+) (C) Zellen

Gruppe 1 und 2: jeweils unseparierte und unstimulierte Milzzellen vor Zellkultur Gruppe 3-6: 48 Stunden nach Zellkultur unter Stimulation mit ConA und LPS. $N=6$ pro Gruppe

Es wurden pro Messung mindestens 10.000 Zellen via Durchflusszytometrie analysiert. 


\subsubsection{Kostimulatorischer Oberflächenmarker CD28}

Trotz der Verwendung zweier unterschiedlicher Antikörper von unterschiedlichen Herstellern konnte das Oberflächenmolekül CD28 zu keinem Zeitpunkt auf den Oberflächen der T-Zellen detektiert werden.

\subsubsection{APC spezifische Oberflächenmarker}

\subsubsection{CD11b und CD11c}

Zur Differenzierung der adhärenten Zellen in Makrophagen (CD11b) und Dendritische Zellen (CD11c) wurden für die jeweilige Population spezifische Oberflächenmarker verwendet.

Die Expression dieser Oberflächenmarker ist vom Aktivierungszustand der jeweiligen Zellpopulation abhängig. So finden sich in dem so genannten gate, welches zu Beginn der Studie aufgrund der Morphologie von APC als Lokalisation derer festgelegt wurde, in den Ansätzen vor Zellseparation (ohne Zellkultur und Stimulation) durchschnittlich 50\% CD11b (+) Zellen (Fig. B, Gruppen 1 und 2) und ca. 3\% CD11c (+) Zellen (Fig. A, Gruppen 1 und 2). Nach der Zellkultur mit der Doppelstimulation mit ConA und LPS zeigen sich eine weitaus geringere Anzahl Zellen als CD11b (+), ca. 5\% (Fig. B, Gruppen 3-6), dafür aber bis zu 15\% der Zellen als CD11c (+) (Fig. A, Gruppen 3-6). Diese Differenzen lassen sich mit geringen und nicht signifikant unterschiedlichen Zahlen auf alle der vier Versuchgruppen der Kokulturen (Gruppen 3-6) übertragen.

Die mittlere Fluoreszenzintensität als dimensionsloses Maß der Rezeptordichte von CD11b und CD11c, war bei beiden Markern deutlich vermindert. So zeigte sich im Fall von CD11c eine Reduktion von ca. 50 MFI direkt 24 Stunden nach Trauma und Schock und noch vor Zellseparation, auf eine durchschnittliche MFI in allen 4 Kokulturen nach Zellkultur und Stimulation von ca. 5 (Gruppen 1+2 vs. Gruppen 3-6).

Noch dramatischer fiel der Verlust an Oberflächenrezeptoren bei CD11b aus. Bei einem Ausgangswert der MFI von durchschnittlich 35 im Fall der Kontrolltiere und ca. 30 MFI bei traumatisch-hämorrhagischem Schock Versuchstieren, wurde der Rezeptor CD11b nahezu auf das Niveau der Isotypkontrollen (ca. 0,4) runterreguliert. Dieser Umstand schränkt damit die mögliche Aussage der Oberflächenexpression von MHC II auf CD11b (+) Zellen ein. 
Fig. 22:
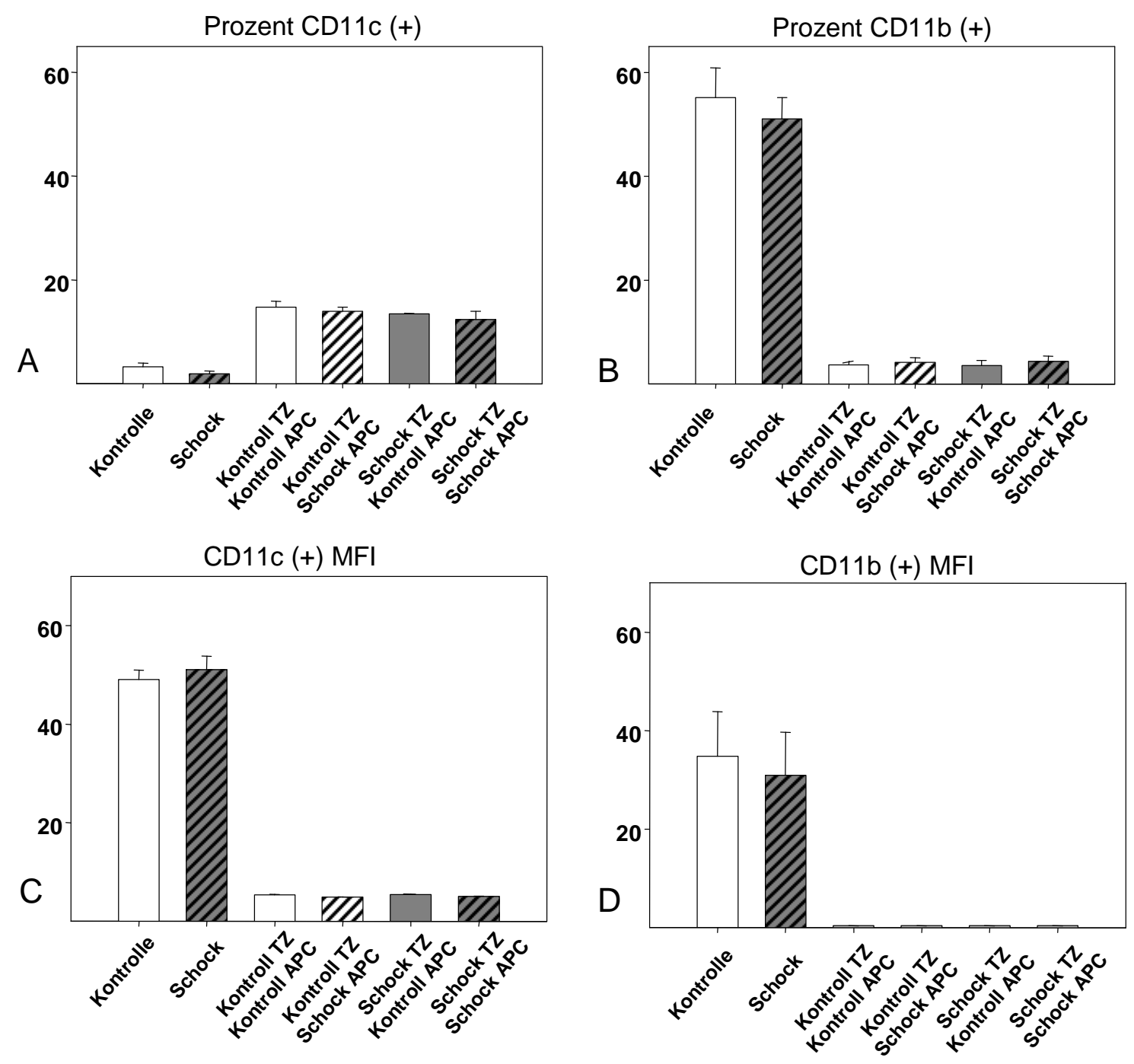

Fig. 22: zeigt die Prozentzahlen und die Mittlere Fluoreszenzintensität von CD11c (+) $(A+C)$ und $C D 11 b(+)(B+D)$ Zellen 24 Stunden nach Kontrolloperation (Kontroll) oder traumatisch-hämorrhagischem Schock (Schock):

Gruppe 1 Kontroll, Gruppe 2 Schock,

oder zusätzlich Zellkultur für 48 Stunden unter Stimulation mit ConA und LPS:

Gruppe 3: Kontroll T-Zellen + Kontroll APC; Gruppe 4 Kontroll T-Zellen + Schock APC,

Gruppe 5: Schock T-Zellen + Kontroll APC, Gruppe 6: Schock T-Zellen + Schock APC;

N=6 pro Gruppe

Es wurden pro Messung mindestens 10.000 Zellen via Durchflusszytometrie analysiert. 


\subsubsection{Kostimulatorische Oberflächenmarker CD80 und CD86}

Die kostimulatorischen Oberflächenmarker CD80 und CD86 zeigen nach der Zellkultur eine gesteigerte Expression auf CD11b (+) und CD11c (+) Zellen in allen vier Versuchsgruppen der Kokulturen (Gruppen 3 und 6) im Vergleich zu Zellen der Gruppen 1 und 224 Stunden nach traumatisch-hämorrhagischem Schock und noch vor Zellkultur. (Fig.23) Dabei zeigte sich aber unter den Versuchsgruppen nach Stimulation (Gruppen 3-6) kein signifikanter Unterschied. 
Fig. 23:
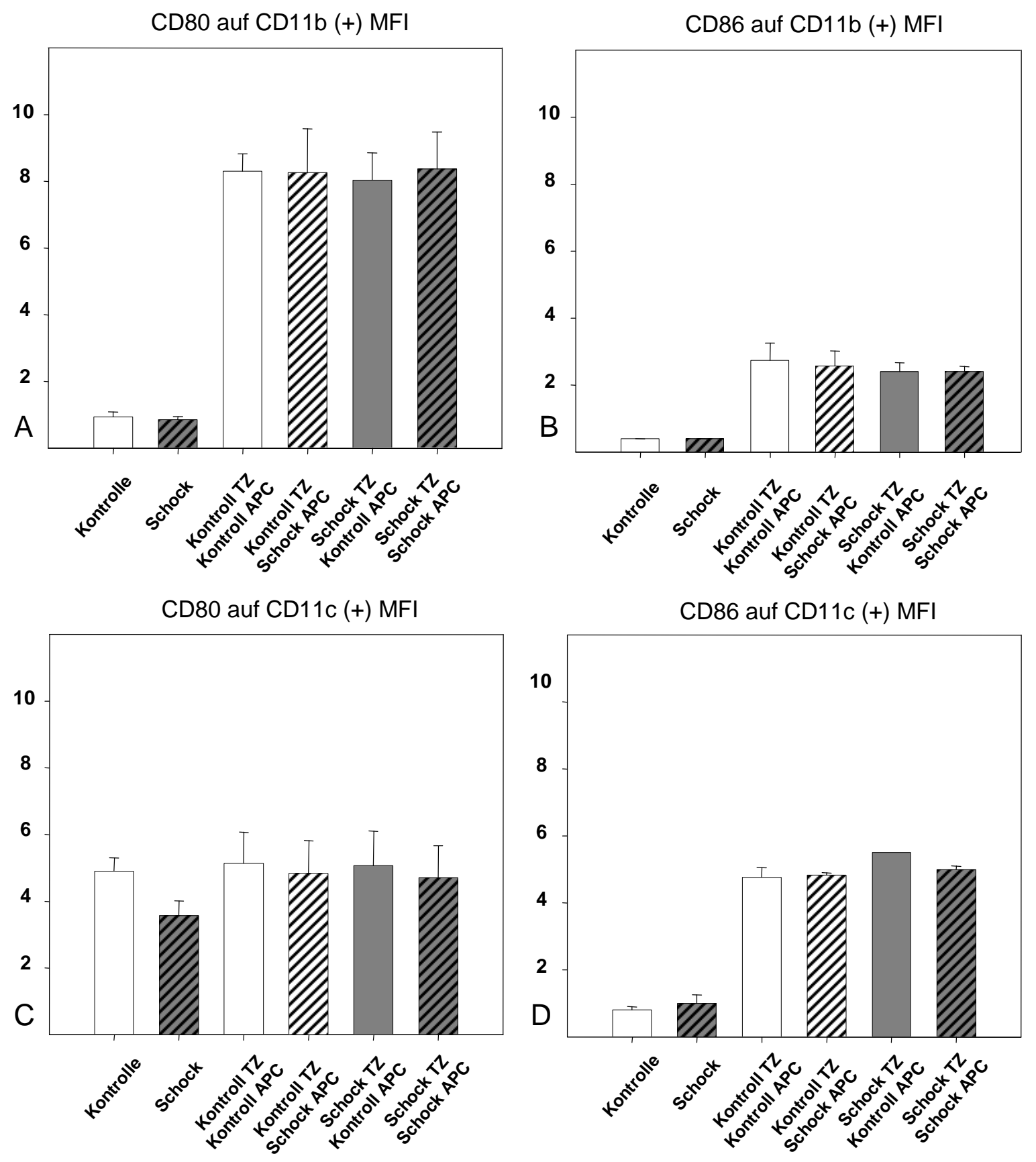

Fig. 23: zeigt die Expression der kostimulatorischen Oberflächenmarker $C D 80(A+C)$ und $C D 86(B+D)$ auf CD11b (+) und CD11c (+) Zellen.

24 Stunden nach Kontrolloperation (Kontroll) oder traumatisch-hämorrhagischem Schock (Schock): Gruppe 1 Kontroll, Gruppe 2 Schock,

oder zusätzlich Zellkultur für 48 Stunden unter Stimulation mit ConA und LPS:

Gruppe 3: Kontroll T-Zellen + Kontroll APC; Gruppe 4 Kontroll T-Zellen + Schock APC,

Gruppe 5: Schock T-Zellen + Kontroll APC, Gruppe 6: Schock T-Zellen + Schock APC;

$N=6$ pro Gruppe

Es wurden pro Messung mindestens 10.000 Zellen via Durchflusszytometrie analysiert. 


\subsubsection{MHC Klasse II Expression}

Direkt nach der Zellgewinnung und noch vor der Zellseparation zeigt sich ein signifikanter Unterschied bei CD11c (+) Zellen (Fig. 24). Die Expression von MHC II war bei den Zellsuspensionen aus geschockten Mäusen (somit noch ungetrennte Milzzellen) signifikant reduziert (Gruppe 2 vs. Gruppe 1).

Diese Beobachtung bestätigte sich auch nach der Zellkultur und Stimulation mit ConA und LPS - hier war die Expression von MHC II auf CD11c (+) Zellen in den Fällen der Kokulturen mit geschockten T-Zellen (Gruppe 3 und 4) im Vergleich zu T-Zellen kontrolloperierter Tiere (Gruppe 1) signifikant reduziert (Fig. 24).

Der traumatisch-hämorrhagische Schock der T-Zellen scheint ausschlaggebend für die Expression dieses Oberflächenmarkers zu sein, da interessanterweise geschockte APC in der Kokultur mit kontrolloperierten T-Zellen (Gruppe 4) keine supprimierte MHC II Expression gegenüber Gruppe 3 aufwies.

Dem gegenüber zeigte sich in der Expression von MHC II auf CD11b (+) Zellen, respektive Makrophagen, kein signifikanter Unterschied noch vor Zellseparation. Der Oberflächenmarker war hier sogar nahe der Nachweisgrenze.

In den vier verschiedenen Zellkulturansätzen nach Kokultur und Stimulation mit ConA und LPS konnte zwar eine gewisse Regeneration der Oberflächenexpression von MHC II auf CD11b (+) Zellen nachgewiesen werden, jedoch bestätigte sich ein ähnlicher Effekt wie bei den CD11c (+) Zellen nicht. 
Fig. 24:
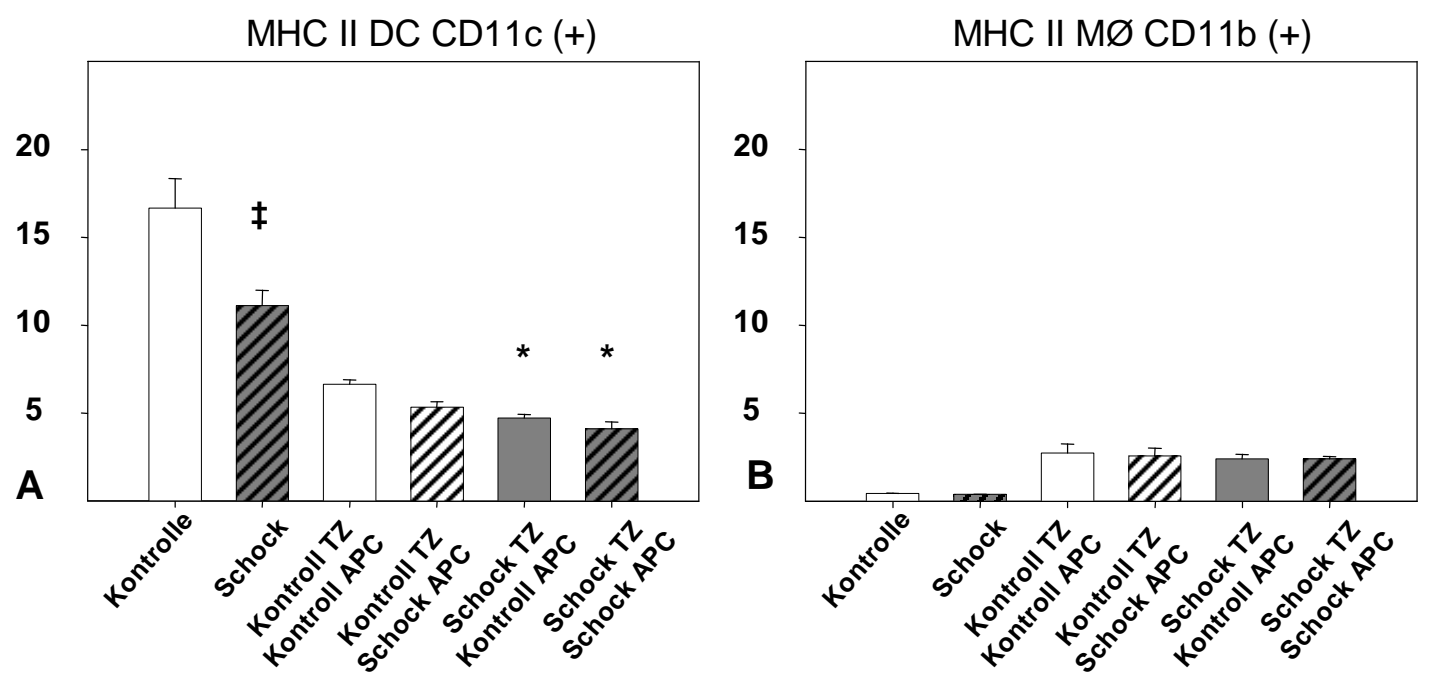

Fig. 24: MHC II Expression auf CDI1c (+) Dendritischen Zellen (A) und CD11b (+) Makrophagen (B).

24 Stunden nach Kontrolloperation (Kontroll) oder traumatisch-hämorrhagischem Schock (Schock): Gruppe 1 Kontroll, Gruppe 2 Schock, oder zusätzlich Zellkultur für 48 Stunden unter Stimulation mit ConA und LPS:

Gruppe 3: Kontroll T-Zellen + Kontroll APC; Gruppe 4 Kontroll T-Zellen + Schock APC, Gruppe 5: Schock T-Zellen + Kontroll APC, Gruppe 6: Schock T-Zellen + Schock APC; $N=3$ pro Gruppe; ${ }^{*} p<0,05$ vs. Gruppe 1; * $p<0,05$ vs. Gruppe 3

Es wurden pro Messung mindestens 10.000 Zellen via Durchflusszytometrie analysiert. 


\section{Diskussion}

\subsection{Problemstellung}

Nach Trauma und Blutverlust treten im Verlauf gehäuft Immundysfunktionen auf, die mit einer erhöhten Rate an septischen Komplikationen vergesellschaftet sind 13,19,95,101,120 . Dabei ist für die erfolgreiche Behandlung von Patienten notwendig, die genauen pathophysiologischen Hintergründe zu eruieren, um eine suffiziente Therapie einleiten zu können.

Primär nach einem Schockereignis bildet sich vor allem lokal an Ort des Traumas eine Phase der Hyperinflammation aus, die mit erhöhten Konzentrationen proinflammatorischer Zytokine einhergeht 7,37,38,81. Eine Ausschwemmung dieser Zytokine kann zu einer generalisierten Entzündungsreaktion (SIRS) führen, was mit einem vermehrten Auftreten von Multiorganversagen $(M O F)$ und erhöhter Sterblichkeitsrate verbunden ist ${ }^{13,36}$. Im Verlauf tritt nun kompensatorisch in dieser Phase eine Immunosuppression auf (CARS), in der sich das Gleichgewicht zwischen pro- und antiinflammatorischer Zytokinsekretion in einem dynamischen Prozess in Richtung Antiinflammation verschiebt ${ }^{48,81,100,101}$.

Im Rahmen dieser Immunosuppression zeigen sich vor allem im Bereich der zellulären Immunabwehr weitreichende funktionelle Defizite ${ }^{83,101}$.

So weisen beispielsweise Antigenpräsentierende Zellen Störungen im Bereich der Sekretion von Zytokinen nach Stimulation in vitro eine unterdrückte Antigenpräsentation auf ${ }^{7,19,81,89}$. Darüber hinaus zeigen T-Zellen ebenfalls bedeutende funktionelle Störungen bezüglich der monoklonalen Proliferationsfähigkeit ${ }^{15,37}$ und der Sekretion von TH-1 Zytokinen (z.B. Il-2 und IFN- $\gamma)^{4,7,89,101}$. Sowohl die Funktionsstörung der APC als auch der T-Zellen erscheint mit erhöhten Raten an septischen Komplikationen verbunden zu sein ${ }^{8,37}$.

Angesichts dieser weitreichenden funktionellen Defizite der APC und der T-Zellen stellt sich hinsichtlich der Entwicklung neuer therapeutischen Strategien die Frage, welche Zellpopulation vorrangig für die Persistenz der Immunosuppression im Verlauf nach traumatisch-hämorrhagischem Schock verantwortlich ist.

Bisherige Studien verwendeten jedoch zur Untersuchung der postoperativen Immunfunktion isolierte Zellpopulationen oder Zellgemische. Diese Daten erlauben daher keine Beantwortung oben genannter Fragestellung.

Im Rahmen dieser Arbeit wurden erstmalig isolierte APC und T-Zellen kokultiviert und anschließend die sezernierten Zytokine und Oberflächenmarker gemessen. 


\subsection{Relevanz des Tiermodells und der erhobenen Parameter}

Um den pathophysiologischen Hintergründen nach Trauma und Schock adäquat untersuchen zu können, bedarf es der Verwendung eines klinisch relevanten Tierversuchmodells. In diesem Zusammenhang besteht jedoch bei der Nutzung von Großtieren ein Mangel an immunologischen Tests und dafür benötigter Antikörper ${ }^{110}$ - darüber hinaus würden diese die Anschaffung und Haltung der Tiere enorme Kosten verursachen.

Daher werden von den meisten in diesem Bereich der Wissenschaft forschenden Arbeitsgruppen Mäuse als Versuchstiere verwendet. In dieser Arbeit wurden Mäuse des Stammes $\mathrm{C} 3 \mathrm{H} / \mathrm{HeN}$ verwendet, da sie über eine ausgewogene T-zelluläre TH-1/TH-2 Antwort verfügen und daher dem menschlichen Immunsystem ähnlich sind ${ }^{18}$.

Diese These wird gestützt durch vergleichbare Ergebnisse aus dem Tiermodell und klinischen Studien. So zeigen beispielsweise gewonnene T-Zellen sowohl aus C3H/HeN Mäusen als auch aus menschlichem Blut eine supprimierte Zytokinsekretion nach traumatisch hämorrhagischem Schock ${ }^{7,9}$. Gleiche Effekte wurden auch im Bereich der Antigenpräsentierenden Zellen beobachtet: deren reduzierte Fähigkeit zur Zytokinsekretion und der Antigenpräsentation sind sowohl im murinen als auch im humanen Bereich zu beobachten ${ }^{7,15,19,38,81}$.

Das verwendete traumatisch hämorrhagische Schockmodell ist seit vielen Jahren etabliert und sehr gut charakterisiert. Es ermöglicht neben der erforderlichen Blutdruckreduktion und permanenten Blutdruckkontrollen über einen der in die Leisten eingebrachten Katheter eine adäquate Flüssigkeitssubstitution nach Durchführung des traumatisch hämorrhagischen Schocks ${ }^{36}$. Das verwendete nichtletale Tierversuchmodell ${ }^{36}$ führt $\mathrm{zu}$ einer Immunosuppression für bis zu sieben Tage ${ }^{141}$, wobei sich in diesem Zeitraum eine erhöhte Anfälligkeit für septische Komplikationen zeigt ${ }^{13,19,95,101,120}$.

Im Rahmen dieser Studie wurden aus den Versuchstieren 24 Stunden nach traumatisch hämorrhagischem Schock oder nach Kontrolloperation die Milzen entfernt um daraus TZellen und Antigenpräsentierende Zellen zu gewinnen. Dieser Zeitpunkt wurde gewählt, da in vorangegangenen Studien sich zu diesem Zeitraum die maximale Immunsuppression zeigte 53

Für die Isolierung der T-Zellen bediente man sich einer immunomagnetischen Zellauftrennung. Dabei existieren zwei verschiedene Methoden, um die T-Zellen zu gewinnen: die Positiv- und die Negativselektion. Bei der Positivselektion werden die T- 
Zellen direkt mittels eines Antikörpers gegen ein spezifisches Oberflächenmolekül (hier CD90) markiert, bei der Negativselektion (Pan-T-Cell Isolation) werden alle anderen in der Zellsuspension vorhandenen Zellen markiert (siehe Material- und Methodenteil).

Beide Systeme wurden in Vorversuchen in ihrer Durchführbarkeit und Effizienz verglichen und mittels Durchflusszytometrie validiert. Die Reinheit der zu gewinnenden T-Zellen war in der Negativselektion höher.

Die Antigenpräsentierenden Zellen wurden nach T-Zellseparation aufgrund ihrer Fähigkeit zur Adhärenz an Plastikoberflächen isoliert ${ }^{65}$. Diese Technik ermöglicht eine Aufreinigung der APC von bis zu 95\% 22, wobei eine Aktivierung der Zellen durch den Kontakt mit Plastikoberflächen nicht auszuschließen ist ${ }^{51}$. In diesem Fall möglicherweise auftretende Veränderung würden jedoch in allen Versuchsgruppen gleichzeitig auftreten und damit die Ergebnisse in gleicher Weise beeinflussen.

Nach der Separation der Zellen wurden die Zellen nach einem festen Schema für 48 Stunden miteinander koinkubiert (s.o.). Um die Zytokinsekretion der zwei Zellpopulationen zu eruieren, wurden zusätzlich von APC und T-Zellen jeweils Monokulturen angesetzt und entsprechend der Kokulturen stimuliert. Es ist jedoch zu berücksichtigen, dass auch bei den verwendeten Monokulturen von einer minimalen Verunreinigung mit T-Zellen bzw. APC auszugehen ist.

Das hier verwendete Versuchmodell basiert auf zwei unterschiedlichen Versuchsanordnungen: in den Gruppen 1 und 4 wurden T-Zellen und APC aus den gleichen entweder kontrolloperierten oder schockierten Versuchstieren koinkubiert. Diese Gruppen dienten als Vergleichsgruppen für vorangehende Studien: es zeigten sich größtenteils kongruente Ergebnisse in den Zytokinproduktion und Antigenpräsentation (s.u.). Diese Tatsache deutet auf die Relevanz der erhobenen Daten und des hier verwendeten Tierversuchmodells hin und ermöglicht somit den Vergleich mit früheren Studien.

Eine entscheidende Neuerung an dieser Studie war jedoch die Koinkubation von vorher isolierten T-Zellen und APC aus unterschiedlichen Versuchstieren. Dadurch wurde es möglich, eine direkte Auswirkung des Schocks von beispielsweise T-Zellen auf kontrolloperierte Antigenpräsentierende Zellen und umgekehrt zu beobachten (Gruppen 2 und 3). Eine dabei möglicherweise auftretenden Reaktion im Sinne einer Abstoßung der Zellen kann jedoch ausgeschlossen werden. Die in dieser Studie verwendeten Tiere waren Inzuchtmäuse und weisen daher eine genetische Homogenität auf. Diese These kann durch 
die in dieser Studie gewonnenen Daten gestützt werden: die Kokulturen beispielsweise von TZellen aus kontrolloperierten Versuchstieren mit APC aus geschockten Tieren offenbarte keinen Unterschied in der Sekretion von IFN- $\gamma$, was einer immunologischen Reaktion entspräche ${ }^{29}$, da die koinkubierten Zellen aus unterschiedlichen Versuchstieren stammten.

Um die Zellen in den Zellkulturplatten zur Sekretion von Zytokinen zu stimulieren, wurden zwei mitogene Substanzen gewählt:

Für die T-Zellstimulation wurde Concanavalin A (ConA) verwendet - dieses Polysaccharid aus der Jakobsbohne (Canavalina ensiformis) bindet an spezifische Oberflächenstrukturen der T-Zellen ${ }^{105}$ und führt zu Zellaktivierung und Sekretion von TH-1 Zytokinen ${ }^{105}$. Für eine maximale Stimulation der T-Zellen durch ConA ist jedoch die Anwesenheit des durch APC sezernierten IL-1 erforderlich ${ }^{105}$. Eine zusätzliche Aktivierung der APC durch ConA ist hier jedoch nicht auszuschließen ${ }^{30}$.

Zur Stimulation der APC wurde Lipopolysaccharid (LPS) als Bestandteil der Zellmembran von Escherichia coli verwendet. Dieses Mitogen bindet in Kombination mit LBP (Lipopolyssacharide Binding Protein) an den spezifischen LPS-Rezeptor CD14 auf den Oberflächen der APC ${ }^{58}$. Dieser Komplex wird internalisiert und via MHC II wieder auf der Zelloberfläche exprimiert ${ }^{59}$. Dies resultiert in einer Aktivierung von APC und stimuliert diese zur Zytokinsekretion ${ }^{84}$. Es sollte betont werden, dass auch für LPS eine eindeutig selektive Stimulation der APC nicht gewährleistet ist: Kaya et al. zeigte in einer Studie die Stimulierbarkeit von T-Zellen durch LPS ${ }^{80}$. In wie weit eine Verunreinigung durch APC in diesen Studien vorhanden war, bleibt jedoch unklar.

Dennoch stellen die Stimulationen der T-Zellen durch ConA 17,20,127 und der Antigenpräsentierenden Zellen durch LPS ${ }^{11,12,19,38,50}$ etablierte Stimulationsbedingungen dar, die in einer Vielzahl klinischen und experimentellen Studien zur Anwendung kamen.

Darüber hinaus wurden zur Ermittlung der spontanen Zytokinsekretion auch unstimulierte Zellen für 48h inkubiert.

Zur Bestimmung der Zytokinkonzentrationen aus den Zellkulturüberständen wurde ein Multiplex assay verwendet. Diese Technik verbindet die klassische ELISA-Technik mit der Durchflusszytometrie und bietet dabei aber im Gegensatz zur ELISA-Technik die Möglichkeit, mehrere Proteine gleichzeitig zu messen. Darüber hinaus ermöglicht dieses Verfahren die Messung der Zytokine in einem größeren Referenzbereich. Während bei der ELISA-Technik ohne Verdünnung der Zellkulturüberstände Konzentrationen nur bis maximal 
3000 pg/ml messbar sind, können laut Herstellerangaben bei der Multiplex-Technik Konzentrationen bis zu 32000 pg/ml gemessen werden, was die Erstellung von Verdünnungsreihen erspart und damit jeden dabei möglicherweise auftretenden Verdünnungsfehler unterbindet.

Die Expression von verschiedenen Oberflächenmolekülen auf T-Zellen und APC wurden mittels Durchflusszytometrie bestimmt. Dabei wurden sowohl Zellen vor Zellkultur, als auch nach der Zellkultur und Stimulation verwendet. Unspezifische Bindungen und Autofluoreszenzen der verwendeten Antikörper wurden durch die Blockade des $\mathrm{F}_{\mathrm{c}}$-Fragments auf APC und die Verwendung von baugleichen Kontrollantikörper (Isotypkontrolle) getestet. Für jeden Antikörper wurden zur Bestimmung der benötigten adäquaten Antikörpervolumina in Vorversuchen Volumentitrationen durchgeführt.

Für die Charakterisierung von T-Zellen wurden fluorchrome Antikörper gegen CD3, CD4 und CD8 verwendet. Dadurch konnten mögliche Veränderungen in den Subpopulationen der THelfer-Zellen (CD4 (+)) und der zytotoxischen T-Zellen (CD8 (+)) detektiert werden. Darüber hinaus wurden auch Antikörper gegen den Oberflächenmarker CD28 eingesetzt. Exprimiert auf T-Zellen, ist dies ein wichtiger Vertreter der kostimulatorischen Moleküle für eine maximale Stimulation für T-Zellen im Rahmen des Zell-zu-Zell Kontaktes von T-Zellen und APC („Immunologische Synapse“) ${ }^{46,97}$. Die Bindung dieses Oberflächenmarker mit den Liganden CD80 und CD86 auf APC ist unabdingbar für eine volle Stimulation und Interaktion der beteiligten Zellen 66,87,104. CD69, auch als very-early-activation-marker bezeichnetes Oberflächenmolekül ${ }^{90,131}$, wurde für die Detektion einer frühen Aktivierung der T-Zellen eingesetzt.

Für die Diskrimination der unterschiedlichen Populationen der Antigenpräsentierenden Zellen bediente man sich der Verwendung von CD11b und CD11c. CD11b gilt als gängiger Makrophagenmarker und wir auf einem Großteil dieser Zellen bei Aktivierung exprimiert 91,92,96, wohingegen CD11c ein hochspezifischer Marker für Dendritische Zellen ist 34,41,92,96,118 . CD80 und CD86 sind, wie bereits erwähnt, Liganden des T-Zell-spezifischen Oberflächenmoleküls CD28 und werden auf den meisten APC exprimiert ${ }^{52}$.

Als Maß für die Fähigkeit der Antigenpräsentation wurde die Expression von MHC II auf CD11b (+) und CD11c (+) Zellen gemessen. Über diesen Komplex präsentieren APC zuvor internalisierte Antigene. Auf beiden Populationen (Makrophagen und Dendritische Zellen) ist dieses Oberflächenmolekül zu finden 19,36,43,79,91. 


\subsection{Bedeutung der gemessenen Zytokine nach Schock}

Zur Charakterisierung der Zellfunktion wurden für die T-Zellen und die Antigenpräsentierenden Zellen folgende Zytokine nach 48 Stunden Zellkultur und Stimulation in den Überständen gemessen: IL-1 $\beta$, IL-2, IL-4, IL-6, IL-10, IL-12p40, IL$12 \mathrm{p} 70, \mathrm{IFN}-\gamma, \mathrm{GM}-\mathrm{CSF}$ und TNF- $\alpha$.

Im folgenden Abschnitt wird die Funktion, Wirkung und Interaktion der gemessenen Zytokine charakterisiert, wobei hier im Besonderen auf die Funktion in Bezug auf Trauma und Blutverlust eingegangen wird.

Der traumatisch-hämorrhagischem Schock induziert innerhalb von wenigen Minuten eine primär lokal begrenzte Hyperinflammation der regional ansässigen Immunzellen wie beispielsweise Makrophagen, wobei es zu enormer Sekretion von IL-1, IL-6 und TNF- $\alpha$ kommt 10,19,84,95,98,115,120,125,140. Diese drei Zytokine besitzen synergistische Effekte in der Initiierung einer „Akuten-Phase-Reaktion“, die beispielsweise zu einer Produktion und Sekretion von in der Leber synthetisiertem CRP, $\alpha_{2}$-Makroglobulin und LBP durch IL-6 führt 27,71,72. Im Rahmen dessen zeigt sich eine direkte Korrelation zwischen IL-6, CRP und der Schwere des Traumas ${ }^{72}$. Zusätzlich lösen diese Zytokine eine lokale Leukozyteninfiltration in das traumatisierte Gewebe aus, um eine adäquate Abräum- und Reparationsleistung erbringen zu können ${ }^{7,95}$.

Ferner zeichnen sich die Zytokine IL-1, IL-6 und TNF- $\alpha$ durch eine extrem kurze Halbwertszeit ${ }^{93}$ und einer zumeist auch lokalen Begrenzung aus ${ }^{28}$. Beispielsweise zeigt das TNF- $\alpha$ eine maximale Gewebekonzentration ca. 2 Stunden nach traumatischhämorrhagischem Schock und eine Rückkehr auf normale Konzentrationen binnen 24 Stunden ${ }^{7,23,111}$. IL-6 offenbart nach traumatisch-hämorrhagischem Schock eine ähnliche Kinetik - es steigt innerhalb von wenigen Stunden an und fällt nach ca. 24 Stunden wieder auf normale Level herab ${ }^{54}$.

Neben einer Stimulation der Zellen zur Sekretion von proinflammatorischem IL-2, IFN- $\gamma$ und IL-12 9,57,69,98,123, deren Wirkung weiter unten skizziert werden, führen die hohen Konzentrationen zur Aktivierung der T-Zellen und APC zur Sekretion von antiinflammatorischen Botenstoffen wie IL-10 und $\mathrm{PGE}_{2}{ }^{3,56,57,95}$

IL-10 sezerniert aus T-Zellen stellt eine negative Rückkopplung zu IL-6 dar ${ }^{19}-$ PGE $_{2}$ ist ein Botenstoff mit stark hemmender Wirkung auf die Neusynthese von IL-2, TNF- $\alpha$ und IL-1. Darüber hinaus weißt $\mathrm{PGE}_{2}$ eine stimulatorische Wirkung auf die Sekretion von IL-10 und IL-4 auf ${ }^{20,106}$. 
Die beiden Zytokine IFN- $\gamma$ und IL-12 werden als direkter Kommunikationsweg der T-Zellen und APC bezeichnet, da beide Zytokine im Rahmen einer positiven Rückkopplung die Synthese des Gegenspielers direkt fördern ${ }^{53}$. Dabei spielt das IFN- $\gamma$ eine zusätzliche und besonders wichtige Rolle in der Antigenpräsentation der APC via MHC II - IFN- $\gamma$ ist ein wichtiger Initiator der MHC II Expression 16,40,53,54,114,132.

Das bereits erwähnte IL-4, dass von T-Zellen sezerniert wird, übernimmt in Zusammenhang mit dem Botenstoff GM-CSF eine wichtige Funktion in der Reifung von Dendritischen Zellen ${ }^{64}$, was in Zusammenschau der hier gewonnenen Ergebnisse eine interessante Rolle spielen könnte. IL-4 wird zumeist in der Fachliteratur als klassisches TH-2 Zytokin gehandelt 20,57,102, jedoch zeigt IL-4 auch TH-1 Effekte, wie die stimulierende Wirkung auf die DCMaturation und die Sekretion von GM-CSF ${ }^{64,124}$. Auch das GM-CSF zeigt zudem bedeutende Effekte auf die Leukozytenproduktion und die Aktivierung von Granulozyten ${ }^{39}$.

In Anbetracht dieser weitreichenden Funktionen und Interaktionen der genannten Zytokine, zeichnet sich das Immunsystem als ein äußerst komplexes Gebilde aus Aktivierung und Deaktivierung der verschiedenen Zellpopulationen aus. Dieses vielschichtige System befindet sich in einem ständigen Fluss aus Sendung und Verarbeitung von Signalen wie beispielsweise Zytokinen, dessen genaue Wirkung und Interaktion bis heute nur in Ansätzen verstanden ist.

Insgesamt könnte diese Kommunikation als Versuch des Immunsystems gedeutet werden, einer notwendigen Aktivierung zur Immunabwehr eine adäquate Antiinflammation gegenüber $\mathrm{zu}$ stellen, um überschießende Immunreaktionen $\mathrm{zu}$ vermeiden. Im Rahmen eines traumatisierenden Ereignisses jedoch offenbart sich dieses System in seinem Ablauf als weitreichend gestört $1,7,15,35,37,38,44,48,57$.

Eine Spezifität bezüglich der sezernierten Zytokine besteht zumeist nicht - einige in dieser Studie bestimmten Zytokine können sowohl von T-Zellen als auch von APC produziert werden. So scheinen Dendritische Zellen unter bestimmten Umständen die Fähigkeit zu besitzen das an sich für T-Zellen hochspezifische IFN- $\gamma$ zu produzieren ${ }^{34}$. Gleiches trifft für das Interleukin-2, IL-4, IL-10 und GM-CSF zu ${ }^{34,41,64,98,122}$.

Auch die meistens als APC spezifisch definierten Mediatoren IL-1, IL-6, IL-12 und TNF- $\alpha$, können von den in dieser Studie koinkubierten T-Zellen produziert werden ${ }^{82}$. Angesichts 
dieser Tatsache wurde versucht, die jeweiligen Ursprungszellen der untersuchten Zytokine durch den Einsatz von Monokulturen der T-Zellen und APC zu eluieren.

Dabei konnten in diesen Versuchsansätzen eine potentielle Spezifität für IL-2, IL-4, IL-10, IFN- $\gamma$ und GM-CSF bezüglich der T-zellulären Herkunft in diesem Versuchsmodell gezeigt werden.

Im Falle der Zytokine IL-1, IL-6, IL-12 und TNF- $\alpha$ war andererseits eine eindeutige Zuordnung nicht möglich, da auf den ersten Blick beide Zellpopulationen diese Zytokine zu sezernieren scheinen. Jedoch ist nochmals darauf hin zu weisen, dass erstens die Reinheit der Zellen in den Monokulturen nicht zu 100\% gegeben war (T-Zellen ca. 93\% und APC ca. 95\%), zweitens die Zellfunktion einer einzelnen Zellpopulation ohne den Interaktionspartner nicht abzuschätzen war. Wie bereits erwähnt, ist durch die verwendeten Stimuli keine selektive Stimulation einer einzelnen Zellpopulation zu erreichen. So scheint das für die Tzelluläre Stimulation eingesetzte ConA auch einen stimulatorischen Effekt auf die APC zu haben, so wie auch T-Zellen durch LPS aktiviert werden können ${ }^{30,80}$. Folglich kann in diesen Fällen nicht davon ausgegangen werden, dass beispielsweise IL-12 hauptsächlich von TZellen produziert wurde. In einer Vielzahl von Studien wird die Produktion von IL-12 nahezu ausschließlich den APC zuerkannt ${ }^{70,73,128,139}$, wobei Dendritische Zellen bereits ohne Stimulation eine spontane IL-12 Produktion zeigen ${ }^{70}$.

Eine mögliche Beeinflussung der Kokulturen durch die minimalen Verunreinigungen der vorher isolierten Zellpopulationen erscheint für die Beantwortung der Fragestellung eher von untergeordneter Rolle. Die Verunreinigungen in den Kokulturen von T-Zellen und APC wären aufgrund des Separationsverfahrens in vergleichbarer Menge in jedem Zellkulturansatz enthalten.

In Anbetracht dieser komplexen Situation ist die Zuordnung der Zytokine zu ihren Ursprungszellen durch die Monokulturen der T-Zellen und APC kaum möglich.

Für die Detektion der Ursprungszellen eines Zytokins könnte in zukünftigen Studien die Detektion intrazellulärer Zytokine via Durchflusszytometrie verwendet werden. Diese Methode würde auch ermöglichen die aktuelle Zytokinproduktion der Zellen zum Zeitpunkt der Messung zu bestimmen, was bei der Messung der Zytokine in den Zellkulturüberständen nicht durchführbar ist. Die Detektion darin entspricht verfahrensbedingt nur einer Darstellung der gesamten Zytokinproduktion über den Zeitraum der Zellkultur, zusätzlich beeinflusst durch die jeweilige Halbwertszeit der zu messenden Zytokine. Eine Aussage über die Kinetik der Sekretion ist bei der hier angewandten Methode nicht möglich. 


\subsection{Zellkultur und Stimulation mit ConA und LPS}

In dieser Studie erwies sich die Sekretion von IL-1, IL-6 und TNF- $\alpha 24$ Stunden nach traumatisch-hämorrhagischem Schock durch die Schockprozedur unbeeinflusst. Die Konzentrationen in den Zellkulturüberständen nach Stimulation mit ConA und LPS war in den Kokulturen mit geschockten APC auf vergleichbarem Niveau, wie in den Kokulturen mit APC aus kontrolloperierten Versuchstieren. Geschockte T-Zellen offerierten hier keinen suppressiven Effekt auf die Zytokinsekretion von IL-1, IL-6 und TNF- $\alpha$. In diesem Zusammenhang muss jedoch nochmals darauf hingewiesen werden, dass diese Zytokine von beiden Zellpopulationen (T-Zellen und APC) sezerniert werden ${ }^{37,41,82,84,98}$.

Ayala et al. zeigte in einem ähnlichem Versuchsansatz eine deutliche Steigerung der Zytokinproduktion von IL-1, IL-6 und TNF- $\alpha$ innerhalb der ersten Stunden nach traumatischhämorrhagischem Schock. Im weiteren Verlauf - innerhalb von 6 Stunden - kehrten die Zytokinlevel jedoch wieder auf ihre physiologischen Ausgangswerte zurück ${ }^{21,23}$. Dies könnte eine Erklärung sein, dass diese Zytokine 24 Stunden nach traumatisch-hämorrhagischem Schock und 48-stündiger Zellkultur keine Veränderung zwischen den vier Versuchgruppen nach traumatisch-hämorrhagischen Schock oder Kontrolloperation zeigen.

Die immunologische Reaktion nach traumatisch-hämorrhagischem Schock mit der Entwicklung eines SIRS und in dessen Verlauf auftretenden CARS stellt einen äußerst dynamischen Prozess dar. Um dieser Problematik Rechnung zu tragen, bedarf es der Bestimmung der Zytokine zu mehreren Zeitpunkten im Verlauf nach traumatischhämorrhagischem Schock.

In einer Vielzahl von klinischen und tierexperimentellen Studien offenbarte sich eine reduzierte Sekretionsfähigkeit von IL-2 der T-Zellen nach traumatisch-hämorrhagischem Schock ${ }^{9,18,57,140,141}$ - dies lässt sich durch die Daten dieser Studie bestätigen: das Zytokin IL-2 wies signifikant erniedrigte Spiegel nach traumatisch-hämorrhagischem Schock der T-Zellen und APC auf. Die Koinkubation von schockierten T-Zellen mit kontrolloperierten APC führte jedoch zu keiner signifikanten Reduktion des IL-2. Folglich ist für eine signifikant reduzierte IL-2-Sekretion aus T-Zellen notwendig, dass beide Zellpopulationen (T-Zellen und APC) durch den traumatisch-hämorrhagischen Schock geschädigt werden.

In mehreren dieser oben genannten Studien wurde zusätzlich die Freisetzung von IL-10 gemessen. Dieses TH-2 Zytokin mit antiinflammatorischer Wirkung zeigt erhöhte Spiegel nach traumatisch-hämorrhagischem Schock ${ }^{9,18,57,95,119}$. 
Die hier vorliegende Studie offenbarte jedoch kein signifikanten Unterschied in der IL-10 Sekretion durch die Schockprozedur der T-Zellen oder APC. In diesem Zusammenhang sei nochmals auf die zeitliche Komponente der Hyperinflammation und kompensatorischen Antiinflammation hingewiesen. Möglicherweise befindet man sich zu diesem Zeitpunkt 24 Stunden nach traumatisch-hämorrhagischem Schock und 48 Stunden Stimulation mit ConA und LPS in einem Bereich, in dem die antiinflammatorische Wirkung des IL-10 sich möglicherweise noch nicht vollständig ausgeprägt ist. Um diese These zu bestätigen sind weiterführende Studien mit unterschiedlichen Zeitpunkten der Überstandsgewinnung notwendig um dem Verlauf der Inflammation und Antiinflammation genauer zu beobachten.

Im Gegensatz zu den bereits genannten Botenstoffen war 24 Stunden nach traumatischhämorrhagischem Schock die Sekretion der T-zellulären Zytokine IL-4 und GM-CSF signifikant reduziert. Dies war unabhängig, ob die T-Zellen mit kontrolloperierten, oder geschockten APC koinkubiert waren. Die Kokultur von geschockten APC mit kontrolloperierten T-Zellen führte zu keiner Suppression der oben genannten Zytokine.

Dies deutet darauf hin, dass die Antigenpräsentierende Zelle auf die T-zelluläre Zytokinsekretion von IL-4 und GM-CSF keinen Einfluss zu nehmen scheint. Nur die direkte Schockprozedur auf die T-Zelle führt zu einer supprimierten Sekretion der beiden Zytokine. Vorangehende Studien mit Fokus auf IL-4 und GM-CSF zeigten teilweise differierende Ergebnisse. Während in einer Patientenstudie von O’Sullivan et al. IL-4 über mehrere Tage hinweg signifikant erhöhte Werte aufwies, offenbarte sich in Studien von Ertel et al. supprimierte Konzentrationen von IL-4 nach Endotoxinschock ${ }^{53,102}$.

Die Funktion des GM-CSF im Forschungsbereich des traumatisch-hämorrhagischen Schocks ist noch relativ ungeklärt. In einer Studie von Rani et al. hatte die Administration von GMCSF nach hämorrhagischem Schock einen positiven Effekt auf die supprimierte Zellfunktion von Peritonealmakrophagen ${ }^{109}$. Husain et al. konnten ebenfalls in einer Studie mit hämorrhagischem Schock Verbesserung der Immunfunktion durch die Administration von GM-CSF zeigen ${ }^{74}$. Folglich könnte der in der vorliegenden Studie bestehende Mangel an GM-CSF nach traumatisch-hämorrhagischem Schock einen weiteren Faktor bei der T-Zell vermittelten Immunosuppression darstellen.

Die beobachtete Suppression von IL-4 und GM-CSF im Rahmen dieser Studie könnte eine mögliche Ursache für die reduzierte MHC Klasse II Expression auf Dendritischen Zellen (CD11c (+)) darstellen. IL-4 und GM-CSF spielen im Reifungsprozess von Monozyten zu maturierten Dendritischen Zellen eine entscheidende Rolle ${ }^{43,64,130}$. Tritt ein Mangel dieser 
Zytokine auf, würde im Rahmen der Immunabwehr nach traumatisch-hämorrhagischem Schock eine wichtige Subpopulation an APC fehlen, die im reifen Stadium potenteste Fähigkeiten zur Antigenpräsentation an T-Zellen hat ${ }^{48,75,117}$ und damit für eine suffiziente Infektabwehr nicht zur Verfügung stehen würden. Dies wiederum könnte eine entscheidende Ursache in der beobachteten Immunosuppression der APC nach traumatischhämorrhagischem Schock darstellen ${ }^{25,48,64,122}$.

Um diese Spekulation zu verifizieren, sollten weiterführende Studien mit besonderem Augenmerk auf die Dendritischen Zellen und deren Reifungsprozess nach Trauma und Blutverlust durchgeführt werden.

Interessanterweise zeigte sich diese Beobachtung bei IL-4 und GM-CSF auch bei den Zytokinen IFN- $\gamma$ und IL-12.

Die Sekretion von IFN- $\gamma$ ist in den Kokulturen mit T-Zellen aus geschockten Mäusen unterdrückt, wohingegen die Kokulturen mit kontrolloperierten T-Zellen keine verminderten Konzentrationen an IFN- $\gamma$ aufweisen. Im Gegensatz dazu führt die Kokultur von kontrolloperierten T-Zellen mit geschockten APC $\mathrm{zu}$ keiner Suppression des IFN- $\gamma$. Kontrolloperierte APC vermochten die unterdrückte IFN- $\gamma$ Sekretion der geschockten TZellen nicht wiederherzustellen. Damit zeigen in dieser Arbeit die Antigenpräsentierenden Zellen keinen Effekt auf die Sekretion von T-zellulärem IFN- $\gamma$.

Interessanterweise verhielt sich das IL-12 kongruent $\mathrm{zu}$ der Sekretion des IFN- $\gamma$. Das hauptsächlich von Antigenpräsentierenden Zellen gebildete IL-12 war in den Kokulturen mit geschockten T-Zellen unterdrückt, selbst wenn die APC aus kontrolloperierten Mäusen separiert waren. Wurden die geschockten APC mit kontrolloperierten T-Zellen inkubiert, erwies sich bemerkenswerterweise die IL-12 Sekretion durch den traumatischhämorrhagischen Schock unbeeinflusst.

In Hinblick auf die Interaktion von IL-12 und IFN- $\gamma$ ist dies eine sehr interessante Beobachtung. Diese beiden Zytokine stellen - wie bereits erwähnt - einen direkten Kommunikationsweg zwischen T-Zellen und APC in Form eines positiven Regelkreises dar 53,70,138. Steigt die Konzentration von IFN- $\gamma$ an, so fördert dies die Sekretion von IL-12 und umgekehrt. Ist eines der beiden Zytokine unterdrückt, so resultiert eine Suppression des anderen Botenstoffes ${ }^{53,70,138}$.

Betrachtet man nun die Ergebnisse dieser Studie, so erscheint es, dass das von T-Zellen sezernierte IFN- $\gamma$ die Führungsrolle im Regelkreis mit IL-12 übernimmt, die Expression von IL-12 steuert und damit möglicherweise auch die Zellfunktion der APC und deren Antigenpräsentation (via MHC Klasse II) direkt beeinflusst. Das hätte zu Folge, dass die 
Suppression der APC nach traumatisch-hämorrhagischen Schocks indirekt durch die kompromittierte T-Zell-Funktion vermittelt ist: die Sekretion von IL-12 der APC war nur reduziert, wenn in den Kokulturen auch weniger IFN- $\gamma$ von geschockten T-Zellen sezerniert wurde. Geschockte APC per se zeigten keine supprimierte Sekretion von IL-12, wie man aus den Kokulturen von kontrolloperierten T-Zellen und geschockten APC (Gruppe 2) ersehen kann. Das unterstützt auch das Bild, dass die APC-Funktion 24 Stunden nach Trauma und Blutverlust nicht direkt durch die Schockprozedur vermittelt wird, sondern die Antigenpräsentierenden Zellen in ihrer Zellfunktion durch supprimierte T-Zellen gestört werden.

Im Gegensatz dazu konnte Kawasaki et al., in einer Studie mit separierten Dendritischen Zellen - also ohne den Einfluss von T-Zellen - eine signifikant reduzierte Sekretion von IL-12 und MHC II Expression nach traumatisch-hämorrhagischem Schock nachweisen ${ }^{79}$.

Diese zunächst widersprüchlichen Daten lassen sich am ehesten durch den unterschiedlichen Zeitpunkt der Zellgewinnung erklären. In dieser Studie wurden die Zellen nicht 24 Stunden, sondern 2 Stunden nach gleicher Schockprozedur gewonnen. In Anbetracht dessen, scheint initial nach Trauma und Blutverlust die Population der APC für die zu beobachtende Immunosuppression verantwortlich sein. Im weiteren Verlauf (24 Stunden nach traumatischhämorrhagischem Schock) gewinnt die kompromittierte T-Zell-Funktion zunehmend an Bedeutung. Das könnte möglicherweise durch den Reifungsprozess der APC nach Trauma und Blutverlust verursacht sein ${ }^{117,122,130}$.

Darüber hinaus scheint der Mangel an IFN- $\gamma$ einen weiteren supprimierenden Effekt auf die APC zu haben: IFN- $\gamma$ stellt einen entscheidenden Mediator in der Antigenpräsentation dar 24,32,40,113,114,138. Bei reduzierten Konzentrationen von IFN- $\gamma$ fehlt den APC der nötige Reiz für die Präsentation von Antigenen via MHC II. Die Hypothese, dass ein Mangel an IFN- $\gamma$ für die Störung der APC verantwortlich ist, wird durch folgende Studien bestätigt: Ertel et al. konnte einen positiven Effekt auf die IL-12 Sekretion und MHC II Expression von APC durch die Zugabe von rekombinantem IFN- $\gamma$ in die hier durchgeführte Zellkultur zeigen ${ }^{55,79}$. Asthana et al. konnte in einer in vivo Studie einen positiven Effekt des IFN- $\gamma$ auf die zelluläre Immunfunktion der APC nachweisen ${ }^{16,79}$.

Daher wäre die Administration von rekombinanten IFN- $\gamma$ und IL-12 ein logischer, weiterführender Schritt in künftigen Versuchen mit diesem Studienmodell. 


\subsection{Unstimulierte Zellen}

Im Rahmen der Zellkultur wurden auch unstimulierte Zellkulturen angefertigt. Diese erhobenen Parameter dienten primär zur Kontrolle der spontanen Zytokinsekretion und der Validierung des Testverfahrens.

Hier zeigten sich aber bei keinem der gemessenen Zytokine nennenswerte Konzentrationen in den Zellkulturüberständen, was die These unterstützt, dass T-Zellen und APC verschiedene Stimulantien / Aktivatoren wie ConA und LPS benötigen, um Zytokine zu sezernieren.

\subsection{Durchflusszytometrie nach Trauma Schock}

\subsubsection{T-Zell spezifische Oberflächenmarker}

Gewebetrauma löst nicht nur funktionelle Defizite bei T-Zellen aus, sondern führt zu einem Verschieben des Gleichgewichts zwischen CD4 (+) und CD8 (+) in Richtung CD8 (+) Zellen 57,86. Die Generierung einer adäquaten Anzahl an T-Helfer-Zellen und eine rasche monoklonale Expansion von zytotoxischen CD8 (+) Zellen sind unabdingbar für die effektive zelluläre Immunantwort ${ }^{116}$. CD4 und CD8-Moleküle sind in diesem Zusammenhang in die Aktivierung der intrazellulären Tyrosinphosphokinase involviert und modulieren den Antigen-erkennenden T-Zell-Rezeptor ${ }^{68,85}$.

In dieser Studie jedoch lässt sich zwar im Vergleich zu den Messungen der Oberflächenmarker direkt vor Zellseparation ein Verlust an CD4 (+) und CD8 (+) Zellen beobachten, dabei findet sich aber kein signifikanter Unterschied in der CD4/CD8 Ratio zwischen den Versuchsgruppen der Kokulturen. Auch die Rezeptordichten (MFI) der beiden Marker für die zwei verschiedenen Subpopulationen der T-Zellen erwiesen sich als niedriger wobei auch hier die Gruppen in der Expression nicht signifikant differierten.

Daraus lässt sich schließen, dass zwar die Zellkultur unter der Doppelstimulation mit ConA und LPS zu einer reduzierten Expression der Marker CD4 und CD8 führt, sich aber 24 Stunden nach traumatisch-hämorrhagischem Schock per se keine supprimierende Wirkung des Traumas auf die Subpopulationen zeigt. Folglich findet kein shift in Richtung CD4 (THelfer-Zellen) oder CD8 (zytotoxische T-Zellen) statt. Der Quotient von CD4 zu CD8 positiven Zellen ist unbeeinflusst. 
Diese Ergebnisse stehen auf dem ersten Blick im Kontrast zu den Ergebnissen beispielsweise von Schneider et al., der eine supprimmierte Ratio de CD4/CD8 Zellen zeigen konnte. Dabei ist aber anzumerken, dass die dabei verwendeten Zellen nicht separiert waren und mit einem anderen Stimulus aktiviert wurden (AntiCD3) ${ }^{116}$. Im Kontrast dazu wies Oberbeck et al. in einem ähnlichen Versuchsmodell eine gesteigerte Ratio von CD4/CD8 (+) Zellen nach, wobei diese Zellen im Vergleich zu den hier verwendeten T-Zellen unstimuliert waren, was die differierenden Ergebnisse erklären könnte ${ }^{103}$. Weiterführende Studien auf diese Problematik zielend sind jedoch notwenig, um diese Diskrepanz genauer zu untersuchen.

Zusätzlich wurde CD69, ein Aktivierungsmarker zur Charakterisierung der T-Zellfunktion bestimmt. Dieses Oberflächenmolekül gilt als erstes Zeichen einer Zellaktivierung auf unterschiedliche Reize - daher wird dieser Marker auch „,very early antigen“" genannt ${ }^{90}$.

CD69 zeigt im Rahmen dieser Studie eine gesteigerte Expression auf den T-Zellen der Kokulturen nach der Zellkultur und Stimulation im Vergleich zu den direkt vor Zellseparation gewonnenen Zellen, was einer Aktivierung der T-Zellen entspricht.

Zwischen den Gruppen der Kokulturen zeigt sich jedoch kein signifikanter Unterschied, was darauf hindeutet, dass auch die Expression des Markers CD69 24 Stunden nach traumatischhämorrhagischem Schock nicht durch die Schockprozedur beeinflusst wird. Die gesteigerte Expression ist auch in diesem Fall auf die Stimulation der Zellen mit ConA und LPS zurückzuführen.

Der Marker CD69 wurde bisher nur in wenigen Studien mit Fokus auf Traumata bestimmt. In einer Studien von Purcell et al. zeigte sich eine gesteigerte Expression nach Verbrennungen 108. Auch in einer Studie von Walsh et al. mit Polytraumapatienten war der Rezeptor CD69 stärker exprimiert ${ }^{137}$.

Zusammenfassend scheint die gesteigerte Expression des Oberflächenmarkers CD69 primär ein Ausdruck einer unspezifischen Zellaktivierung zu sein. Der traumatisch-hämorrhagische Schock per se scheint jedoch keinen Einfluss auf dessen Expression zu nehmen.

Für eine vollständige Aktivierung in der Interaktion von T-Zellen und APC ist die Kopplung der beiden Zelltypen via CD28 und dessen Liganden CD80 (B7.1) und CD86 (B7.2) unabdingbar. Daher sollte im Rahmen dieser Studie auch diese Oberflächenmarker bestimmt werden. CD28 war jedoch weder direkt vor Zellseparation der T-Zellen und APC, noch nach Zellkultur und Stimulation mit ConA und LPS auf den Zelloberflächen der T-Zellen zu messen. 
Die Verwendung eines weiteren Antikörpers eines anderen Herstellers gegen CD28 löste dieses Problem dennoch nicht. Nichts desto trotz exprimieren T-Zellen aus den Milzen von $\mathrm{C} 3 \mathrm{H} / \mathrm{HeN}$ Mäusen diesen Marker ${ }^{88}$, da ohne diesen Oberflächenmarker die Tiere keine volle Immunkompetenz aufweisen würden. Die Klärung dieses Problems ist Gegenstand weiterführender Experimente.

\subsubsection{APC spezifische Oberflächenmarker}

Im Rahmen dieser Studie wurden Antigenpräsentierende Zellen mit T-Zellen koinkubiert. Dabei wurden APC verwendet, die zuvor durch ihre Fähigkeit der Adhärenz an Plastikoberflächen separiert wurden. Die wichtigsten Vertreter der Antigenpräsentierenden Zellen sind B-Lymphozyten, Makrophagen und Dendritische Zellen, wobei nur Makrophagen ${ }^{92}$ und Dendritische Zellen ${ }^{96}$ die Fähigkeit zu Adhärenz zeigen. Um diese Zellen zu markieren verwendete man CD11c als Dendritische Zellen-Marker und CD11b als Makrophagen-Marker.

Bei dem Marker CD11b jedoch trat folgendes Problem durch die Antikörper induzierte Negativselektion der T-Zellen auf: entgegen der Herstellerangaben konnte in der vorliegenden Studie eine Beeinträchtigung der Oberflächenmarker nachgewiesen werden. Laut Herstellerangaben würden im Rahmen dieser Oberflächenbindung des Antikörpers CD11b auf Makrophagen ca. 30-40\% der vorhandenen Epitope auf den Zelloberflächen besetzt. Die restlichen Epitope würden für die Markierung mit Markern für die Durchflusszytometrie unbesetzt bleiben. Diese Aussage konnte aber in der vorliegenden Studie nicht bestätigt werden. Der Rezeptor CD11b, der auf aktivieren Makrophagen zu finden ist, zeigte sich direkt vor der Zellseparation als relativ gering exprimiert, jedoch waren in dem für APC spezifischen Bereich Messbereich bei der Durchflusszytometrie (gate) vor der Separation durchschnittlich noch $65 \%$ der Zellen CD11b positiv. Nach der Zellkultur und Stimulation mit ConA und LPS konnten nur noch ca. 5\% der Zellen in diesem gate als CD11b (+) gezählt werden.

Fraglich bleibt, ob diese Beobachtung bedingt durch eine Zellinaktivierung in der Zellkultur ist (Internalisierung des Oberflächenmoleküls inkl. Antikörper), oder zu viele Rezeptoren durch die in der T-Zell-Separation verwendeten Antikörper besetzt wurden und damit zu wenig Epitope für die Anfärbung zur Verfügung standen. Scannell et al. zeigte bereits 1995 
in einer Studie mit Traumapatienten eine deutlich reduzierte Oberflächenexpression von CD11b auf humanen Leukozyten ${ }^{112}$.

CD11c fand sich direkt vor der Zellseparation der T-Zellen und APC auf ca. 3\% der Zellen in dem für APC typischen gate, nach der Zellkultur waren jedoch in allen Kokulturen ca. 15\% der Zellen CD11c positiv. Das könnte auf eine Aktivierung oder alternativ Maturation der Dendritischen Zellen hindeuten. Andererseits wirkte sich dies aber nicht auf die Mittlere Fluoreszenzintensität (MFI) des Markers aus - die Rezeptordichte war um ein vielfaches reduziert. Noch deutlicher viel der Verlust der Fluoreszenzintensität bei dem Oberflächenmarker CD11b auf den Makrophagen aus. Vor der Zellkultur waren noch durchschnittlich $65 \%$ der Zellen aus dem für APC spezifischen gate noch positiv für CD11b, nach der Zellkultur und Stimulation mit ConA und LPS nur noch 5\% der Zellen. Dieser Umstand hat entscheidende Auswirkung auf die folgenden Aussagen über die Expression der kostimulatorischen Oberflächenmarker CD80 und CD86 sowie auf die MHC Klasse II Präsentation auf den CD11b (+) Zellen. Die gewonnenen Ergebnisse treffen folglich auf maximal 5\% der Zellen zu, was deren Aussagekraft massiv einschränkt.

Zusammenfassend sind die gewonnenen Ergebnisse in Bezug auf die Expression der Oberflächenmarker CD11b und CD11c wohl eher auf die Zellkulturbedingungen zurückzuführen. Ein Effekt des traumatisch-hämorrhagischen Schocks lässt sich hier nicht bestätigen.

Die Expression der kostimulatorischen Oberflächenmarker CD80 und CD86 wurde auf CD11b (+) und CD11c (+) Zellen gemessen.

Beide Marker zeigten auf CD11b (+) Zellen nach Zellkultur und Stimulation eine gesteigerte Oberflächenexpression im Vergleich $\mathrm{zu}$ den nicht stimulierten Zellen direkt nach der Zellgewinnung. Zwischen den vier Untersuchungsgruppen der Kokulturen offenbarte sich jedoch kein signifikanter Unterschied in der Rezeptordichte, sodass die gesteigerte Expression auf die Stimulation und nicht auf den traumatisch-hämorrhagischen Schock zurückzuführen ist.

Ein ähnliches Bild zeigte sich auf den CD11c (+) Dendritischen Zellen. Die Expression von CD86 war nach der Zellkultur und Stimulation in allen vier Kokulturen gesteigert, wobei sich auch hier zwischen den Versuchsgruppen kein signifikanter Unterschied offenbarte. Der Oberflächenmarker CD80 hingegen zeigte bereits vor der Zellkultur eine vergleichbare Rezeptorendichte auf den CD11c (+) Zellen. Nach der Stimulation und Zellkultur konnte 
jedoch kein Effekt der Trauma-Schock Prozedur in den vier Versuchsgruppen der Kokulturen auf die Expression von CD86 gezeigt werden.

Zusammenfassend ist die gesteigerte Expression der Oberflächenmarker CD80 und CD86 auf den CD11b (+) und CD11c (+) in dieser Studie auf die Stimulation zurückzuführen. Die erhöhte Rezeptordichte auf den Zelloberflächen entspricht einer Aktivierung ${ }^{129}$.

Weitere Arbeiten mit unterschiedlichem Studiendesign zeigten unterschiedliche Ergebnisse über die Expression der beiden Oberflächenmarker CD80 und CD86: so wurden diese Oberflächenmoleküle auf Peritonealmakrophagen in einer Sepsisstudie von Ding et al. für mehrere Tage geringer exprimiert, Milzmakrophagen zeigten hingegen keine Änderung in der Oberflächenexpression von CD80 und CD86 ${ }^{47}$. Newton et al. jedoch konnte eine reduzierte Expression von CD86 aber nicht von CD80 auf Peritoneal-, Milz- und Lebermakrophagen nachweisen ${ }^{99}$.

Weiterführende Studien werden zur Klärung dieser Diskrepanz benötigt, da es nicht geklärt werden konnte, ob die veränderte Oberflächenexpression der kostimulatorischen Marker CD80 und CD86 durch die unterschiedlichen Zellkulturbedingungen bedingt wurden, oder andere noch unbekannte Mechanismen zu dieser Änderungen führen.

Als direktes Maß für die Fähigkeit Antigene auf den Oberflächen zu exprimieren, wurde bei den CD11b (+) und CD11c (+) Zellen die Expression von MHC Klasse II sowohl direkt vor der Zellseparation 24 Stunden nach traumatisch-hämorrhagischem Schock, wie auch 48 Stunden nach Zellkultur und Stimulation gemessen.

Bereits zum ersten gemessenen Zeitpunkt 24 Stunden nach traumatisch-hämorrhagischem Schock wiesen die Dendritischen Zellen (CD11c (+)) eine reduzierte MHC II Präsentation nach der Trauma-Schock-Prozedur auf. Da die Suppression der MHC II Expression schon vor der Stimulation auftrat schließt dies Möglichkeit aus, dass diese Suppression durch die Stimulation, sondern durch den traumatisch-hämorrhagischen Schock vermittelt wurde.

Diese Beobachtung zeigte sich bereits in früheren Studien ${ }^{78,117,135}$. In diesen Arbeiten offenbarte sich eine signifikante Reduktion der MHC II Expression auf CD11c (+) Dendritischen Zellen. Die Ergebnisse dieser Studien sind damit mir dem hier verwendeten Versuchsmodell vergleichbar, was die Relevanz dieser Arbeit unterstreicht.

Nach der Zellkultur und Stimulation mit ConA und LPS war dieser Effekt ebenfalls zu beobachten, wobei hier die MFI bereits in allen Gruppen deutlich geringer ausfiel. Auch hier zeigte sich eine signifikante Reduktion der MHC II Expression in den Kokulturen mit 
geschockten T-Zellen - ungeachtet, ob die APC aus kontrolloperierten oder schockierten Versuchstieren stammten.

Es wird der Eindruck erweckt, dass die Expression von MHC II auf Dendritischen Zellen direkt gekoppelt ist an den funktionellen Zustand der koinkubierten T-Zellen. Die Fähigkeit zur Antigenpräsentation der Dendritischen Zellen via MHC II ist folglich nicht bedingt durch die eigene unterzogene Prozedur des traumatisch-hämorrhagischen Schocks oder der Kontrolloperation, sondern scheint durch die T-Zellen vermittelt zu werden. Koinkubation von schockierten Dendritischen Zellen mit kontrolloperierten T-Zellen resultiert in keiner reduzierten MHC II Expression. Im Falle einer Koinkubation von schockierten T-Zellen in der Kokultur mit kontrolloperierten Dendritischen Zellen zeigt sich andererseits ein signifikanter negativer Effekt auf die MHC II Expression. Folglich scheint eine Regeneration der APC nach Trauma-Schock-Prozedur möglich, was sich in einer suffizienten Antigenpräsentation via MHC II trotz unterzogenem traumatisch-hämorrhagischen Schocks der APC widerspiegelt.

Diese Regulation der MHC II Expression durch die T-Zellen ist möglicherweise bedingt durch den Mangel an IFN- $\gamma$. Bereits in früheren Studien konnte ein Einfluss des IFN- $\gamma$ auf die MHC II Expression nachgewiesen werden: Ayala et al. zeigte in einer Studie einen protektiven Effekt des IFN- $\gamma$ auf die MHC II Expression ${ }^{19}$. Asthana et al. konnte ein Wiederherstellen der Immunkompetenz von unseparierten APC nach Trauma und Blutverlust durch die Administration von IFN- $\gamma$ vorweisen ${ }^{16}$. Darüber hinaus konnte Ertel et al. in Anbetracht der Kommunikation der T-Zellen und APC über die Interaktion von INF- $\gamma$ und IL-12 einen positiven Effekt durch die Zugabe von IFN- $\gamma$ auf die Freisetzung von IL-12 belegen ${ }^{53}$. Nichts desto trotz wären weitere Studien mit der Zugabe von rekombinanten Botenstoffen wie IL-12 und IFN- $\gamma$ nötig um diese Vermutung zu bestätigen.

Diese entscheidende Beobachtung der Expression von MHC II auf CD11c (+) Zellen konnte hingegen bei den CD11b (+) Zellen - respektive Makrophagen - nicht beobachtet werden. Im ersten Blick widerspräche das vorangehenden Studien aus unserer Arbeitsgruppe von Angele et al.: Mayr et al. zeigte einen negativen Effekt des traumatisch-hämorrhagischen Schocks auf die MHC II Expression von CD11b (+) Zellen ${ }^{91}$.

Diese Diskrepanz muss jedoch in Anbetracht der weiter oben diskutierten Problematik des Oberflächenmarkers CD11b gesehen werden. Die Aussage, dass sich kein suppressiver Effekt der traumatisch-hämorrhagischem Schock Prozedur auf die MHC II Expression zeigte träfe nur für 5\% der noch vor Zellkultur CD11b (+) Zellen zu. Die Expression von MHC II 
auf den nun verbliebenen nach der Stimulation CD11b negativen Makrophagen konnte aufgrund der Versuchsanordnung nicht abgeschätzt werden.

\subsection{Mögliche Ursachen der Suppression}

Der traumatisch-hämorrhagische Schock führt nach 24 Stunden zu weitreichenden funktionellen Defiziten. Dabei konnte im Rahmen dieser Studie durch die Verwendung der Zellaufreinigungsmethoden erstmals der direkte Effekt von geschockten Zellen auf kontrolloperierte Zellen untersucht werden.

Besonderes Augenmerk galt hier den Gruppen 2 und 3 - diese Gruppen ermöglichten die Beobachtung des direkten Einflusses von beispielsweise geschockten T-Zellen auf kontrolloperierte APC (Gruppe 2), was in einer supprimierten APC-Funktion resultierte. Andererseits zeigte sich kein Zellfunktion unterdrückender Effekt der geschockten APC auf kontrolloperierte T-Zellen (Gruppe 3).

Besonders in Hinblick auf den Regelkreis von IFN- $\gamma$ und IL-12 sind die gewonnenen Ergebnisse sehr interessant. Diese beiden Zytokine regeln gegenseitig deren Produktion, wobei IFN- $\gamma$ die Ausschüttung von IL-12 steigert und umgekehrt ${ }^{53}$. Nun zeigt sich aber nur in den Zellkulturen mit geschockten T-Zellen eine reduzierte IFN- $\gamma$ und IL-12 Sekretion, was auf eine gewisse Führungsposition des IFN- $\gamma$ hindeutet. Tritt ein Mangel dieses Zytokins auf, führt das zur Störung der zellulären Funktion der APC.

Diese Theorie wird durch die gewonnenen Ergebnisse aus der Durchflusszytometrie gestützt. Die Expression der MHC Klasse II ist in den Kokulturen mit T-Zellen supprimiert - auch wenn die APC für sich aus kontrolloperierten Tieren stammten. Folglich haben die geschockten T-Zellen einen supprimierenden Effekt auf die MHC Klasse II Expression.

Ein möglicher Ursache dessen könnte auch hier das IFN- $\gamma$ sein, dass eines der wichtigsten Regulatoren der Expression von MHC II auf APC darstellt ${ }^{24,40,53}$. Fehlt dieses Zytokin, wird weniger MHC II auf APC exprimiert und damit auch weniger Antigene den T-Zellen präsentiert, was per se wieder eine deletäre Wirkung auf die Immunabwehr nach Trauma und Schock besitzt.

Anzumerken ist, dass dieser suppressive Effekt in den hier erhobenen Daten auf die MHC II Expression auf die Dendritischen Zellen beschränkt ist. Die Expression auf Makrophagen konnte aus oben genannten Gründen nicht suffizient gemessen werden, was jedoch ein gleichartiges Verhalten (reduzierte Oberflächenexpression von MHC II) nicht ausschließt. 
Dennoch ist gerade die Beobachtung bezüglich der Dendritischen Zellen besonders interessant. Dendritische Zellen sind hochspezialisierte Antigenpräsentierende Zellen, die aus unterschiedlichen Ursprungsgeweben stammen (Lymphatisches Gewebe und Knochenmark) und keiner einheitlichen Zellklasse entsprechen ${ }^{75,117}$. Im Maturationsprozess zu reifen Dendritischen Zellen ändert sich auch die Fähigkeit zur Antigenpräsentation. Unreife Dendritische Zellen (immature DC, iDC) zeigen zwar eine stark ausgeprägte Fähigkeit zur Internalisierung von Antigenen, haben aber andererseits nur eine beschränkte Fähigkeit diese via MHC II an der Oberfläche den T-Zellen zu präsentieren ${ }^{75,117,135}$. Dies spiegelt sich in einer geringeren MFI der MHC II Moleküle in der Durchflusszytometrie wider. Nach Ausreifen der Zellen dreht sich das beschriebene Bild um: reife Dendritischen Zellen können zwar weniger Antigene aufnehmen, exprimieren aber exzessiv MHC II auf deren Oberfläche und stellen in ihrer Zahl zwar eine kleine, jedoch eine sehr bedeutende Populationen der APC $\operatorname{dar}^{75,117}$

Darüber hinaus wird beim Reifungsprozess der Dendritischen Zellen die Präsenz von T-Zell spezifischen Zytokinen wie IL-4 und GM-CSF benötigt ${ }^{43,64}$. Tritt ein Mangel an diesen Zytokinen auf, was auch im Rahmen dieser Studie zu beobachten war, könnte es zu einer Maturationsstörung der Dendritischen Zellen kommen. Zusätzlich zeigen die Dendritischen Zellen im Rahmen eines Traumas einen massiven Schwund an unreifen Dendritischen Zellen, was die Populationsdichte der Dendritischen Zellen wohl weiter minimiert ${ }^{43,49}$. Um diese Thesen bestätigen zu können bedarf es weiterer Untersuchungen speziell mit Fokus auf die Dendritischen Zellen.

\subsection{Weiterführende Experimentelle Ansätze}

In der hier vorliegenden Studie, konnte erstmalig ein direkter hemmender Einfluss der TZellen auf die immunologische Funktion der APC nach traumatisch-hämorrhagischem Schock nachwiesen werden. Dennoch sind weitere Studien nötig, um die gewonnenen Daten zu ergänzen und um therapeutische Ansätze zu entwickeln:

Im Rahmen dieser Promotionsarbeit wurde nur ein Zeitpunkt für die Zellgewinnung gewählt. Daher sind die gewonnenen Erkenntnisse als „Momentaufnahme“ im Verlauf eines traumatisch-hämorrhagischen Schocks zu sehen. Interessanterweise findet sich jedoch im Gegensatz dazu in Studien von Kawasaki et al. ein reduzierte APC-Funktion nach traumatisch-hämorrhagischem Schock ${ }^{79}$ : Dabei zeigte sich eine reduzierte IL-12 Produktion 
von isolierten Dendritischen Zellen vier Stunden nach traumatisch-hämorrhagischem Schock, ohne T-zellulären Einfluss. Das könnte darauf hindeuten, dass initial die APC die Ursache für eine Immunsuppression nach traumatisch-hämorrhagischem Schock wären, wohingegen im Verlauf die T-Zelle und deren Funktion eine supprimierende Wirkung auf die APC ausüben.

Für die Klärung dieser Problematik könnte man das hier beschriebene Versuchmodell an früheren bzw. späteren Zeitpunkten nach traumatisch-hämorrhagischem Schock durchführen, um den Verlauf der Immunosuppression noch besser beobachten zu können (time course).

Des Weiteren könnte in Anbetracht des Mangels an IFN- $\gamma$ und IL-12 nach traumatischhämorrhagischem Schock deren Zugabe in rekombinanter Form von Nutzen sein. Würde man hier bei der Administration von IFN- $\gamma$ beispielsweise eine Wiederherstellung der Antigenpräsentation via MHC II auf das Ausgangsniveau von kontrolloperierten Zellen beobachten können, würde dies die oben bereits erwähnte Theorie der negativen Wirkung der T-Zellen auf die Zellfunktionen der APC unterstützen.

Darüber hinaus wäre es interessant, die zugrunde liegende Reifungsstörung der Dendritischen Zellen noch genauer zu observieren. Dabei könnte man bestimmte Maturationsmarker für Dendritischen Zellen und deren Expression nach Trauma und Blutverlust im Vergleich zur Kontrolloperation eruieren. Beispielsweise DC-LAMP oder CD83 wären hier als Marker zu untersuchen - diese werden selektiv von reifen DC exprimiert ${ }^{42,142}$.

Neben der Möglichkeit die Zytokine in den Zellkulturüberständen zu messen, steht, wie bereits erwähnt, eine weitere Methode der Zytokindetektion zur Verfügung. Mit Hilfe der Durchflusszytometrie könnte man direkt intrazellulär die Zytokine mit Fluorchromen markieren und dadurch die zu diesem Zeitpunkt der Messung produzierte Zytokinmenge bestimmen. Weiterer Vorteil dieser Methode wäre die morphologische Einordnung der Ursprungszelle des jeweils bestimmten Zytokine. Dadurch könnte man eine genauere Aussage treffen, welches Zytokin, von T-Zellen oder von APC produziert wird.

Eine Bestätigung der in dieser in vitro-Studie gewonnenen Daten in vivo wird durch einen Zelltransfer ermöglicht. In diesem Fall könnten isolierte T-Zellen aus Versuchstieren nach traumatisch-hämorrhagischem Schock in kontrolloperierte Tiere durch Injektion transferiert werden. Ein supprimierender Effekt auf beispielsweise die Dendritischen Zellen und Makrophagen könnte dann durch Zellgewinnung aus diesen Tieren gemessen werden. 


\subsection{Klinische Relevanz}

Der traumatisch-hämorrhagische Schock ist assoziiert mit weitreichenden immunologischen Störungen vor allem auf zellulärer Ebene der Immunabwehr ${ }^{14,81,83,100}$.

Für die Entwicklung neuartiger Therapieschemata zur erfolgreichen Behandlung dieses akuten Krankheitsbildes ist es daher von Nöten, die genauen pathophysiologischen Hintergründe und Ursachen der immunologischen Störungen nach traumatischhämorrhagischem Schock zu eruieren.

So arbeiten viele Arbeitsgruppen im Bereich der Schockforschung mit der therapeutischen Gabe von rekombinant hergestellten Botenstoffen, wie beispielsweise IFN- $\gamma$, IL-12 16,24,53,60,62,114 mit dem Ziel, die gestörte zelluläre Immunabwehr wiederherzustellen.

Die bisherigen Therapieversuche zeigten jedoch nicht den gewünschten Erfolg, was ein möglicherweise weitaus komplexeres Bild der funktionellen Störungen vermuten lässt (Frage der benötigten Konzentration, Zeitpunkt der Administration). Möglicherweise könnte durch alternative Applikationswege oder die Verwendung von viralen Gensonden für einen Gentransfer deren therapeutische Effektivität erhöhen.

Nichts desto trotz war es Inhalt dieser Studie einen weiteren Beitrag zur Klärung der zugrunde liegenden Störungen im Bereich der zellulären Immunabwehr zu leisten. Weiterführende Studien sind dennoch notwendig, um die in dieser Studie gewonnenen Erkenntnisse zu vertiefen und als Grundlage für zukünftige Therapiekonzepte zu verwenden. 


\section{Zusammenfassung}

Der traumatisch-hämorrhagische Schock führt zu weitreichenden funktionellen Störungen im Bereich der zellulären Immunantwort. Dieses Krankheitsbild resultiert aus unterschiedlichen Ätiologien (ausgedehnte operative Eingriffe, Polytraumata, usw.) und führt zu einer erhöhten Mortalität. Die Klärung der zugrunde liegenden pathophysiologischen Grundlagen in der Ausbildung eines traumatisch-hämorrhagischen Schocks und dessen mit großer Häufigkeit auftretenden Komplikationen (Sepsis, MOF und Tod) steht im Zentrum vieler klinischer und tierexperimenteller Studien.

Auf zellulärer Ebene zeigen sowohl T-Zellen als auch Antigenpräsentierende Zellen (z.B. Makrophagen und Dendritische Zellen) nach traumatisch-hämorrhagischem Schock ein gestörtes Gleichgewicht an pro- und antiinflammatorischer Zytokinfreisetzung, was sich in einer gesteigerten Anfälligkeit für septische Komplikationen und erhöhten Mortalitätsraten widerspiegelt. Darüber hinaus offenbaren Antigenpräsentierende Zellen nach Trauma und Blutverlust eine reduzierte Fähigkeit zur Antigenpräsentation via MHC Klasse II, was ebenfalls mit oben genannten Komplikationen korreliert.

Trotz einer Vielzahl von Studien, die diese funktionellen Störungen untersuchten, bleibt es nicht ausreichend geklärt, welcher Zelltyp nach traumatisch-hämorrhagischem Schock hauptsächlich diese prolongierte Immunosuppression vermittelt.

Darum war es Ziel dieser tierexperimentellen Studie, erstmalig isolierte T-Zellen und Antigenpräsentierende Zellen aus den Versuchtieren zu gewinnen, um diese kontrolliert zu koinkubieren, und deren Effekte auf die jeweils andere Zellpopulation zu untersuchen.

So wurden aus jeweils einer kontrolloperierten und einer geschockten Maus nach 24 Stunden die Milz entnommen und hieraus die T-Zellen und Antigenpräsentierenden Zellen separiert und kokultiviert. Nach 48-stündiger Zellkultur und Stimulation mit ConA und LPS wurden in den Überständen Zytokine zur Charakterisierung der T-Zell- und APC-Funktion bestimmt. Darüber hinaus detektierte man die MHC Klasse II Expression auf Makrophagen und Dendritische Zellen via Durchflusszytometrie.

Im Rahmen dieser Studie war die Freisetzung von IL-4, GM-CSF und IFN- $\gamma$ aus T-Zellen nach traumatisch-hämorrhagischem Schock supprimiert - unabhängig, ob die koinkubierten Antigenpräsentierenden Zellen aus einem kontrolloperierten oder schockierten Versuchstier stammten. Dagegen zeigte sich kein supprimierender Effekt der schockierten Antigenpräsentierenden Zellen auf kontrolloperierte T-Zellen und deren Produktion von IL-4, GM-CSF und IFN- $\gamma$. 
Das von den Antigenpräsentierenden Zellen sezernierte IL-12 war ebenfalls in den Überständen der Kokulturen der schockierten T-Zellen signifikant unterdrückt - selbst wenn die Antigenpräsentierenden Zellen kontrolloperiert waren. Hingegen führte die Kokultur von schockierten Antigenpräsentierenden Zellen mit kontrolloperierten T-Zellen zu keiner verminderten Sekretion von IL-12. Andererseits war die Sekretion der Zytokine IL-1, IL-6 und TNF- $\alpha$ im Rahmen dieser Studie 24 Stunden nach dem traumatisch-hämorrhagischem Schock nicht unterdrückt.

Dennoch zeigte sich ein weiterer supprimierender Effekt der T-Zellen auf die Funktion der Antigenpräsentierenden Zellen: die MHC II Expression auf CD11c (+) Zellen (Dendritische Zellen) war ebenfalls in den Kokulturen mit geschockten T-Zellen supprimiert - selbst wenn die Antigenpräsentierenden Zellen aus kontrolloperierten Versuchstieren stammten. Dies deutet auf eine durch T-Zellen bedingte Suppression der Antigenpräsentierenden Zellen hin, was durch das T-zelluläre IFN- $\gamma$ bedingt sein könnte. IFN- $\gamma$ stellt einen wichtigen Mediator für die Antigenpräsentation via MHC II der Makrophagen und Dendritischen Zellen dar.

Darüber hinaus könnte die supprimierte Expression der T-zellulären Zytokine IL-4 und GMCSF eine Rolle in Bezug auf die supprimierte MHC II Expression der Dendritischen Zellen spielen, da beiden Zytokine eine wichtige Funktion in der Maturation von Dendritischen Zellen übernehmen.

Die Ergebnisse dieser Studie lassen den Schluss zu, dass die T-Zellen eine entscheidende Funktion in der Vermittlung der prolongierten Immunosuppression nach Trauma und Schock spielen. Im Gegensatz dazu ist die Zellfunktion der Antigenpräsentierenden Zellen durch den traumatisch-hämorrhagischen Schock nicht direkt supprimiert, vielmehr scheinen deren funktionellen Defizite durch die T-Zellen vermittelt.

Daher sollten zukünftige Therapiestrategien zur Verbesserung der persistierenden Immunsuppression nach traumatisch-hämorrhagischem Schock gegen die funktionellen Defizite der T-Zellen gerichtet sein. 


\section{Literaturverzeichnis}

1. Abraham E. Physiologic stress and cellular ischemia: relationship to immunosuppression and susceptibility to sepsis. Crit Care Med 1991; 19:613-618.

2. Abraham E, Freitas AA. Hemorrhage in mice induces alterations in immunoglobulinsecreting B cells. Crit Care Med 1989; 17:1015-1019.

3. Alexander M, Chaudry IH, Schwacha MG. Relationships between burn size, immunosuppression, and macrophage hyperactivity in a murine model of thermal injury. Cell Immunol 2002; 220:63-69.

4. Angele MK, Ayala A, Cioffi WG, Bland KI, Chaudry IH. Testosterone: the culprit for producing splenocyte immune depression after trauma hemorrhage. Am J Physiol 1998; 274:C1530-C1536.

5. Angele MK, Ayala A, Monfils BA, Cioffi WG, Bland KI, Chaudry IH. Testosterone and/or low estradiol: normally required but harmful immunologically for males after trauma-hemorrhage. J Trauma 1998; 44:78-85.

6. Angele MK, Catania RA, Ayala A, Cioffi WG, Bland KI, Chaudry IH.

Dehydroepiandrosterone: an inexpensive steroid hormone that decreases the mortality due to sepsis following trauma-induced hemorrhage. Arch Surg 1998; 133:1281-1288.

7. Angele MK, Chaudry IH. Surgical trauma and immunosuppression: pathophysiology and potential immunomodulatory approaches. Langenbecks Arch Surg 2005; 390:333341.

8. Angele MK, Frantz MC, Chaudry IH. Gender and sex hormones influence the response to trauma and sepsis: potential therapeutic approaches. Clinics 2006; 61:479488.

9. Angele MK, Knoferl MW, Ayala A, Bland KI, Chaudry IH. Testosterone and estrogen differently effect Th1 and Th2 cytokine release following trauma-haemorrhage. Cytokine 2001; 16:22-30. 
10. Angele MK, Knöferl MW, Schwacha MG, Ayala A, Cioffi WG, Bland KI, Chaudry IH. Sex steroids regulate pro- and anti-inflammatory cytokine release by macrophages after trauma-hemorrhage. Am J Physiol 1999; 277:C35-C42.

11. Angele MK, Nitsch S, Knoferl MW, Ayala A, Angele P, Schildberg FW, Jauch KW, Chaudry IH. Sex-specific p38 MAP kinase activation following trauma-hemorrhage: involvement of testosterone and estradiol. Am J Physiol Endocrinol Metab 2003; 285:E189-E196.

12. Angele MK, Nitsch SM, Hatz RA, Angele P, Hernandez-Richter T, Wichmann MW, Chaudry IH, Schildberg FW. L-arginine: a unique amino acid for improving depressed wound immune function following hemorrhage. Eur Surg Res 2002; 34:53-60.

13. Angele MK, Schwacha MG, Ayala A, Chaudry IH. Effect of gender and sex hormones on immune responses following shock. Shock 2000; 14:81-90.

14. Angele MK, Wichmann MW, Ayala A, Cioffi WG, Chaudry IH. Testosterone receptor blockade after hemorrhage in males. Restoration of the depressed immune functions and improved survival following subsequent sepsis. Arch Surg 1997; 132:1207-1214.

15. Angele MK, Faist E. Clinical review: immunodepression in the surgical patient and increased susceptibility to infection. Crit Care 2002; 6:298-305.

16. Asthana D, Yang WC, Fuller L, Zucker K, Lu P, Zheng S, Esquenazi V, Carreno M, Roth D, Burke GW. Differential effects of IFN-gamma on kidney cell expression of MHC class II molecules, kidney cell associated molecules and their stimulatory capacity in mixed lymphocyte kidney cell culture. Transpl Immunol 1993; 1:282-293.

17. Ayala A, Chung Cs, Xy YX, Evans TA, Redmond KM, Chaurdy IH. Increased inducible apoptosis in CD4+ T lymphocytes during polymicrobial sepsis is mediated by Fas ligand and not endotoxin. Immunology 1999; 97:45-55.

18. Ayala A, Deol ZK, Lehman DL, Herdon CD, Chaudry IH. Polymicrobial sepsis but not low-dose endotoxin infusion causes decreased splenocyte IL-2/IFN-gamma release while increasing IL-4/IL-10 production. J Surg Res 1994; 56:579-585. 
19. Ayala A, Ertel W, Chaudry IH. Trauma-induced suppression of antigen presentation and expression of major histocompatibility class II antigen complex in leukocytes. Shock 1996; 5:79-90.

20. Ayala A, Lehman DL, Herdon CD, Chaudry IH. Mechanism of enhanced susceptibility to sepsis following hemorrhage. Interleukin-10 suppression of T-cell response is mediated by eicosanoid-induced interleukin-4 release. Arch Surg 1994; 129:1172-1178.

21. Ayala A, Perrin MM, Meldrum DR, Ertel W, Chaudry IH. Hemorrhage induces an increase in serum TNF which is not associated with elevated levels of endotoxin. Cytokine 1990; 2:170-174.

22. Ayala A, Perrin MM, Wagner MA, Chaudry IH. Enhanced susceptibility to sepsis after simple hemorrhage. Depression of Fc and C3b receptor-mediated phagocytosis. Arch Surg 1990; 125:70-75.

23. Ayala A, Wang P, Ba ZF, Perrin MM, Ertel W, Chaudry IH. Differential alterations in plasma IL-6 and TNF levels after trauma and hemorrhage. Am J Physiol 1991; 260:R167-R171.

24. Ayala A, Wang P, Chaudry IH. Insights into the mechanism by which interferongamma improves macrophage function following hemorrhage and resuscitation. $\mathrm{J}$ Surg Res 1993; 54:322-327.

25. Banchereau J, Steinman RM. Dendritic cells and the control of immunity. Nature $1998 ; 392: 245-252$.

26. Bateman RM, Sharpe MD, Ellis CG. Bench-to-bedside review: microvascular dysfunction in sepsis-hemodynamics, oxygen transport, and nitric oxide. Cirt Care Med 2003; 7:359-373.

27. Baumann H, Gauldie J. The acute phase response. Immunol Today 1994; 15:74-80.

28. Bocci V. Interleukins. Clinical pharmacokinetics and practical implications. Clin Pharmacokinet 1991; 21:274-284. 
29. Brandacher G, Margreiter R, Fuchs D. Implications of IFN-gamma-mediated tryptophan catabolism on solid organ transplantation. Curr Drug Metab 2007; 8:273282.

30. Brummer E, Sugar AM, Stevens DA. Activation of peritoneal macrophages by concanavalin A or Mycobacterium bovis BCG for fungicidal activity against Blastomyces dermatitidis and effect of specific antibody and complement. Infect Immun 1983; 39:817-822.

31. Buhren V. Pathophysiology of shock. Unfallchirurg 1996; 99:207-220.

32. Celada A, Gray PW, Rinderknecht E, Schreiber RD. Evidence for a gamma-interferon receptor that regulates macrophage tumoricidal activity. J Exp Med 1984; 160:55-74.

33. Chain B, Kaye PM, Shaw MA. The biochemistry and cell biology of antigen processing. Immunol Rev 1988; 106:33-58.

34. Chaudhry UI, Kingham TP, Plitas G, Katz SC, Raab JR, DeMatteo RP. Combined stimulation with interleukin-18 and $\mathrm{CpG}$ induces murine natural killer dendritic cells to produce IFN-gamma and inhibit tumor growth. Cancer Res 2006; 66:10497-10504.

35. Chaudry IH, Ayala A. Immunological aspects of hemorrhage. 1992.

36. Chaudry IH, Ayala A. Immunological aspects of hemorrhage. Austin, TX: Medical Intelligence Unit; R.G. Landes Company. 1992.

37. Chaudry IH, Ayala A, Ertel W, Stephan RN. Hemorrhage and resuscitation: immunological aspects. Am J Physiol 1990; 259:R663-R678.

38. Chaudry IH, Stefan RN, Harkema JM, Dean RE. Immunological alterations following simple hemorrhage. In Immune concequences of trauma, shock and sepsis: mechanism and therapeutic approaches. 1989:363-373.

39. Cioffi WG, Jr., Burleson DG, Jordan BS, Becker WK, McManus WF, Mason AD, Jr., Pruitt BA, Jr. Effects of granulocyte-macrophage colony-stimulating factor in burn patients. Arch Surg 1991; 126:74-79. 
40. de Metz J, Romijn JA, Endert E, Ackermans MT, Weverling GJ, Busch OR, de Wit LT, Gouma DJ, ten Berge IJ, Sauerwein HP. Interferon-gamma increases monocyte HLA-DR expression without effects on glucose and fat metabolism in postoperative patients. J Appl Physiol 2004; 96:597-603.

41. de Saint-Vis B, Fugier-Vivier I, Massacrier C, Gaillard C, Vanbervliet B, Ait-Yahai S, Banchereau J, Liu YJ, Lebecque S, Caux C. The cytokine profile expressed by human dendritic cells is dependent on cell subtype and mode of activation. J Immunol 1998; 160:1666-1676.

42. de Saint-Vis B, Vincent J, Vandenabeele S, Vanbervliet B, Pin JJ, Ait-Yahia S, Patel S, Mattei MG, Banchereau J, Zurawski S, Davoust J, Caux C, Lebecque S. A novel lysosome-associated membrane glycoprotein, DC-LAMP, induced upon DC maturation, is transiently expressed in MHC class II compartment. Immunity 2007; 9:325-336.

43. De AK, Laudanski K, Miller-Graziano CL. Failure of monocytes of trauma patients to convert to immature dendritic cells is related to preferential macrophage-colonystimulating factor-driven macrophage differentiation. J Immunol 2003; 170:63556362.

44. Deitch EA. Multi organ failure: pathophysiology and potentia future therapiey. Ann Surch 1992; 216:117-134.

45. Deitch EA. Animal models of sepsis and shock: a review and lessons learned. Shock 1998; 9:1-11.

46. Delon J, Stoll S, Germain RN. Imaging of T-cell interactions with antigen presenting cells in culture and in intact lymphoid tissue. Immunol Rev 2002; 189:51-63.

47. Ding Y, Chung Cs, Newton S, Chen Y, Carlton S, Albina JE, Alyala A. Polymicrobial sepsis induces divergent effects on splenic and peritoneal dendritic cell function in mice. J Shock 2004; 22:137-144.

48. Efron P, Moldawer LL. Sepsis and the dendritic cell. Shock 2003; 20:386-401. 
49. Efron PA, Martins A, Minnich D, Tinsley K, Ungaro R, Bahjat FR, Hotchkiss R, Clare-Salzler M, Moldawer LL. Characterization of the systemic loss of dendritic cells in murine lymph nodes during polymicrobial sepsis. J Immunol 2004; 173:3035-3043.

50. Eisenmenger SJ, Wichmann MW, Angele P, Faist E, Hatz R, Chaudry IH, Jauch KW, Angele MK. Differences in the expression of LPS-receptors are not responsible for the sex-specific immune response after trauma and hemorrhagic shock. Cell Immunol 2004; 230:17-22.

51. Elkord E, Williams PE, Kynaston H, Rowbottom AW. Human monocyte isolation methods influence cytokine production from in vitro generated dendritic cells. Immunology 2005; 114:204-212.

52. Engel P, Gribben JG, Freeman GJ, Zhou LJ, Nozawa Y, Abe M, Nadler LM, Wakasa H, Tedder TF. The B7-2 (B70) costimulatory molecule expressed by monocytes and activated B lymphocytes is the CD86 differentiation antigen. Blood 1994; 84:14021407.

53. Ertel W, Keel M, Neidhardt R, Steckholzer U, Kremer JP, Ungethuem U, Trentz O. Inhibition of the defense system stimulating interleukin-12 interferon-gamma pathway during critical Illness. Blood 1997; 89:1612-1620.

54. Ertel W, Morrison MH, Ayala A, Chaudry IH. Chloroquine attenuates hemorrhagic shock-induced suppression of Kupffer cell antigen presentation and major histocompatibility complex class II antigen expression through blockade of tumor necrosis factor and prostaglandin release. Blood 1991; 78:1781-1788.

55. Ertel W, Morrison MH, Ayala A, Dean RE, Chaudry IH. Interferon-gamma attenuates hemorrhage-induced suppression of macrophage and splenocyte functions and decreases susceptibility to sepsis. Surgery 1992; 111:177-187.

56. Faist E, Mewes A, Strasse T, Walz A, Alkan S, Baker C, Ertel W, Heberer G. Alteration of monocyte function following major injury. Arch Surg 1988; 123:287292. 
57. Faist E, Schinkel C. Update on the mechanisms of immune suppression of injury and immune modulation. World J Surg 1996; 20:454-459.

58. Fenton MJ, Golenbock DT. LPS-binding proteins and receptors. J Leukoc Biol 1998; 64:25-32.

59. Forestier C, Moreno E, Meresse S, Phalipon A, Olive D, Sasonetti P, Gorvel JP. Interaction of Brucella abortus lipopolysaccharide with major histocompatibility complex class II molecules in B lymphocytes. Infect Immun 1999; 67:4048-4054.

60. Franke A, Lante W, Kurig E, Zoller LG, Weinhold C, Markewitz A. Is interferon gamma suppression after cardiac surgery caused by a decreased interleukin-12 synthesis? Ann Thorac Surg 2006; 82:103-109.

61. Gardinger KR, Crockar AD, Hallida MI, Rowlands BJ. Class II major histocompatibility complex antigen expression on peripheral blood monocytes in patients with inflammatory bowel disease. Gut 1994; 35:511-516.

62. Goebel A, Kavanagh E, Lyons A, Saporoschetz IB, Soberg C, Lederer JA, Mannick JA, Rodrick ML. Injury induces deficient interleukin-12 production, but interleukin-12 therapy after injury restores resistance to infection. Ann Surg 2000; 231:253-261.

63. Goris RJA. The result of hole body inflammation. In Host defense dysfunction in trauma, shock and sepsis. Springer; 1993:161-170.

64. Granucci F, Zanoni I, Feau S, Ricciardi-Castagnoli P. Dendritic cell regulation of immune responses: a new role for interleukin 2 at the intersection of innate and adaptive immunity. EMBO J 2003; 22:2546-2551.

65. Gregg EO, Denis M. The effect of macrophage activation state on antigen presenting capability as defined by helper T-cell function. Int J Immunopharmacol 1991; 13:217225.

66. Harding FA, McArthur JG, Gross JA, Raulet DH, Allison JP. CD28-mediated signalling co-stimulates murine $\mathrm{T}$ cells and prevents induction of anergy in T-cell clones. Nature 1992; 356:607-609. 
67. Harris NL, Ronchese F. The role of B7 costimulation in T-cell immunity. Immunol Cell Biol 1999; 77:304-311.

68. He X, Kappes DJ. CD4/CD8 lineage commitment: light at the end of the tunnel? Curr Opin Immunol 2006; 18:135-142.

69. Heinzel FP, Sadick MD, Mutha SS, Locksley RM. Production of interferon gamma, interleukin 2, interleukin 4, and interleukin 10 by CD4+ lymphocytes in vivo during healing and progressive murine leishmaniasis. Proc Natl Acad Sci U S A 1991; 88:7011-7015.

70. Heufler C, Koch F, Stanzl U, Topar G, Wysocka M, Trinchieeri G, Enk A, Steinman RM, Romani N, Schuler G. Interleukin-12 is produced by dendritic cells and mediates $\mathrm{T}$ helper 1 development as well as interferon-gamma production by $\mathrm{T}$ helper 1 cells. Eur J Immunol 1996; 26:659-668.

71. Hildebrandt U, Kessler K, Pistorius G, Lindemann W, Ecker KW, Feifel G, Menger MD. Granulocyte elastase and systemic cytokine response after laparoscopic-assisted and open resections in Crohn's disease. Dis Colon Rectum 1999; 42:1480-1486.

72. Hildebrandt U, Kessler K, Plusczyk T, Pistorius G, Vollmar B, Menger MD. Comparison of surgical stress between laparoscopic and open colonic resections. Surg Endosc 2003; 17:242-246.

73. Hogg KG, Kumkate S, Anderson S, Mountford AP. Interleukin-12 p40 secretion by cutaneous CD11c+ and F4/80+ cells is a major feature of the innate immune response in mice that develop Th1-mediated protective immunity to Schistosoma mansoni. Infect Immun 2003; 71:3563-3571.

74. Husain B, Lendemans S, Ackermann M, Wendel A, Schade FU, Flohe S. GM-CSF counteracts hemorrhage-induced suppression of cytokine-producing capacity. Inflamm Res 2004; 53:13-21. 
75. Inaba K, Steinman RM, Van Voorhis WC, Muramatsu S. Dendritic cells are critical accessory cells for thymus-dependent antibody responses in mouse and in man. Proc Natl Acad Sci U S A 1983; 80:6041-6045.

76. Janeway CA, Bottomly K, Babich J, Conrad P, Conzen S, Jones B, Kaye J, Katz M, McVay L, Murphy DB, Tite J. Quantitative variation in Ia antigen expression plays a central role in immune regulation. Immunol Today 1984; 5:99-105.

77. Kang SC, Matsutani I, Choudry MA, Schwacha MG, Rue LW, Bland IK, Chaudry IH. Are the immune responses different in middle-aged and young mice following bone fracture, tissue trauma and hemorrhage? Cytokine 2004; 26:223-230.

78. Kawasaki T, Hubbard WJ, Choudry MA, Schwacha MG, Bland KI, Chaudry IH. Trauma-hemorrhage induces depressed splenic dendritic cell functions in mice. $\mathrm{J}$ Immunol 2006; 177:4514-4520.

79. Kawasaki T, Hubbard WJ, Choudry MA, Schwacha MG, Bland KI, Chaudry IH. Depressed splenic dendritic cell antigen presentation function following traumahemorrhage. Shock Suppl 2006; 25:50.

80. Kaya Z, Tretter T, Schlichting J, Leuschner F, Afanasyeva M, Katus HA, Rose NR. Complement receptors regulate lipopolysaccharide-induced T-cell stimulation. Immunology 2005; 114:493-498.

81. Keel M, Trentz O. Pathophysiology of polytrauma. In 2005:691-709.

82. Kelner GS, Zlotnik A. Cytokine production profile of early thymocytes and the characterization of a new class of chemokine. J Leukoc Biol 1995; 57:778-781.

83. Knaus WA, Draper DP, Wagner DP, Zimmerman JE. Prognosis in acute organ-system failure. Ann Surg 1995; 202:685-693.

84. Kobayashi H, Kobayashi M, Heming TA, Bidani A, Pollard RB, Suzuki F. Cytokine production by rabbit alveolar macrophages: differences between activated and suppressor cell phenotypes. Immunol Lett 1999; 69:339-346. 
85. Laky K, Fowlkes BJ. Receptor signals and nuclear events in CD4 and CD8 T cell lineage commitment. Curr Opin Immunol 2005; 17:116-121.

86. Lederer JA, Rodrick ML, Mannick JA. The effects of injury on the adaptive immune response. J Shock 1999; 11:153-159.

87. Lenschow DJ, Walunas TL, Bluestone JA. CD28/B7 system of T cell costimulation. Annu Rev Immunol 1996; 14:233-258.

88. Li Y, McGowan P, Hellstrom I, Hellstrom KE, Chen L. Costimulation of tumorreactive $\mathrm{CD} 4+$ and $\mathrm{CD} 8+\mathrm{T}$ lymphocytes by $\mathrm{B} 7$, a natural ligand for $\mathrm{CD} 28$, can be used to treat established mouse melanoma. J Immunol 1994; 153:421-428.

89. Mach B, Steimle V, Mrtinez-Soria E, Reith W. Regulation of MHC class II genes: lessons from a disease. Annu Rev Immunol 1996; 14:301-331.

90. Marizo R, Mauel J, Betz-Corradin S. CD69 and regulation of the immune function. Immunopharmacol Immunotoxicol 2007; 21:565-582.

91. Mayr S, Walz CR, Angele P, Hernandez-Richter T, Chaudry IH, Loehe F, Jauch KW, Angele MK. Castration prevents suppression of MHC class II (Ia) expression on macrophages after trauma-hemorrhage. J Appl Physiol 2006; 101:448-453.

92. Mazzone A, Ricevuti G. Leukocyte CD11/CD18 integrins: biological and clinical relevance. Haematologica 1995; 80:161-175.

93. McBride WT, Armstrong MA, McBride SJ. Immunomodulation: an important concept in modern anaesthesia. Anaesthesia 1996; 51:465-473.

94. McHoney M, Klein NJ, Eazon S, Pierro A. Decreased monocyte class II MHC expression following major abdominal surgery in children is related to operative stress. Pediatr Surg Int 2006; 22:330-334.

95. Menger MD, Vollmar B. Surgical trauma: hyperinflammation versus immunosuppression? Langenbecks Arch Surg 2004; 389:475-484. 
96. Metlay JP, Witmer-Pack MD, Agger R, Crowley MT, Lawless D, Steiman RM. The distinct leukocyte integrins of mouse spleen dendritic cells as identified with new hamster monoclonal antibodies. J Exp Med 1990; 171:1753-1771.

97. Montoya MC, Sancho D, Vicente-Manzanares M, Sanchez-Madrid F. Cell adhesion and polarity during immune interactions. Immunol Rev 2002; 186:68-82.

98. Nagorsen D, Marincola FM, Panelli MC. Cytokine and chemokine expression profiles of maturing dendritic cells using multiprotein platform arrays. Cytokine 2004; 25:3135.

99. Newton S, Ding Y, chung CS, Chen Y, Lomas-Neira JL, Ayala A. Sepsis-induced changes in macrophage co-stimulatory molecule expression: CD86 as a regulator of anti-inflammatory IL-10 response. Surg Infect (Larchmt ) 2004; 5:375-383.

100. Ni Choileain N, Redmond HP. The immunological consequences of injury. Surgeon 2006; 4:23-31.

101. Ni Choileain N, Redmond HP. Cell response to surgery. Arch Surg 2006; 141:11321140.

102. O'Sullivan ST, Lederer JA, Horgan AF, Chin DH, Mannick JA, Rodrick ML. Major injury leads to predominance of the T helper-2 lymphocyte phenotype and diminished interleukin-12 production associated with decreased resistance to infection. Ann Surg $1995 ; 222: 482-490$.

103. Oberbeck R, Nickel E, von Griensven M, Tschernig T, Wittwer T, Schmitz D, Pape HC. The effect of dehydroepiandrosterone on hemorrhage-induced suppression of cellular immune function. Intensive Care Med 2002; 28:963-968.

104. Onodera K, Chandraker A, Schaub M, Stadlbauer TH, Korom S, Peach R, Linsley PS, Sayegh MH, Kupiec-Weglinski JW. CD28-B7 T cell costimulatory blockade by CTLA4Ig in sensitized rat recipients: induction of transplantation tolerance in association with depressed cell-mediated and humoral immune responses. J Immunol 1997; 159:1711-1717. 
105. Palacios R. Concanavalin A triggers T lymphocytes by directly interacting with their receptors for activation. J Immunol 1982; 128:337-342.

106. Phipps RP, Stein SH, Roper RL. A new view of prostaglandin E regulation of the immune response. Immunol Today 1991; 12:349-352.

107. Pruitt JH, Copeland EM, Moldawer LL. Interleukin-1 and interleukin-1 antagonism in sepsis, systemic inflammatory response syndrome, and septic shock. J Shock 1995; $3: 235-251$.

108. Purcell EM, Dolan SM, Kriynovich S, Mannick JA, Lederer JA. Burn injury induces an early activation response by lymph node CD4+ T cells. Shock 2006; 25:135-140.

109. Rani M, Husain B, Lendemans S, Schade FU, Flohe S. Haemorrhagic shock in mice-intracellular signalling and immunomodulation of peritoneal macrophages' LPS response. Immunobiology 2006; 211:711-719.

110. Redl H, Dinges HP, Buurman WA, van der Linden CJ, Pober JS, Cotran R, Schlag G. Expression of endothelial leukocyte adhesion molecule-1 in septic but not traumatic/hypovolemic shock in the baboon. Am J Pathol 1991; 139:461-466.

111. Roumen RM, Hendriks T, van d, V, Nieuwenhuijzen GA, Sauerwein RW, van der Meer JW, Goris RJ. Cytokine patterns in patients after major vascular surgery, hemorrhagic shock, and severe blunt trauma. Relation with subsequent adult respiratory distress syndrome and multiple organ failure. Ann Surg 1993; 218:769776.

112. Scannell G, Waxman K, Vaziri ND, Zhang J, Kaupke CJ, Jalali M, Hect C. Effects of trauma on leukocyte intercellular adhesion molecule-1, CD11b, and CD18 expressions. J Trauma 1995; 39:641-644.

113. Schinkel C. The role of IFN-gamma in surgical patients. J Interferon Cytokine Res $2003 ; 23: 341-349$. 
114. Schinkel C, Licht K, Zedler S, Schinkel S, Fraunberger P, Fuchs D, Neugebauer E, Kreuzer E, Faist E. Interferon-gamma modifies cytokine release in vitro by monocytes from surgical patients. J Trauma 2001; 50:321-327.

115. Schmand JF, Ayala A, Chaudry IH. Effects of trauma, duration of hypotension, and resuscitation regimen on cellular immunity after hemorrhagic shock. Crit Care Med $1994 ; 22: 1076-1083$.

116. Schneider CP, Schwacha MG, Chaudry IH. Influence of gender and age on T-cell responses in a murine model of trauma-hemorrhage: differences between circulating and tissue-fixed cells. J Appl Physiol 2006; 100:826-833.

117. Schuurhuis DH, Fu N, Ossendorp F, Melief CJ. Ins and outs of dendritic cells. Int Arch Allergy Immunol 2006; 140:53-72.

118. Schuurhuis DH, Fu N, Ossendorp F, Melief CJ. Ins and outs of dendritic cells. Int Arch Allergy Immunol 2006; 140:53-72.

119. Seekamp A, Jochum M, Ziegler M, van Griensven M, Martin M, Regel G. Cytokines and adhesion molecules in elective and accidental trauma-related ischemia/reperfusion. J Trauma 1998; 44:874-882.

120. Shelley O, Murphy T, Paterson H, Mannick JA, Lederer JA. Interaction between the innate and adaptive immune systems is required to survive sepsis and control inflammation after injury. J Shock 2003; 20:123-129.

121. Shevach EM, Rosenthal AS. Function of macrophages in antigen recognition by guinea pig T lymphocytes. II. Role of the macrophage in the regulation of genetic control of the immune response. J Exp Med 1973; 138:1213-1229.

122. Shi Y, Liu CH, Roberts AI, Das J, Xy G, Ren G, Zhang Y, Zhang L, Yuan ZR, Tan HS, Das G, Devadas S. Granulocyte-macrophage colony-stimulating factor (GM-CSF) and T-cell responses: what we do and don't know. Cell Res 2006; 16:126-133.

123. Smith KA. Interleukin-2: inception, impact, and implications. Science 1988; 240:1169-1176. 
124. Sonoda Y. Interleukin-4--a dual regulatory factor in hematopoiesis. Leuk Lymphoma $1994 ; 14: 231-240$.

125. Spolarics Z, Siddiqi M, Siegel JH, Garcia ZC, Stein DS, Denny T, Deitch EA. Depressed interleukin-12-producing activity by monocytes correlates with adverse clinical course and a shift toward Th2-type lymphocyte pattern in severely injured male trauma patients. Crit Care Med 2003; 31:1722-1729.

126. Stephan RN, Ayala A, Chaudry IH. Monocyte and lymphocyte responses following trauma. In Pathophysiology of shock, sepsis and oragn failure. Springer; 1999:131144.

127. Stephan RN, Kupper TS, Geha AS, Baue AE, Chaudry IH. Hemorrhage without tissue trauma produces immunosuppression and enhances susceptibility to sepsis. Arch Surg $1987 ; 122: 62-68$.

128. Stern AS, Magram J, Presky DH. Interleukin-12 an integral cytokine in the immune response. Life Sci 1996; 58:639-654.

129. Sun ZW, Qiu YJ, Tao R, Chen J, Ge Y, Hu YM, Ma HB, Shi Q, Zhang XG. Time courses of B7 family molecules expressed on activated T-cells and their biological significance. Cell Immunol 2005; 236:146-153.

130. Takashima A, Kitajima T. T cell-mediated terminal maturation of dendritic cells, a critical transition into fully potent antigen presenting cells. Pathol Biol (Paris) 1998; 46:53-60.

131. Testi R, D Ambrosio D, DeMaria R, Santoni A. The CD69 receptor: a multipurpose cell-surface trigger for hematopoietic cells. Immunol Today 1994; 15:479-483.

132. Turina M, Dickinson A, Gardner S, Polk HC, Jr. Monocyte HLA-DR and interferongamma treatment in severely injured patients--a critical reappraisal more than a decade later. J Am Coll Surg 2006; 203:73-81.

133. Ulevitch RJ, Mathison JC, Schumann RR, Tobias PS. A new model of macrophage stimulation by bacterial lipopolysaccharide. J Trauma 1990; 30:S189-S192. 
134. Unanue ER, Beller DI, Lu CY, Allen PM. Antigen presentation: comments on its regulation and mechanism. J Immunol 1984; 132:1-5.

135. Vendetti S, Chai JG, Dyson J, Simpson E, Lombardi G, Lechler R. Anergic T cells inhibit the antigen-presenting function of dendritic cells. J Immunol 2000; 165:11751181.

136. Wakefield CH, Carey PD, Foulds S, Monson JR, Guillou PJ. Changes in major histocompatibility complex class II expression in monocytes and T cells of patients developing infection after surgery. Br J Surg 1993; 80:205-209.

137. Walsh DS, Siritongtaworn P, Pattanapanyasat K, Thavichaigarn P, Kongcharoen P, Jiarakul N, Tongtawe P, Yongvanitchit K, Komoltri C, Dheeradhada C, Pearce FC, Wiesmann WP, Webster HK. Lymphocyte activation after non-thermal trauma. Br J Surg 2000; 87:223-230.

138. Walz CR, Zedler S, Schneider CP, Mayr S, Loehe F, Bruns CJ, Faist E, Jauch KW, Angele MK. Depressed T cell-derived IFN-gamma following trauma-hemorrhage: a potential mechanism for diminished APC responses. Langenbecks Arch Surg 2007.

139. Weihgardt H, Heidecke CD, Westerholt A, Emmanuilidis K, Maier S, Veit M, Gerauer K, Matevossian E, Ulm K, Siewert JR, Holzmann B. Impaired monocyte IL12 production before surgery as a pedictive factor for the lethal outcome of postoperative sepsis. Ann Surg 2002; 235:560-567.

140. Xu YX, Ayala A, Chaudry IH. Prolonged immunodepression after trauma and hemorrhagic shock. J Trauma 1998; 44:335-341.

141. Zellweger R, Ayala A, DeMaso CM, Chaudry IH. Trauma-hemorrhage causes prolonged depression in cellular immunity. Shock 1995; 4:149-153.

142. Zhou LJ, Tedder TF. CD14+ blood monocytes can differentiate into functionally mature CD83+ dendritic cells. Proc Natl Acad Sci U S A 2007; 93:2588-2592. 


\section{Danksagung}

Ich danke meinem Doktorvater Privatdozent Dr. med. Martin K. Angele (Chirurgische Klinik und Poliklinik der Ludwig-Maximilians-Universität München, Klinikum Großhadern) für die Bereitstellung des Themas und den damit verbundenen wissenschaftlichen Vorarbeiten.

Seine einmalige sich selbst aufopfernde Unterstützung jederzeit bei auftretenden Fragen war jenseits meiner Erwartungen an einen Promotionsbetreuer. Er stand jederzeit mit Rat und Tat mir und anderen von ihm betreuten Doktoranten zur Seite. Er lehrte mir das wissenschaftliche Arbeiten und Denken, was mir für mein zukünftiges Berufsleben von größtem Nutzen sein wird. Er ermöglichte mir die Teilnahme an mehreren internationalen Kongressen und unterstützte mich tatkräftig in der Anfertigung der im Rahmen dieser Kongresse gehaltenen Vorträge und den verfassten Publikationen.

Ich danke in besonderem Maße Dr. rer. biol. hum. Siegfried Zedler für seine intensive Unterstützung im Rahmen des experimentellen Teiles dieser Arbeit. Seine Fachkompetenz ermöglichte die Optimierung des Versuchsmodells und dem damit verbundenen Erfolg.

Ebenfalls dem Dank verpflichtet bin ich Dr. med. Stefan Mayr cand. med. dent., der mir in so manchem zweifelndem Moment als Freund und Vorreiter zur Seite stand und mich durch seine exzellente wissenschaftliche Kompetenz unterstützte.

Ich danke Dr. rer nat Natasja van den Engel für ihren kompetenten Rat in Fragen bei der praktischen Durchführung der Zellkultur. Ihre Fröhlichkeit und Freundlichkeit lies das Labor erstrahlen.

Auch möchte ich unserem ehemaligen Zivildienstleistenden Michael Köppe für seine Mithilfe bei Teilen der praktischen Durchführung der Experimente danken. Seine freundschaftliche Art hellte so manche etwas triste Stunde im Labor auf.

Zu größtem Dank bin ich meinem Eltern verpflichtet, die mir mein ganzes Leben selbstlos zur Seite standen. Ihnen habe ich meinen bisherigen Werdegang zu verdanken - sie ermöglichten mir das Studium der Humanmedizin und die Durchführung dieser Dissertation. 


\title{
9. Lebenslauf
}

\author{
Name: $\quad$ Christian Rudolf WALZ \\ geboren: $\quad 08.06 .1979$ in Augsburg \\ Eltern: $\quad$ Dipl. oec. Gerhard Hermann Christian Walz, Rosa-Maria Walz $\dagger$ \\ Geschwister: $\quad$ Sabine Gertraud Stalder, geb. Walz, Cornelia Klaus, geb. Walz \\ Familienstand: ledig \\ Konfession: römisch - katholisch
}

1985-1989

\section{Schule}

1989-1998

Grundschule Westheim, Neusäß

Justus von Liebig Gymnasium, Neusäß ,Abschluss mit Allgemeine

Hochschulreife

\section{Wehrdienst}

1998-2000

18-monatiger Grundwehrdienst bei der Bundeswehr im Sanitätsdienst Jagdbombergeschwader 32, Klosterlechfeld

\section{Berufspraxis vor dem Studium}

2000-2001

2-monatiges Pflegepraktikum am Klinikum Augsburg

3-monatiges Praktikum (Chirurgie) bei Dres. Krumme, Müller, Tögel,

Klinik Vincentinum, Augsburg

3-monatiges Praktikum (Anästhesie) bei Dres. Dierig, Zeravik Klinik

Vincentinum, Augsburg

\section{Studium}

$04 / 2001$

Aufnahme des Medizinstudiums an der Ludwig-Maximilians-

Universität, München

$04 / 2003$

Ärztliche Vorprüfung - Physikum

$06 / 2004$

Beginn der Doktorarbeit an der Chirurgischen Klinik und Poliklinik, Ludwig-Maximilians-Universität, München

$11 / 2007$

2. Ärztliche Prüfung nach neuer Approbationsordnung

seit $12 / 2007$

Assistenzarzt Unfall-, Hand-, und Wiederherstellungschirurgie, Zentralklinikum Augsburg 